NBER WORKING PAPER SERIES

\title{
ARE SUFFICIENT STATISTICS NECESSARY? NONPARAMETRIC MEASUREMENT OF DEADWEIGHT LOSS FROM UNEMPLOYMENT INSURANCE
}

\author{
David S. Lee \\ Pauline Leung \\ Christopher J. O'Leary \\ Zhuan Pei \\ Simon Quach \\ Working Paper 25574 \\ http://www.nber.org/papers/w25574
}

\author{
NATIONAL BUREAU OF ECONOMIC RESEARCH \\ 1050 Massachusetts Avenue \\ Cambridge, MA 02138
}

February 2019, Revised December 2019

We are extremely grateful to Ken Kline for facilitating the analysis of the data, and to Camilla Adams, Victoria Angelova, Amanda Eng, Nicole Gandre, Jared Grogan, Suejin Lee, Bailey Palmer, and Amy Tarczynski for excellent research assistance. We are grateful for valuable discussions with Henrik Kleven, and thank David Card and two anonymous referees for their helpful comments. We have also benefited from feedback by Raj Chetty, Steve Coate, Nate Hendren, Erzo Luttmer, Brian McCall, Doug Miller, Emmanuel Saez, Seth Sanders, and participants of the DADA conference, Princeton labor workshop, Cornell public seminar, IZA/ SOLE Transatlantic Meeting, NBER Summer Institute, Econometric Society Meetings, IIPF conference, and National Tax Association conference. At the Washington State Employment Security Department, we thank Jeff Robinson and Madeline Veria-Bogacz for facilitating our use of the data for this project. The views expressed herein are those of the authors and do not necessarily reflect the views of the National Bureau of Economic Research.

NBER working papers are circulated for discussion and comment purposes. They have not been peer-reviewed or been subject to the review by the NBER Board of Directors that accompanies official NBER publications.

(C) 2019 by David S. Lee, Pauline Leung, Christopher J. O'Leary, Zhuan Pei, and Simon Quach. All rights reserved. Short sections of text, not to exceed two paragraphs, may be quoted without explicit permission provided that full credit, including $\odot$ notice, is given to the source. 
Are Sufficient Statistics Necessary? Nonparametric Measurement of Deadweight Loss from Unemployment Insurance

David S. Lee, Pauline Leung, Christopher J. O'Leary, Zhuan Pei, and Simon Quach

NBER Working Paper No. 25574

February 2019, Revised December 2019

JEL No. C14,C20,C31,H2,H23,J64,J65,J68

\section{ABSTRACT}

Central to the welfare analysis of income transfer programs is the deadweight loss associated with possible reforms. To aid analytical tractability, its measurement typically requires specifying a simplified model of behavior. We employ a complementary "decomposition" approach that compares the behavioral and mechanical components of a policy's total impact on the government budget to study the deadweight loss of two unemployment insurance policies. Experimental and quasi-experimental estimates using state administrative data show that increasing the weekly benefit is more efficient (with a fiscal externality of 53 cents per dollar of mechanical transferred income) than reducing the program's implicit earnings tax.

David S. Lee

Industrial Relations Section

Louis A. Simpson International Bldg.

Princeton University

Princeton, NJ 08544

and NBER

davidlee@princeton.edu

Pauline Leung

Dept. of Policy Analysis and Management

424 Kennedy Hall

Cornell University

Ithaca, NY 14853

pl532@cornell.edu

Christopher J. O'Leary

W.E. Upjohn Institute for Employment Research

300 S. Westnedge Ave.

Kalamazoo, MI 49007

USA

oleary@upjohn.org
Zhuan Pei

Dept. of Policy Analysis and Management

431 Kennedy Hall

Cornell University

Ithaca, NY 14853

peizhuan@gmail.com

Simon Quach

Industrial Relations Section

Louis A. Simpson International Bldg.

Princeton University

Princeton, NJ 08544

squach@ princeton.edu 


\section{Introduction}

In designing social insurance and income transfer programs, policymakers are primarily interested in how to best provide adequate material support at minimal taxpayer cost. It has long been recognized that increasing the generosity of income or in-kind transfers may in theory generate unintended work disincentives that lead to additional program costs. In the context of unemployment insurance (UI) programs, the focus of this paper, more generous benefits may reduce job search effort, leading to longer periods of unemployment. These negative labor supply effects have been estimated in an extensive literature (for comprehensive reviews, see Krueger and Meyer, 2002 and Schmieder and von Wachter, 2016).

More recent studies have sought to better understand the normative implications of these estimated behavioral effects for UI (e.g., Gruber 1997; Chetty 2008; Schmieder, von Wachter and Bender 2012; Lawson 2015, 2017; Nekoei and Weber 2017; Kolsrud et al. 2018). ${ }^{1}$ The welfare analysis of UI by Chetty (2008), which builds on work by Baily (1978), specifies a stylized job search model in which a representative worker optimizes her search effort in response to UI benefits and a fixed-wage job offer distribution. Using this model, one can express the full benefits and costs of a reform using a small number of reduced-form parameters, one of them corresponding to the labor supply effects that have been central to the empirical labor literature. Using this "sufficient statistics" method, Schmieder and von Wachter (2016) systematically review the most recent wave of empirical studies on UI and provide a mapping of existing estimates of labor supply behavioral elasticities to the fiscal externality-the excess fiscal cost that results from behavioral responses-associated with marginal changes in benefit levels and benefit lengths, which are meant to summarize the deadweight loss of the policy.

While this approach makes welfare analyses analytically tractable, it is unclear to what extent the choice of behavioral model (and hence the consequent sufficient statistics formulae) might itself affect estimates of fiscal costs. As one example, optimal UI models typically assume that eligible claimants receive full benefits for each week that they are unemployed. However, this is not true in practice as individuals can choose to forgo claiming benefits in any given week, or receive partial benefits for working part time while claiming UI. These additional margins of adjustment could have consequential effects on the fiscal costs that are not captured by standard models of UI in the sufficient statistics literature.

\footnotetext{
${ }^{1}$ The framework has been adapted to study policy design in other social insurance and transfer program settings, such as Pell grant (Denning, Marx and Turner, 2017), workers' compensation (Bronchetti, 2012), and sick pay (Bockerman, Kanninen and Suoniemi, 2015).
} 
This paper proposes a complementary, nonparametric strategy for measuring the fiscal externality associated with changes to income-transfer programs and applies the approach to UI policies. Instead of specifying a particular behavioral model that leads to an expression for the fiscal externality as a function of reduced-form elasticities or other model primitives, we utilize an accounting identity that holds both for every individual data point and in the aggregate: the impact of a UI reform on total government net expenditures can be decomposed into a "mechanical component," the budgetary impact in the absence of behavioral responses, and a component driven by responses to the reform, the fiscal externality. This externality is nonparametrically identified by the difference between the total effect on benefit expenditures net of tax receipts and the "mechanical effect," both of which, given some policy variation of interest, can be easily and directly measured in the data. ${ }^{2}$ This "decomposition" approach naturally follows from the widely understood notion in public economics that the impact of a marginal reform on government revenues can be sufficient to characterize marginal efficiencies or deadweight loss. A key benefit of our methodology is that it will produce the same quantity across a very broad class of behavioral models and requires minimal assumptions regarding individual-specific heterogeneity. Although this strategy is the logical consequence of well-known principles in public economics, it has not been employed to estimate the fiscal externalities of UI policies. To the best of our knowledge, the approach has yet to be employed in other income-transfer and taxation settings more broadly. ${ }^{3}$

We apply our decomposition approach to a study of the fiscal externalities associated with two distinct policies that affect the UI benefit generosity. First, we estimate the fiscal externality induced by an incremental change in the UI weekly benefit amount, a magnitude that plays a key role in the recent optimal UI literature and the margin of interest in a large number of empirical studies of UI (Moffitt, 1985; Meyer, 1990; Card et al., 2015a,b; Lalive, van Ours and Zweimüller 2006; Chetty 2008; Kroft and Notowidigdo 2016; and DellaVigna et al., 2017). Second, we also estimate the fiscal externality induced by a seldom-discussed feature of UI systems — the fact that all U.S. states allow workers to be "partially unemployed" (i.e., with some limited earnings) and still be able to receive some UI benefits, as dictated by an earnings deduction

\footnotetext{
${ }^{2}$ We use the term "nonparametric" to describe this strategy because it allows the behavioral model to have parameters of arbitrary dimension. Instead of deriving an expression for the fiscal externality as a function of a small number of elasticities, we are estimating the fiscal externality directly.

${ }^{3}$ For example, the optimal tax literature focuses on using elasticities (such as the elasticity of taxable income) to estimate the efficiency of taxation (Feldstein, 1999; Saez, Slemrod and Giertz, 2012), though it has been acknoweledged that an alternative method is to focus directly on the behavioral component of the government revenue impact (Auerbach, 1985, Slemrod, 1998, Kleven and Kreiner, 2005, Chetty, 2009a). Hendren (2016)'s framework emphasizes the sufficiency of examining the impact of various tax and transfer policies on government budgets but empirically relies on existing elasticities estimated in the literature.
} 
formula. While some studies (McCall, 1996; Le Barbanchon, 2016) have investigated the behavioral response to variation in the disregard amount (i.e., earnings threshold above which UI benefits are reduced), our paper examines the response to a reduction in the implicit tax rate.

We study these policies in the context of Washington State in the mid-nineties. In 1994, the Washington State legislature authorized a randomized experiment to examine the impact of changing the benefit formula for partially unemployed workers. One quarter of all new UI claimants starting from the fourth quarter of 1994 and lasting for one year were randomized into a treatment group that saw their weekly benefit amount reduced by $\frac{2}{3}$ of every dollar earned as opposed to the control group's rate of 75 cents per dollarsee the report by O'Leary (1997) for details. We use the experimental variation to estimate the total and behavioral effects of a change in this implicit tax rate on the government's budget. Furthermore, we provide quasi-experimental evidence on the fiscal externality of a marginal change in the weekly benefit amount by applying a regression kink design along the lines of Card, Lee and Pei (2009); Card et al. (2015a,b). Our analysis uses detailed UI claim and quarterly earnings data for the entire universe of claimants eligible for the experiment in the quarters leading up to the filing and for four quarters or more after the initial date of the claim.

Our empirical analysis finds statistically significant estimates of the fiscal externalities for both the experimental reduction in the implicit tax rate on earnings and the quasi-experimental variation in the weekly benefit amount. For the marginal dollar that is transferred to inframarginal UI claimants via an increase in the weekly benefit amount, we estimate that between 27 cents and 79 cents are spent on the behavioral response to the change. In comparison, the reduction in the implicit tax rate - for which there was hope of a negative behavioral cost - incurred a fiscal externality of $\$ 1.38$, and we can statistically rule out magnitudes less than $\$ 0.49$ per dollar of mechanical transfer. Most of this fiscal externality appears to be driven by the impact of the behavioral response on benefit expenditures, as opposed to lost tax revenue. Comparing our RKD and experimental results suggests that the relatively more fiscally efficient way to transfer income is via an increase in the weekly benefit amount, not a reduction in the implicit tax rate. ${ }^{4}$ The total behavioral costs found here are on the high end of the range reported for the U.S. in the survey by Schmieder and von Wachter (2016). Finally, when we take a typical "sufficient statistics" approach and obtain an expression for the same fiscal externality using a job search model, we arrive at a significantly higher estimate, suggesting

\footnotetext{
${ }^{4}$ Although we show that one policy is more fiscally efficient, a full welfare comparison requires information on the relative social benefits of each policy, which may depend on the specific behavioral responses to the policy.
} 
that the choice of the simplified behavioral model affects the measurement of fiscal externality. We further show that the magnitude of the estimate is quite sensitive to other simplifying approximations that would be common in typical "sufficient statistic" exercises.

The remainder of the paper is organized as follows. Section 2 uses a standard public economics framework to define fiscal externality and to contrast existing identification strategies to the decomposition approach taken in this paper. In Section 3, we describe the Washington State's UI system, the earnings deduction experiment, and aspects of the administrative data relevant to our analysis. We present our results in Section 4 and conclude in Section 5 by summarizing our findings and their implications, as well as identifying some important directions for further work.

\section{Conceptual and Econometric Framework}

Using a standard public economics framework, this section defines the fiscal externality parameter of interest and reviews its role in the literature on the welfare analysis of UI. First, we contrast the typical sufficient statistics approach used to empirically analyze the problem with the complementary decomposition strategy that we adopt. Then, we describe its implementation in the specific cases of using UI benefit variation from a randomized experiment and a regression kink design, which we later employ in our empirical analysis.

\subsection{The Fiscal Externality Parameter}

We first introduce notation to define the fiscal externality parameter of interest. Let the vector-valued function $\mathbf{Y}_{i}(\theta, \tau)$ represent the reduced-form optimal choices of individual $i$ in response to the UI policy rules, parameterized by $\theta$ (e.g. benefit levels) and the tax schedule $\tau$ (a tax parameter). For simplicity of exposition, we consider $\theta$ and $\tau$ to be scalars. ${ }^{5} \mathbf{Y}_{i}$ could include, for example, a "reservation wage" for accepting a job offer, job search effort, the number of hours worked in a given week, an individual's benefit take-up threshold above which the individual will take up the benefit, or any other related labor supply, consumption, or program participation choices; the function represents the individual's optimal response for any given value of the parameters $\theta, \tau$. Let the net transfer (UI benefits less taxes paid) to the individual be represented by the function $B\left(\mathbf{Y}_{i}(\theta, \tau), \theta\right)-T\left(\mathbf{Y}_{i}(\theta, \tau), \tau\right)$, where $B(\cdot, \cdot)$ are UI benefits and $T(\cdot, \cdot)$ are taxes, both of which depend on the choices $\mathbf{Y}_{i}(\theta, \tau)$ and the policy parameters $\theta$ and $\tau$. This function com-

\footnotetext{
${ }^{5}$ The discussion below can be extended to the case of vectors of parameters.
} 
bines the UI benefit formula (e.g. benefits are paid out according to past and future earnings), and the tax schedule, with choices to determine the actual benefits and taxes paid.

We now consider making benefits more generous through an increase in $\theta$. Letting the expectation operator $E[\cdot]$ represent averaging over all individuals in the heterogeneous population and suppressing subscript $i$, we can decompose the marginal cost of the increase in $\theta$ in terms of net dollars transferred into two components $^{6}$ :

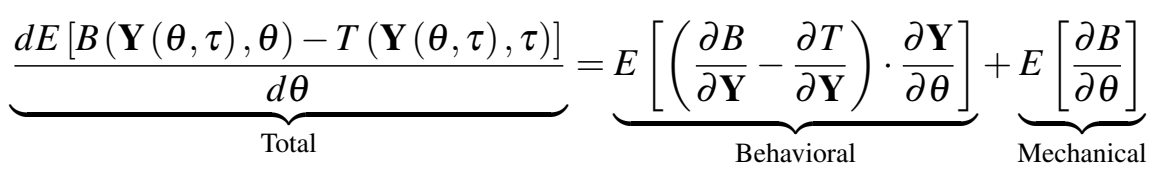

The "behavioral" component is composed of the impact of the policy change on individual behavior $\frac{\partial \mathbf{Y}_{i}}{\partial \theta}$ and the impact of the behavior on benefits and taxes $\frac{\partial B}{\partial \mathbf{Y}_{i}}-\frac{\partial T}{\partial \mathbf{Y}_{i}}$, averaged over the population. The "mechanical" component, $E\left[\frac{\partial B}{\partial \theta}\right]$, is the average change in benefit expense in the absence of any behavioral response; note that by definition, a change in $\theta$ has no direct effect on taxes paid. The ratio

$$
\frac{\text { "Behavioral Effect" }}{\text { "Mechanical Effect" }}=\frac{E\left[\frac{\partial B}{\partial \mathbf{Y}} \cdot \frac{\partial \mathbf{Y}}{\partial \theta}\right]-E\left[\frac{\partial T}{\partial \mathbf{Y}} \cdot \frac{\partial \mathbf{Y}}{\partial \theta}\right]}{E\left[\frac{\partial B}{\partial \theta}\right]} \equiv \beta+\gamma
$$

is the fiscal externality parameter of interest. Measured as a proportion of the intended transfer to inframarginal UI claims, it represents the additional net transfer that must occur because of the behavioral response to the policy change. It is an intuitive and easily interpretable magnitude of the unintended fiscal consequence of increasing UI benefits and can be further decomposed into the parts attributable to changes in benefit expenditures $\beta \equiv \frac{E\left[\frac{\partial B}{\partial \mathbf{Y}} \cdot \frac{\partial \mathbf{Y}}{\partial \theta}\right]}{E\left[\frac{\partial B}{\partial \theta}\right]}$ and tax revenues $\gamma \equiv \frac{-E\left[\frac{\partial T}{\partial \mathbf{Y}} \cdot \frac{\partial \mathbf{Y}}{\partial \theta}\right]}{E\left[\frac{\partial B}{\partial \theta}\right]}$.

\section{Relation to Optimal Unemployment Insurance}

While this "marginal excess burden" parameter stands on its own as an interpretable summary of the fiscal consequences of the policy change, it also plays a central role in existing welfare analyses of UI. To review these standard results from the literature, let $V_{i}(\cdot, \cdot, \cdot)$ be individual $i$ 's utility function with $B\left(\mathbf{Y}_{i}, \theta\right), T\left(\mathbf{Y}_{i}, \tau\right)$, and $\mathbf{Y}_{i}(\theta, \tau)$ as arguments. To aggregate individual utilities to social welfare, we use the function $G_{i}(\cdot)$ to translate an individual's utility to a metric that can be averaged across individuals. The social planner's

\footnotetext{
${ }^{6}$ More precisely, we use $E[\cdot]$ to denote a simple average , $E\left[x_{i}\right] \equiv \frac{1}{N} \sum_{i=1}^{N} x_{i}$, where $N$ equals individuals in the population.
} 
objective is to maximize

$$
W=E[G(V(B, T, \mathbf{Y}))]
$$

subject to a balanced budget constraint $E[B-T]=0$ (where we have suppressed arguments of $B$ and $T$ and subscript $i$ for readability). ${ }^{7}$ The balanced budget constraint defines the implicit function $\tau(\theta)$, where

$$
\frac{d \tau}{d \theta}=-\frac{d E[B-T] / d \theta}{d E[B-T] / d \tau}
$$

describes the necessary change in tax parameter $\tau$ that is required to offset the budgetary impact of a marginal change in UI parameter $\theta .^{8}$

Taking the derivative of (3) with respect to $\theta$ subject to a balanced budget, a marginal increase in the UI parameter will impact social welfare as follows:

$$
\begin{aligned}
\frac{d W}{d \theta} & =E\left[G^{\prime} \cdot V_{1} \cdot \frac{\partial B}{\partial \theta}\right]+E\left[G^{\prime} \cdot V_{2} \cdot \frac{\partial T}{\partial \tau} \frac{d \tau}{d \theta}\right] \\
& =E\left[G^{\prime} \cdot V_{1} \cdot \frac{\partial B}{\partial \theta}\right]-E\left[G^{\prime} \cdot V_{2} \cdot \phi\right] \frac{d E[B-T]}{d \theta}
\end{aligned}
$$

where $\phi=\frac{\partial T / \partial \tau}{d E[B-T] / d \tau}$ represents the dollar amount of increased taxation each individual experiences to offset a one dollar increase in the deficit. The first line uses the fact that all terms in the total derivative with respect to $\theta$ that reflect changes in welfare through changes in $\mathbf{Y}_{i}$ (i.e. the terms that involve $\frac{\partial B}{\partial \mathbf{Y}_{i}}, \frac{\partial T}{\partial \mathbf{Y}_{i}}$, and $\frac{\partial V_{i}}{\partial \mathbf{Y}_{i}}$ ) will sum to zero, because we have assumed all individuals are already optimizing (i.e. we apply the envelope theorem). This optimization assumption is both standard and crucial in the welfare analysis literature. $^{9}$

Normalizing by $E\left[G^{\prime} \cdot V_{2} \cdot \phi\right] E\left[\frac{\partial B}{\partial \theta}\right]$ to express welfare as a money-metric, the above expression shows that the social planner assesses optimality by comparing two quantities (after some re-arrangement, and

\footnotetext{
${ }^{7}$ More generally, loosening the budget neutrality constraint (e.g., Hendren, 2016) will not change the fiscal externality expression (the focus of this paper) when we later normalize the welfare change by the social valuation of an increased government budget. See Pei (2017) for an example of a planner objective function that does not impose a balanced budget. Lawson (2017) considers the existence of non-UI expenditures while also requiring budget balance, which leads to the same expression of the fiscal externality, but in implementing the formula, the tax rate required to fund the policy change is much larger.

${ }^{8}$ The numerator is as defined in equation (1) and the denominator is $\frac{d E[B-T]}{d \tau}=E\left[\left(\frac{\partial B}{\partial \mathbf{Y}}-\frac{\partial T}{\partial \mathbf{Y}}\right) \cdot \frac{\partial \mathbf{Y}}{\partial \tau}\right]-E\left[\frac{\partial T}{\partial \tau}\right]$.

${ }^{9}$ Note that, as is standard in this literature, individuals do not internalize the social planner's changes in the tax parameter associated with an increase in $\theta$ (i.e., individual $i$ 's response function remains $\mathbf{Y}_{i}(\theta, \tau)$ even as the social planner adjusts $\tau$ to balance the budget).
} 
using the accounting identity (1)),

$$
\alpha \equiv \frac{E\left[G^{\prime} \cdot V_{1} \cdot \frac{\partial B}{\partial \theta}\right]}{E\left[G^{\prime} \cdot V_{2} \cdot \phi\right] E\left[\frac{\partial B}{\partial \theta}\right]}-1 \lessgtr \frac{E\left[\frac{\partial B}{\partial \mathbf{Y}} \cdot \frac{\partial \mathbf{Y}}{\partial \theta}\right]-E\left[\frac{\partial T}{\partial \mathbf{Y}} \cdot \frac{\partial \mathbf{Y}}{\partial \theta}\right]}{E\left[\frac{\partial B}{\partial \theta}\right]} \equiv \beta+\gamma
$$

Although the framework above is introduced with unrestricted heterogeneity, it is helpful to build intuition by considering the simpler (and more commonly adopted) case of a representative agent (see, e.g., Schmieder and von Wachter, 2016). In this standard case without heterogeneity, $\alpha$ simplifies to $\frac{V_{1}}{V_{2} \cdot \phi}-1$, where $\frac{V_{1}}{V_{2} \cdot \phi}$ represents the individual's valuation of an extra dollar of UI benefits (via an increase in $\theta$ ) relative to the value of the increase in taxes (via $\tau$ ) levied to pay for the increase in $\theta$. Since individuals pay taxes when employed and receive UI benefits when unemployed, $\alpha$ reflects the insurance value of transferring income from the employed to the unemployed state. In the more general case with heterogeneous agents, $\alpha$ will contain the the ratio of aggregate welfare gain from an increased UI transfer to the aggregate welfare gain from decreased taxation.

Equally important to the social planner's cost-benefit analysis is the right side of the relation (4) - the fiscal externality from the transfer, $\beta+\gamma \cdot{ }^{10} \beta$ represents the amount of additional benefits that need to be paid out per one dollar of "mechanical transfer" as a consequence of the behavioral response to the policy change, while $\gamma$ represents the analogous loss in tax receipts. The higher the quantity $\beta+\gamma$ is, the less likely one is to conclude that there is a net welfare gain to increasing $\theta$; or put differently, the larger the $\alpha$ would need to be in order to justify the marginal increase in $\theta . \beta+\gamma$ can also be computed for different policies and compared to determine which policy transfers income more efficiently (e.g., increase in the maximum weekly benefit level or increasing the potential duration of benefits), as suggested in Schmieder and von Wachter (2016).

The comparison of $\alpha$ and $\beta+\gamma$ in (4) is central to a number of studies in the optimal UI literature. A typical approach entails specifying a job search model in which a representative unemployed agent decides the effort with which to search for a new job or the minimum wage at which a job offer is accepted, while the social planner chooses the benefit policy that maximizes the agent's utility subject to a balanced budget constraint (Baily, 1978; Gruber, 1997; Shimer and Werning, 2007; Chetty, 2008; Schmieder, von Wachter

\footnotetext{
${ }^{10}$ Our definition of fiscal externality captures the externality that occurs when individuals do not account for the impact of their actions on the government budget, similar to the recent work by Hendren (2016). Note that this is different from the definition in Lawson (2017), who defines "fiscal externality" as the impact of individual actions on the non-UI portion of the government budget.
} 
and Bender, 2012; Landais, 2015). Under the assumptions of these models, the social costs of a policy, $\beta+\gamma$, can typically be expressed as a function of a reduced-form behavioral elasticity, such as the elasticity of unemployment durations with respect to benefits, while the social benefits $\alpha$ can be expressed as a function of a risk aversion parameter and the change in consumption associated with job loss. ${ }^{11}$ A driving motivation for this "sufficient statistics" approach is its empirical tractability: it conveniently allows one to use existing reduced-form estimates of behavioral responses from the literature to inform welfare analyses.

However, the degree of sensitivity of the conclusions of these welfare analyses to the choice of equally plausible alternative behavioral models - each of which would presumably lead to different expressions - is unknown. Each optimal UI formula in the studies above relies on simplifying assumptions and approximations that rule out what is believed to be second-order behavioral aspects in order to express $\alpha$ and $\beta+\gamma$ as a function of a small number of parameters. For example, the model of Chetty (2008) assumes that an individual is initially unemployed, and once a job offer is accepted, she remains employed until the final period, even though movements back and forth between UI receipt and employment are observed in the data. ${ }^{12}$ Additionally, as is typically the case in optimal UI analyses, there is little or no discussion of imperfect take-up and the possibility that more generous benefits may impact take-up even though the take-up rate of benefits is far from complete. ${ }^{13}$ Furthermore, the model assumes a fixed pretax wage and a "representative agent," ruling out various forms of heterogeneity. Although these models can be extended to rely on fewer simplifications, doing so without offsetting assumptions leads to more parameters to estimate (which may or may not be available in the literature) but does not meaningfully resolve the question of whether the welfare conclusions are sensitive to the choice of an inevitable set of modeling restrictions one must make.

\section{Complementary Decomposition Approach}

In this paper, we propose using a complementary decomposition approach to measure $\beta$ and $\gamma$. Specifically, instead of assuming a particular structure and functional form for $B(\cdot, \cdot), T(\cdot, \cdot)$, and $\mathbf{Y}_{i}(\theta, \tau)$ that would lead

\footnotetext{
${ }^{11}$ Alternative forms of the optimal UI formula may contain unemployment duration responses to lump-sum transfers (Chetty, 2008) or reservation wage responses to benefit increases (Shimer and Werning, 2007).

${ }^{12}$ Thirty percent of the claimants in our data have at least two unemployment spells over the course of their benefit year, where we define the end of a spell to be three or more weeks without a claim.

${ }^{13}$ See Blank and Card (1991), Anderson and Meyer (1997), and Vroman (2009) for evidence of incomplete take-up in UI, and Kroft (2008) for a discussion of the theoretical implications of this imperfect take-up. Although this literature focuses on the fraction of eligible unemployed workers who do not receive any UI over the unemployment spell, another type of "imperfect take-up" could occur if workers start claiming UI, but decide not to claim benefits in specific weeks despite being eligible. While the approach proposed in our paper can in theory capture the fiscal effects of both types of take-up given sufficient data, we focus on the latter type in our empirical application.
} 
to expressing $\beta+\gamma$ in (2) as functions of reduced-form behavioral elasticities, we rely on the decomposition in (1). The fiscal externality parameter $\beta+\gamma$ is identified as the behavioral component $E\left[\left(\frac{\partial B}{\partial \mathbf{Y}}-\frac{\partial T}{\partial \mathbf{Y}}\right) \cdot \frac{\partial \mathbf{Y}}{\partial \theta}\right]$, the simple difference between the directly measured total impact of the policy change on benefits (net of taxes) $\frac{d E[B-T]}{d \theta}=E\left[\frac{d B}{d \theta}\right]-E\left[\frac{d T}{d \theta}\right]$, and the direct measurement of the mechanical effect $E\left[\frac{\partial B}{\partial \theta}\right]$, normalized by $E\left[\frac{\partial B}{\partial \theta}\right] .{ }^{14}$ This approach requires policy variation in $\theta$ (which is needed in any case) and enough information about individuals to simulate the mechanical effect $E\left[\frac{\partial B}{\partial \theta}\right]$.

This empirical approach follows naturally from the insight of the public economics literature that within a broad class of models, the behavioral impact on the government budget is sufficient for measuring economic efficiency for welfare analysis. However, although the decomposition of impacts on government revenue has been implicitly and explicitly suggested in numerous papers throughout the public economics literature, the estimation of the fiscal externality directly from microdata has yet to be employed in studies of UI, or to the best of our knowledge, in studies of other income transfer programs. ${ }^{15}$

This decomposition approach to estimating the fiscal externality has two potential advantages. First, when working with administrative program data, which is increasingly prevalent in analyses of UI (Schmieder and von Wachter, 2016), data on government expenses and revenues are often more complete, compared to measures of labor supply or job search behavior that are required to faithfully estimate hypothesized behavioral models that might be constructed to conduct welfare analysis. ${ }^{16}$ In the absence of the true labor supply measures, the observed data are used to proxy for those behaviors. For example, it is common in the US context to construct a single spell of UI receipt from claim data, and to presume that these spells

\footnotetext{
${ }^{14}$ Another technical advantage of this approach is that for a non-marginal reform it is often easier to estimate the mechanical effect of the reform and infer the behavioral effect as a "residual" than to estimate the behavioral effects of the reform directly, which requires information about how behavioral elasticities change over the policy path (see Chetty $2009 \mathrm{~b}$ and Kleven 2018 for details). Appendix A shows that the mechanical effect of a large reform can be approximated using the trapezoid rule by the average of mechanical effects from two decompositions.

${ }^{15}$ Attributing the idea to Auerbach (1985) and Slemrod (1998), Chetty (2009a) notes that one way of measuring the deadweight loss of income taxation is to estimate the behavioral component of the overall impact on the government budget. Hendren (2016) recently emphasizes the sufficiency of a policy's causal impact on government revenue for welfare analysis but computes the fiscal externality of several policies using existing labor supply or taxable income elasticities. In a review and extension of the sufficient statistics approach, Kleven (2018) notes the generality of the principle that marginal efficiency loss is given by the behavioral impact on government revenue, tracing the clarification of these principles to discussions in Feldstein (1999), Saez (2004), and Kleven and Kreiner (2005). Ashenfelter and Plant (1990) use a similar decomposition method to analyze labor supply responses to the SIME/DIME experiment by computing the difference between actual NIT payments of an experimental group and the predicted payments using the control group, but does not consider its relation to measures of efficiency and welfare as recognized in the public economics literature.

${ }^{16} \mathrm{We}$ do note here that the scope of our study is limited by the available data to studying UI as an isolated system, which is typical in the optimal UI literature. A more comprehensive view, which would embed the UI system and incorporate interactions with the rest of the government budget (see Lawson, 2015 and Leung and O'Leary, Forthcoming for discussions of UI program interactions), would require a dataset that contains all government expenses and revenues (related and unrelated to the UI program), for both the beneficiary and non-beneficiary populations, firms, and other entities.
} 
approximately correspond to actual spells of non-employment, when we know empirically that this is not necessarily the case. As another example, specific models of behavior may have predictions about weekly wages and hours which are typically not observed for those who do not file a weekly claim. Finally, richer behavioral models that allow for heterogeneity in wage offer distributions or in reservation wages are likely to require data that are even more difficult or infeasible to obtain.

Second, and more importantly, given that $\mathbf{Y}_{i}(\theta, \tau)$ can take on a very general form, with arbitrary dimension, the decomposition approach is consistent with a wide range of behavioral models. Because of this degree of model-insensitivity, the decomposition measures of $\beta+\gamma$ can serve as a nonparametric, complementary benchmark to these other strategies. Since the decomposition approach uses a strict subset of assumptions compared to a "sufficient statistics" or structural approach, if one uses all three approaches on the same data and obtains different estimates of the same fiscal parameter $\beta+\gamma$, then one must conclude that the differences are being driven by the additional modeling assumptions that undergird either the "elasticities-to-welfare" formula of the sufficient statistics approach, or the structural estimation of the fiscal externality.

We point out three important qualifications to the application of the decomposition approach that we present in the paper. First, throughout this paper, we use the term "sufficient statistics approach" to refer to the general idea of leaving primitives of an underlying behavioral model unindentified, while focusing on how high-level parameters (i.e. elasticities) that can inform a welfare analysis of a policy (see Chetty, 2009b). In this context, our main point is that a decomposition that leaves the behavioral effect as the "residual" allows one to inform welfare analysis, while making even fewer assumptions about the structure of the problem than a standard "sufficient statistics approach." On the other hand, we note that typically, when the "sufficient statistics approach" is applied to a specific context-such as an assessment of the optimality (or non-optimality) of the level of UI-one needs to ascertain estimates of both $\beta+\gamma$ (the fiscal externality) and $\alpha$ (the consumption smoothing benefit). Since we only focus on $\beta+\gamma$, we can only make directional statements, like the minimal value of $\alpha$ that would justify a marginal increase in benefit levels; or, alternatively, it can address the question of the relative efficiency of different mechanisms of transfer (as discussed in Schmieder and von Wachter, 2016). In order to answer the question of whether current levels of UI are optimal, we would have to combine our nonparametric estimate of $\beta+\gamma$ with estimates of $\alpha$ obtained through an alternative approach. It is clear from equation (4) that any claim of identifying $\alpha$ must be implicitly or explicitly making a claim about the nature of social and individual utility functions $G_{i}$ and 
$V_{i}$, which is beyond the scope of the current paper.

Second, the decomposition approach does not circumvent the need to maintain other assumptions about the broader economy, ones that are unavoidably invoked in either a "sufficient statistics" or structural approach. For example, in a standard sufficient statistics analysis, in order to interpret the fiscal externality parameter as capturing the full welfare costs of a policy, one must abstract away from other pre-existing distortions in the economy. In the UI setting, this abstraction is problematic if economic agents are not optimizing or if markets are not fully efficient, which creates the potential for UI policies to have additional externalities that are relevant for welfare analysis. For example, Spinnewijn (2014) shows that when unemployed workers are (sub-optimally) overly optimistic or pessimistic about job finding probabilities, there is an additional cost or saving (to the individual) in changing UI benefit generosity beyond the impact on government budgets. In terms of market inefficiencies, Landais, Michaillat and Saez (2018) show that UI may have an effect on labor market tightness if a worker's search effort impacts others who are also looking for a job. The decomposition approach does not require any additional assumptions beyond that which are already invoked to abstract from these effects.

Finally, we also note that the decomposition approach cannot circumvent the need to make extrapolative parametric restrictions if there is interest in making predictions of marginal efficiency for large changes of $\theta$ that are far beyond the variation observed in the data (e.g. a reduction in the implicit tax rate from 0.75 to 0.20 in the earnings deduction experiment). In order to make predictions beyond the range of the observed policy variation, one clearly needs to make parametric assumptions, whether that comes in the form of a stylized model that is the basis of a sufficient statistics approach or a structural model that specifies primitives (see Kleven, 2018 for a recent discussion of these issues). This is why we view the decomposition approach as a useful complementary benchmark: in principle, since any particular structural model is contained within the broad class of models for which the decomposition approach is valid, then if it is correctly specified, it should produce the same magnitude of $\beta+\gamma$. If it does not, it would indicate that the structure itself is distorting measurement of the fiscal externality. In Section 4.3, we show in our empirical setting how the necessary model and simplifying approximations adopted in Schmieder and von Wachter (2016) for comparing fiscal externalities across studies using only reported elasticities may lead to different estimates of $\beta+\gamma$. 


\subsection{Experimental and Quasi-Experimental Measurement of the Fiscal Externality}

\section{Fiscal Externality from a Randomized Experiment: Changing the Implicit Tax Rate on Earnings}

The decomposition equation (1) shows that the fiscal externality of a change in a transfer policy can be computed from two values: the total effect of the policy on average benefits less taxes, $E\left[\frac{d B}{d \theta}\right]-E\left[\frac{d T}{d \theta}\right]$, and the mechanical effect on benefit payments, $E\left[\frac{\partial B}{\partial \theta}\right]$. In the case of the Washington State earnings deduction experiment, credible identification of these parameters in response to a change in the implicit marginal tax rate of benefits is straightforward. In the experiment, one quarter of the sample was randomly assigned to an alternative UI benefit schedule. The most important difference between the benefit schedules of the treatment and control groups was the variation in the implicit marginal tax rate. In the control group, workers' weekly UI benefits were reduced by 75 cents for every dollar earned above $\$ 5$ (the "disregard"), whereas the benefits of members in the treatment group were reduced by $\frac{2}{3}$ of every dollar earned above a $\$ 15$ disregard.

Due to randomization, $E\left[\frac{d B}{d \theta}\right]-E\left[\frac{d T}{d \theta}\right]$ is identified by the simple difference between the treatment and control means of benefits (less taxes) received by claimants. Identification of the mechanical effect $E\left[\frac{\partial B}{\partial \theta}\right]$ is achieved by using the observed data from the control group and calculating the benefits that they would have received if their benefits were instead determined by the treatment group's benefit schedule, assuming no behavioral response (e.g., no change in earnings or take-up). The difference between this simulated average and the control average yields the mechanical effect. ${ }^{17}$

As discussed more fully in Section 3.2, in practice we do not observe actual tax receipts, but the administrative data do contain individual earnings as reported by the employer to the UI agency, which are the amounts used to determine the actual tax amount. Thus, we very closely approximate actual tax receipts at the individual level by approximating the statutory tax schedule.

\section{Fiscal Externality from a Regression Kink Design: Changing the Weekly Benefit Amount}

Fiscal externalities corresponding to a marginal change in the weekly benefit amount can be identified using quasi-experimental variation from a regression kink design (Card et al., 2015b). Specifically, most

\footnotetext{
${ }^{17}$ An alternative decomposition can be obtained by applying the control schedule to the treated group. If the reform is small enough, the difference between the mechanical effect calculations should be minimal. For a larger reform, however, the average of the two mechanical effects more closely approximates the actual mechanical effect, as we show in Appendix A. In our application, the second decomposition - simulating the treatment group's benefits under the control formula - leads to an overstatement of the mechanical effect because some treated units are observed to have exhausted their benefits, which censors the simulated outcome (i.e., we do not observe simulated spells that extend beyond the actual weeks claimed).
} 
UI systems determine the weekly benefit amount for the fully employed as a constant fraction of some measure of past earnings, but the benefit amount is capped at a fixed nominal level. This feature of the UI formula creates a kink in the relationship between past earnings and the benefit amount.

More concretely, let $\tilde{X}$ denote past earnings and wba the UI weekly benefit amount. The statutory relationship between $w b a$ and $\tilde{X}$ is $w b a=\min (\lambda \tilde{X}, \theta)$, where $\lambda$ is the constant multiplier on past earnings and $\theta$ the cap. The cap induces a kink in the formula at $\tilde{X}=\theta / \lambda$, and we introduce a normalized running variable $X=\tilde{X}-\theta / \lambda$ so that the location of the kink is $X=0$. The UI weekly benefit amount formula in terms of $X$ is

$$
w b a=\theta+\min (\lambda X, 0),
$$

which is graphically represented in panel A of Figure 1. Panel B of Figure 1 represents the conceptual policy reform of raising wba by $\$ 1$, which is equivalent to raising the cap $\theta$ by $\$ 1$ as seen in equation (5).

Since there is a sudden change in the UI marginal replacement rate as $X$ moves across 0 , the kink in the weekly benefit formula offers quasi-experimental leverage to identify the total effect of the reform. In particular, there is an RKD analogue to the identification statements made above for the earnings deduction experiment. Under various smoothness assumptions as specified in Card et al. (2015b) and assuming a sharp design with no deviation from formula (5), the ratio of the slope change in the conditional expectation of total benefit $B(\operatorname{tax} T)$ to the slope change in the $w b a$ formula identifies a weighted average of the total effect of increasing $w b a$, or equivalently $\theta$, on total benefit $B(\operatorname{tax} T)$ :

$$
\begin{aligned}
R K D_{B} \equiv \frac{\left.\lim _{x_{0} \rightarrow 0^{+}} \frac{d E[B \mid X=x]}{d x}\right|_{x=x_{0}}-\left.\lim _{x_{0} \rightarrow 0^{-}} \frac{d E[B \mid X=x]}{d x}\right|_{x=x_{0}}}{\left.\lim _{x_{0} \rightarrow 0^{+}} \frac{d w b a}{d x}\right|_{x=x_{0}}-\left.\lim _{x_{0} \rightarrow 0^{-}} \frac{d w b a}{d x}\right|_{x=x_{0}}}=E\left[\omega \frac{d B}{d \theta}\right] \\
R K D_{T} \equiv \frac{\left.\lim _{x_{0} \rightarrow 0^{+}} \frac{d E[T \mid X=x]}{d x}\right|_{x=x_{0}}-\left.\lim _{x_{0} \rightarrow 0^{-}} \frac{d E[T \mid X=x]}{d x}\right|_{x=x_{0}}}{\left.\lim _{x_{0} \rightarrow 0^{+}} \frac{d w b a}{d x}\right|_{x=x_{0}}-\left.\lim _{x_{0} \rightarrow 0^{-}} \frac{d w b a}{d x}\right|_{x=x_{0}}}=E\left[\omega \frac{d T}{d \theta}\right] .
\end{aligned}
$$

The difference between the causal parameters identified by RKD, i.e., right hand side of equation (6), and $E\left[\frac{d B}{d \theta}\right]$ and $E\left[\frac{d T}{d \theta}\right]$ is captured in the population weight $\omega$. In a model of unrestricted heterogeneity in marginal effects across individuals, we must acknowledge that the RKD estimands identify a weighted average of marginal effects, where the weights $\omega$ reflect the relative likelihood of an individual having $X$ near the threshold. ${ }^{18}$

\footnotetext{
${ }^{18}$ For a detailed explanation of this interpretation see Card et al. (2015b).
} 
We identify a "weighted average" version of $E\left[\frac{\partial B}{\partial \theta}\right]$, the mechanical effect, by first simulating the quantity

$$
\frac{\partial B_{i}}{\partial \theta}=B\left(\mathbf{Y}_{i}(\theta, \tau), \theta+1\right)-B\left(\mathbf{Y}_{i}(\theta, \tau), \theta\right)
$$

for each individual worker $i$. The second term on the right hand side of equation (7), $B\left(\mathbf{Y}_{i}(\theta, \tau), \theta\right)$, is the total UI payment under the existing regime; the first term, $B\left(\mathbf{Y}_{i}(\theta, \tau), \theta+1\right)$ is the simulated total UI payment under the reform represented by the dashed line in panel B of Figure 1. In simulating $B\left(\mathbf{Y}_{i}(\theta, \tau), \theta+1\right)$, we keep UI duration, labor supply and take-up behavior fixed while allowing the worker one more dollar in weekly benefit amount. ${ }^{19}$ The expectation of this variable, conditional on $X=0$, is

$$
E\left[\frac{\partial B}{\partial \theta} \mid X=0\right]=E\left[\omega \cdot \frac{\partial B(\mathbf{Y}(\theta, \tau), \theta)}{\partial \theta}\right]
$$

This represents the weighted mechanical effect of the marginal increase in $\theta$, where the weight is the same as that in equation (6). ${ }^{20}$

With the quantities in (6) and (8), we can thus identify, analogous to the randomized experiment, the fiscal externality as

$$
\frac{R K D_{B}-R K D_{T}-E\left[\frac{\partial B}{\partial \theta} \mid X=0\right]}{E\left[\frac{\partial B}{\partial \theta} \mid X=0\right]}=\frac{E\left[\omega \cdot \frac{\partial B}{\partial \mathbf{Y}} \cdot \frac{\partial \mathbf{Y}}{\partial \theta}\right]-E\left[\omega \cdot \frac{\partial T}{\partial \mathbf{Y}} \cdot \frac{\partial \mathbf{Y}}{\partial \theta}\right]}{E\left[\omega \cdot \frac{\partial B(\mathbf{Y}(\theta, \tau), \theta)}{\partial \theta}\right]}
$$

While this "weighted average" version of the fiscal externality of an increase in the weekly benefit amount resembles the expression in (2), there is an important difference between (9) and (2): the total marginal effect applies only to individual's responses when they are at the maximum benefit level. This qualification is inevitable for regression kink designs. Although the weights $\omega$ are unobservable, we can examine the conditional mean of any observable baseline characteristic $C$ at $X=0, E[C \mid X=0]$, which is equal to $E[\omega \cdot C]$. By comparing the characteristics of overall claimant population and those at the threshold,

\footnotetext{
${ }^{19}$ As will be evident in our discussion in Section 4 , this is a simplification of the simulation of the mechanical effect that we must perform. In particular, the above expression does not incorporate limits on the maximum benefits payable. In our empirical analysis, we ensure that we adjust the data to account for the fact that a higher weekly benefit will cause some individuals to exhaust benefits earlier than observed in the data.

${ }^{20}$ In our application, the first stage is very strong but falls short of being deterministic, as a small fraction (6 percent) of observations appear to deviate from the statutory schedule. Instead of the sharp regression kink design discussed here for ease of presenting the main idea, our empirical setting requires the application of a fuzzy RKD. The weights for the mechanical and total effects are generally not the same in a fuzzy RKD, but we propose a testable condition in Appendix C that imply the same weighting scheme for both the mechanical and total effects, and present evidence that this condition is met in our setting.
} 
one can get a sense of the extent to which the resulting RKD estimate applies to all other claimants. We report estimates of these characteristics in Section 3.

For the fiscal externality quantity in (9) to correspond to a policy such as increasing the weekly benefit amount uniformly for all workers, some additional restrictions on unobserved heterogeneity are required. One approach that would respect the fact that the mechanical effect of these policies may be heterogeneous, and that also avoids making assumptions about the weights $\omega$, is to adopt the approximation that the behavioral effects are constant proportions of the mechanical effects for each individual. That is, $\frac{\partial B}{\partial \mathbf{Y}_{i}} \cdot \frac{\partial \mathbf{Y}_{i}}{\partial \theta}=k_{0} \frac{\partial B}{\partial \theta}$ and $\frac{\partial T}{\partial \mathbf{Y}_{i}} \cdot \frac{\partial \mathbf{Y}_{i}}{\partial \theta}=k_{1} \frac{\partial B}{\partial \theta}$, where $k_{0}$ and $k_{1}$ are constant across the population. This would imply that the RKD fiscal externality quantity in (9) would equal $k_{0}-k_{1}$ and also equal the fiscal externality (2) for the full population. We elaborate on the assumptions that would permit this extrapolation in Appendix B.

\section{The Unemployment Insurance System in Washington State}

This section describes the unemployment insurance benefit formula, the state of Washington's randomized experiment for studying the effects of partial UI, and the data used for our empirical analysis.

In Washington, UI claimants are eligible to receive a weekly benefit amount based on the earnings and hours in their "base year" (or "base period"), which is defined as the first four of the last five completed calendar quarters before the week of the initial claim. ${ }^{21}$ A claimant must have worked at least 680 hours in the base year to be eligible for UI benefits, a feature that is unique to Washington and thereby leads to employers' reporting of claimants' history of hours worked. If the applicant is eligible, two quantities are computed for her: the weekly benefit amount and the maximum benefits payable. The weekly benefit amount — the amount they can receive while unemployed, subject to a job search requirement—is calculated as $1 / 50$ of the sum of the two highest quarterly earnings within the base year, subject to a maximum and minimum. ${ }^{22}$ The maximum benefits payable is the total amount of UI payments that can be made within one year of the initial filing date. This total amount is equal to the lesser of 30 times their weekly benefit amount and $1 / 3$ of their total base year earnings.

Formally, the weekly benefit amount $(w b a)$ and the maximum benefits payable $(m b p)$ can be expressed

\footnotetext{
${ }^{21}$ For example, if an individual first files a claim in February 1995, then their base year is defined as starting on October 1 , 1993 and ending on September 30, 1994. Claimants who are ineligible for UI benefits under the primary definition of the base year can use the most recent four completed quarters (in this example, from January 1, 1994 to December 31, 1994) to determine their eligibility and benefits.

${ }^{22}$ We will omit the minimum weekly benefit amount from our analysis and in the following discussion because that threshold is binding for only a small proportion of our sample.
} 
as functions of the quarterly earnings in the base year in the following way: Let $Q_{1}$ (highest), $Q_{2}, Q_{3}$, and $Q_{4}$ (lowest) be the quarterly earnings within the base year. Suppose, for this example, that the maximum weekly benefit amount is $\$ 350 .{ }^{23}$ Then

$$
\begin{gathered}
w b a=\min \left(\frac{Q_{1}+Q_{2}}{50}, 350\right) \\
m b p=\min \left(30 \cdot w b a, \frac{Q_{1}+Q_{2}+Q_{3}+Q_{4}}{3}\right)
\end{gathered}
$$

To identify the impact of a change in the weekly benefit level, we exploit the kink in the wba formula as a function of the sum of the two highest quarter earnings in the base year. However, as is clear from the $m b p$ formula, there is an additional kink in the maximum benefits as a function of the total base year earnings. To visualize where these kinks occur, and how they relate to each other, let $\tilde{X}=Q_{1}+Q_{2}$ and $R=\frac{Q_{3}+Q_{4}}{Q_{1}+Q_{2}}$, and consider regions of $\tilde{X}-R$ space, as in Figure 2.

The figure shows that there are four regions where the $w b a$ and $m b p$ will be computed differently, and as a result, the boundaries between these regions will coincide with a kink in those quantities. ${ }^{24}$ Focusing on the evolution of $w b a$ as a function of $\tilde{X}$, note that $w b a$ is kinked at $\tilde{X}=\$ 17,500$. Furthermore, when $R>0.8$, $m b p$ is also kinked as a function of $\tilde{X}$ at $\tilde{X}=\$ 17,500$ (denoted boundary I). When $R<0.8$, there is only a kink in the relation between $\tilde{X}$ and $w b a$ at $\tilde{X}=\$ 17,500$ (denoted boundary II). This means that a regression kink design using normalized $\tilde{X}$ as the running variable identifies the marginal effect of simultaneously increasing both the $w b a$ (e.g. by a dollar) and the $m b p$ (e.g. by 30 dollars) for those who have $R>0.8$, and the effect of just increasing the $w b a$ (keeping $m b p$ constant) for those with $R<0.8$. In our analysis, which pools the individuals above and below $R=0.8$ to estimate the marginal effect of $w b a$, we acknowledge that for a subsample of individuals (those with $R>0.8$ ), the marginal effect is overstating the effect of $w b a$ to the extent that there is an independent marginal effect of $m b p$. In our analysis, we normalize $\tilde{X}$ to be zero at the threshold (denoted $X$ ) as mentioned in Section 2.2. ${ }^{25}$

\footnotetext{
${ }^{23}$ The maximum weekly benefit amount was \$343 from July 1994-95, and \$350 from July 1995-96.

${ }^{24}$ In principle, we can also exploit the kinks labeled III and IV on the graph in separate RKD analyses. For individuals for whom $\tilde{X}<\$ 17,500$, with a running variable to $R$, there is a kink in the relation between $R$ and $m b p$ at boundary III, but not between $R$ and $w b a$. This allows identification of the impact of a marginal increase in $m b p$, keeping $w b a$ constant. The same kind of marginal effect can be identified using $Q_{1}+Q_{2}+Q_{3}+Q_{4}$ as the running variable, where there is a discontinuous relation between the full base year earnings and $m b p$ at boundary IV.

25 The threshold was at $\$ 17,150$ before July 1995 , and $\$ 17,500$ thereafter.
} 
The benefits that claimants are paid in any given week also depends on the amount of labor income they earn while claiming UI. Similar to other states in the U.S., Washington has a disregard amount $d$ for which claimants can earn each week without penalty, and a rate $\rho$ at which benefits are deducted for each dollar earned above $d$. During the period of our sample, Washington reduces the amount that they pay a claimant by $\$ 0.75$ for each dollar that the individual earns above $\$ 5$ in the week of the claim. Formally, if $Y$ is the amount of labor income that a claimant earns in a given week, $d$ is the disregard, and $\rho$ is the implicit tax on earnings above $d$, then the amount of benefits that the claimant would receive that week is given by

$$
\tilde{B}=\max (0, w b a-\rho(Y-d) \mathbf{1}[Y>d])
$$

To summarize, as in many states in the U.S., the Washington UI system can be characterized by four parameters: $w b a, m b p, \rho$ and $d$. Our goal is to examine the fiscal externality of marginal changes in $w b a$ and $\rho$. While there is an extensive literature that studies the effects of changes to $w b a$, less is known about the effect of changes to the partial unemployment insurance parameters. Two papers that have focused on partial unemployment insurance have used different kinds of variation in the disregard level $d$. McCall (1996) studied whether the level of the partial UI earnings disregard influences a UI recipient's job search behavior. He used variation in the level of earnings disregard across states and within states over time and found that a higher earnings disregard increases both the part-time and overall re-employment hazards. More recently, Le Barbanchon (2016) uses bunching at the disregard level to show how kinks in the benefit schedule with respect to labor income can lead to intensive margin responses. That study's estimated earnings elasticity with respect to the tax rate and the corresponding counterfactual simulation suggests an optimal benefitreduction rate of 80 percent. In practice, the disregard level $d$ is quite low in Washington ( $\$ 5$ a week; $\$ 15$ in the treatment group), so our interpretation of the effects will center around the impacts resulting from variation in $\rho .^{26}$

\subsection{The Washington State Unemployment Insurance Earnings Deduction Experiment}

For one year starting in October 1994, Washington conducted a large randomized experiment to investigate the effects of reducing the amount of benefits deducted from claimants who work while on UI. In partic-

\footnotetext{
${ }^{26}$ Furthermore, we note that we find no evidence of "bunching" at the disregard levels, which would be evidence of behavioral responses to the disregard.
} 
ular, Washington randomly assigned 25 percent of all eligible UI claimants to an alternate unemployment insurance system whereby claimants faced a disregard rate of \$15 (rather than the usual \$5) per week and a marginal tax rate of $2 / 3$ (compared to the usual 3/4). These individuals each received a letter in the mail that explained their more generous benefit schedules. Figure 3 illustrates the net income as a function of their weekly earnings (under a scenario where the calculated wba is $\$ 300$ ), for both the treatment and control groups. Although the baseline disregard was more than 0 , and the treatment group faced a higher disregard (\$15), the treatment can largely be thought of as a "pivot" of the benefit schedule outward, reflecting the lower $\rho$.

To give a sense of the magnitude of transfers from being in the treatment group, consider how much a claimant with a weekly benefit amount of $\$ 300$ would receive. According to Figure 3 , an individual who does not work would see no difference between the treatment and control benefit schedules. On the other hand, if the individual earned $\$ 405$, their benefits would have been just reduced to zero in the control regime, but would be eligible to receive an extra $\$ 42$ a week-about a 10 percent increase in total income-under the treatment regime.

The goal of the experiment was to measure the extent to which the lower implicit tax rate could induce claimants to work more than they otherwise would and, as a consequence, reduce the amount of UI benefits paid. In the evaluation report of the experiment, O'Leary (1997) found that claimants in the treatment group received $\$ 67$ more in benefits in the benefit year than the control group, and furthermore, that this amount was greater than what the control group would have received if the more generous benefit formula were mechanically applied to the control group's reported earnings. Thus, the behavioral response to the reduction in the marginal tax rate was cost-increasing, rather than cost-reducing. Our analysis interprets these experimental findings (including the impacts on earnings) within the fiscal externality framework, and compares those effects to the quasi-experimental evidence on the marginal effect of increasing $w b a$ from using the regression kink design.

\subsection{Administrative Claims and Employer Earnings and Hours Data}

We use administrative data for all individuals who filed for unemployment insurance in Washington between October 1, 1994, and September 30, 1995. The dataset contains detailed records of claimants' demographic characteristics, earnings and hours as reported by the employer on a quarterly basis before and during the 
benefit year, the weekly benefit amount, maximum benefits payable, and actual UI payment each week. The administrative measure of quarterly hours is a distinct feature of the Washington data that most other state UI systems do not track, and it provides an alternative measure of work activity throughout the period. The great advantage of using the employer-reported information is that the coverage is probably as complete as any single data source could be: we can capture work activity post-UI-filing irrespective of claiming activity. The alternative source, which is more commonly available in existing UI studies of administrative data, is the employee-reported earnings on the continuing claim forms, which are missing in any week for which the individual does not claim benefits. This source complicates any interpretation of results regarding earnings due to non-random sample selection.

While we have highly detailed information on individuals' earnings, we do not know the exact amount of UI tax paid by each individual, which is needed to compute the tax component of the fiscal externality. ${ }^{27}$ Washington, like other states, uses an experience rating system whereby an employer's payroll tax rate depends on its history of contributions to and withdrawals from the state's UI trust fund. Since we do not observe the employers' tax rates, we apply the average tax rate of each year in Washington state, defined as total employer contributions divided by total taxable wages within the year, to individual earnings, up to the statutory cap on taxable earnings. ${ }^{28}$

There were 300,957 UI claimants subject to randomization during the year of the experiment. After removing individuals from the sample who were either 1) ineligible for benefits, ${ }^{29}$ 2) ineligible for the experiment because they were part of a timber industry retraining program, or 3) had unexplained errors in their data, ${ }^{30}$ the evaluation report used a final sample of 278,055 for their analysis (O'Leary, 1997). The analysis in this paper begins with these 278,055 observations. We further drop a relatively small fraction of observations in order to make our analysis less sensitive to outliers in the RKD analysis, bringing our main analysis sample to 272,261 observations. ${ }^{31}$

\footnotetext{
${ }^{27}$ We calculate our fiscal externality from the perspective of the state UI agency, who may be interested in the impact of policies on the UI trust fund only. If we were to take a more expansive view (e.g., from the perspective of the state or federal government), we will need to account for impacts on state and federal tax revenues. We provide alternative estimates using a "full tax wedge" (as in Schmieder, von Wachter and Bender, 2016) to calculate the fiscal externality below and in the Appendix.

${ }^{28}$ Only the first $\$ 19,900$ of each employee's wages are taxable in 1994 and 1995 (\$20,300 in 1996). Total contribution and taxable wage information is available on the US Department of Labor website: https://workforcesecurity.doleta.gov/unemploy/hb394.asp

${ }^{29}$ Most of these individuals either did not work or worked less than the required 680 hours in their base year to qualify for unemployment benefits.

${ }^{30}$ There are 927 individuals for whom it could not be explained why their weekly UI benefits did not follow the actual benefit formula, minus any deductions recorded in the data.

${ }^{31}$ Specifically, we identified an unusually large number of claimants with their highest two quarterly earnings in the base year totaling to a handful of specific values, which originated from a few employers. This concentration of observations generated "spikes" in the distribution of the running variable. In order to prevent our RKD estimates from being too heavily influenced by
} 
Table 1 reports the means of baseline characteristics of our main analysis sample by treatment status. The means of these variables are of similar magnitudes to what one might expect to see in the unemployed population, as measured by the Current Population Survey. ${ }^{32}$ For example, 64 percent of the claimants are male and 80 percent are white, whereas the percentages for the unemployed population (including nonclaimants) from Washington State in 1994-95 from the CPS are 56 percent and 91 percent, respectively. The average age is 37 , and average years of schooling is 10.7 years in our sample. The corresponding estimates using CPS data are 35 and 12.8 years. The small variation in means between the treatment and control groups across all the characteristics is consistent with effective randomization of treatment status.

The RKD analysis will produce "weighted average" marginal impacts of an increase in the weekly benefit amount, as described in Section 2.2. Also as mentioned in Section 2.2, while those weights are unobserved, we can nevertheless estimate the weighted means of the baseline characteristics using those same weights. This is given by estimates of the means of the characteristics, conditional on $X=0$. We estimate regressions of each of the characteristics on a polynomial of order 6 in $X$, adding an interaction between $X$ and a treatment indicator, as well as the treatment indicator variable itself. The regression intercepts serve as estimates of these conditional means and are reported in Column (4) of Table 1. They show that the implicit weights discussed in Section 2.2 are such that the resulting weighted means are similar in magnitude to the overall means from the treatment and control groups. As one might expect, given that the weights will disproportionately upweight those expected to have earnings close to the threshold (which is about $\$ 6,000$ more than the overall average for two highest quarter earnings), the weighted average age, fraction male, fraction white, and years of schooling — all attributes positively correlated with earnings—are larger than the overall means in the sample.

Column (5) of Table 1 shows the estimated jump in the derivatives from the regressions above. If the conditions for valid causal inference from an RKD hold (Card et al., 2015b), we would expect there to be no kinks in any of these baseline characteristics, and overall the estimates are consistent with that prediction. Finally, in Column (6), we report the coefficients on the treatment indicator, which measures the gap between the conditional expectation functions for the treatment and control groups. Since treatment was assigned randomly, the detection of significant differences would be driven by an overly-restrictive a very small number of employers, we dropped all claimants who were previously employed there, leaving us with a final sample size of 272,261 .

${ }^{32}$ The CPS sample consists of 1,126 individuals surveyed in Washington between 1994 and 1995 who reported being unemployed. 
functional form (e.g. the 6th-order polynomial). Overall, there are no significant differences found from this specification, indicating that the polynomial of order 6 is a reasonable approximation for gauging these rough magnitudes. That said, in our RKD analysis, we will explore local polynomial estimators of different orders and bandwidths, as is standard in the RDD and RKD literature.

\section{Experimental and Quasi-Experimental Fiscal Externality Estimates}

This section presents the findings from the Washington UI Earnings Deduction Experiment and the regression kink design analysis. The experiment yields variation in the implicit tax rate $\rho$, whereas the RKD yields variation in the weekly benefit amount $w b a$. For both sources of variation, our focus is on estimating the fiscal externality described in the conceptual framework, $\beta+\gamma$. To better understand the factors driving the fiscal externality, we also estimate the behavioral costs due to changes in UI payments $(\beta)$ and tax receipts $(\gamma)$ separately, as well as the impact of the policy on various measures of labor supply.

We estimate quantities within varying periods of time since the quarter of the first filing, ranging from the same quarter of the initial filing (indicated in the tables as "Q1") to four quarters ("Q1 to Q4") after the filing. Specifically, since some of our parameters combine behavioral effects on UI payments and tax receipts (which are measured using quarterly earnings), we aggregate the weekly UI payment data so that we measure total payments within calendar quarters. Therefore, "Q1" covers the entire quarter in which the individual initiated the claim, and "Q1 to Q4," for example, covers Q1 and the subsequent three calendar quarters. $^{33}$

\subsection{Estimates from the UI Earnings Deduction Experiment}

To estimate the fiscal externality of decreasing the earnings deduction rate, we must first decompose the effect of the experiment on UI payments into its behavioral and mechanical components. The top four rows of Table 2 show the average UI payments within each time frame for the treatment and control group. On average, the control group receives a total of $\$ 2,689$ over four quarters, with most of that amount $(\$ 2,447)$ accumulating within the first three quarters. As in O'Leary (1997), we find with statistical significance that

\footnotetext{
${ }^{33}$ Since the initial filing can occur any time within the quarter, the length of the post-filing window varies from 1 to 13 weeks for Q1. Note that in all of our time frames, all outcomes will include pre-filing data; with successful randomization and a valid RKD design, this inclusion should "difference out" and should not impact the consistency of the estimates, but could increase sampling variability.
} 
the treatment group received more UI benefit payments than the control group. The causal effect of the lower implicit tax rate grows over time, from \$16 in Q1 to \$67 for the full Q1-Q4 time frame.

A positive effect on total UI payments is to be expected even in the absence of any behavioral response to the more generous benefit schedule. In Table 3, we break the effect up into mechanical and behavioral components. The former measures the additional payments that would result from a formulaic application of the treatment benefit schedule to the control population. To compute these amounts, we simply infer each control group member's implied weekly earnings from their received weekly benefits and then apply the treatment group's benefit formula to the control group. ${ }^{34}$ The difference in total UI payments between the simulated treatment group and the control group is our estimate of the mechanical effect. The difference between the full treatment effect and the mechanical effect is the effect that can be attributed to a behavioral response to the different benefit formula. Our estimates imply that by the fourth quarter, the mechanical effect accounts for $\$ 28$ of the total difference, while the remaining $\$ 39$ is due to behavioral responses. ${ }^{35}$

With the mechanical effect in hand, we are able to estimate the fiscal externality. We compute the difference in UI payments net of taxes between the treatment and control groups, where tax receipts are estimated by applying the average payroll tax rate schedule on earnings. ${ }^{36}$ By subtracting the mechanical effect from this treatment effect, and then taking the ratio of this difference with the mechanical effect, we obtain an estimate of the fiscal externality $\beta+\gamma$, which we report in column (5) of Table 3 . The fiscal externality over four quarters is $\$ 1.38$ (standard error $\$ 0.45$ ) per dollar of mechanical transfer, meaning that for every dollar transferred inframarginally via a decrease in the earnings deduction rate $\rho$, there is an additional cost of $\$ 1.38$ to the government budget due to behavioral responses.

To understand how much of the fiscal externality is driven by increased UI payments or reduced tax re-

\footnotetext{
${ }^{34}$ For those receiving the zero benefits, we apply the treatment group formula assuming that earnings exceed the break-even point above which a claimant in the treatment group would no longer receive benefits. In effect, we impose that individuals who receive zero benefits in the control group would continue to receive zero benefits in the treatment group. In principle though, earnings can be above the control schedule's break-even point but below the treatment schedule's. An alternative approach to calculating the mechanical effect is to use the reported earnings in the claimant data. In practice, there are some unexplained deviations between the UI payments and that which would be predicted by the earnings reported on the weekly continuing claim form. Our approach will be favorable if the payment data are considered to be measured with less error than the earnings variable in the claims data.

${ }^{35}$ As mentioned in Section 2.2, we can obtain an alternative estimate of the mechanical effect by simulating UI payments using the treatment group, and averaging the two effects. In that case, we get a mechanical effect estimate of $\$ 35$ (standard error 0.3 ) and a behavioral effect of $\$ 32$ (standard error 12.6). However, this mechanical effect is overstated because we do not observe the full simulated payments under the control regime of treated units who exhaust UI. Therefore, the resulting fiscal externality estimate of 0.90 (standard error 0.36) should be viewed as a lower bound of the true fiscal externality.

${ }^{36}$ We use average UI payroll tax rates, which were 1.96 percent, 1.92 percent, and 1.88 percent for 1994, 1995, and 1996, respectively. We conduct our welfare analysis from the perspective of the state considering only the fiscal impacts of each policy on the UI benefits and taxes. If one takes a more expansive view of government (i.e. from the perspective of the federal government), one could also consider the impact of the policy on federal income tax receipts, which would be larger. See Schmieder and von Wachter (2016) and Lawson (2017) for more a more detailed discussion.
} 
ceipts, we also estimate $\beta$ and $\gamma$ separately in Table 3. The component of the externality due to UI payments $\beta$ is computed by taking the ratio of the behavioral UI payment effect (column 3) to the mechanical effect (column 2), while the component due to tax receipts is the ratio of the experimental impact on taxes (column 4) to the mechanical payment effect. ${ }^{37}$ The results suggest that the entire $\$ 1.38$ of the fiscal externality over four quarters is due to the behavioral impacts on UI payments. Alternatively, as shown in Appendix Table A.1, when we use the "full tax wedge" tax rate (31.54 percent) of Schmieder and von Wachter (2016), we obtain a $\gamma$ of 65 cents and a larger fiscal externality estimate of $\$ 2.03$ over four quarters.

We also document the experimental impacts on various measures of labor supply directly. Indeed, one of the motivating questions behind the Washington earnings deduction experiment was whether a lower implicit tax rate in the benefit schedule will increase employment and earnings. The second set of rows in Table 2 reports the average effect of the experiment on earnings. Unlike with UI payments, we do not find any statistically significant differences in earnings between the treatment and control group in any time frame. Furthermore, the magnitudes that we can statistically rule out are small relative to the means. For example, for Q1 to Q4, the 95 percent confidence interval is between $\$ 184$ to $\$ 68$ on a base of $\$ 13,388$ - or 1.4 percent to 0.5 percent. Consistent with the null earnings effects, we find no statistically significant impacts of the experiment on cumulative hours over any time frame and the range of the 95 percent confidence intervals are small relative to the mean (third set of rows in Table 2). As seen in the fourth and fifth set of rows in Table 2, we also detect no extensive margin effects: the proportion of non-zero earnings or hours in the treatment and control groups are nearly identical in all time frames, with standard errors between 0.0010 and 0.0018 on means ranging from 0.80 to 0.95 . The intensive margin effects, shown in the sixth and seventh set of rows in Table 2 in terms of $\log$ (earnings) and $\log$ (hours) mirror the results for levels. The treatment and control means are identical to the second decimal place, with differences never greater than 0.004 and statistically indistinguishable from zero. ${ }^{38}$ Overall, we consistently find no impact of the experiment on labor supply.

To gain further insight on the drivers of the behavioral effect captured in $\beta$, we report in the last six rows of Table 2 the experimental impacts on the frequency of claiming UI and the duration of the first UI

\footnotetext{
${ }^{37}$ The standard errors account for the covariance between the estimators for the behavioral and mechanical effects via a stacked regression, in which we estimate the two equations jointly and cluster the standard error by individual (similar stacked regressions can be seen in more detail in Section 4.4.2. of Lee and Lemieux, 2010 and Section 5.3 of Pei, Pischke and Schwandt, forthcoming).

${ }^{38}$ By construction, the logarithm drops all observations with zero earnings or hours, so the treatment and control means are conditioned on a potentially selected sample. However, as discussed in Lee (2009), if we assume that the treatment effect on sample selection is characterized by a monotonicity condition, then given that we found no differences in the proportions of missing values in the treatment and control populations, we can interpret the observed log-earnings and log-hours differences as reflecting causal impacts of the treatment.
} 
spell. From Q1 to Q4, the average number of weeks claimed is 13.23 in the control group and 13.76 weeks (4 percent higher) in the treatment group. This statistically significant increase in claims can potentially be explained by the length of the initial UI spell, defined as the number of weeks of UI payments with no more than a three-week gap, which is 0.60 greater in the treatment group than in the control group. Since there was no detectable effect of the experiment on earnings, this evidence suggests that an increased propensity to claim is the driving force behind the behavioral response to the more generous benefit formula. While we find that much of the fiscal externality is driven by claiming or take-up behavior, it is important to note that, to the extent that the social planner values increased take-up (which may be indicative of individual optimization frictions), a complete welfare analysis will need to account for the social value of this change in behavior, along with measures of the social benefit of the transfer (i.e., $\alpha$ in equation (4)).

Finally, we point out that while the earnings effects are statistically insignificant, they are roughly on par (and opposite in sign) to the point estimates of the UI payment effects. An interesting question from a policy perspective, which goes beyond the welfare framework described in Section 2, is whether the policy had an impact on workers' incomes, where income includes both earnings and UI payments. Adding up the effects from the first two sets of rows in Table 2, we find that the the point estimate suggests a small positive impact of about $\$ 9$ on income over the four quarters. If we scale this number by treatment-control difference in UI payments, $\$ 67$, this implies that a one dollar increase in UI transferred increases the income of workers by 13 cents. A 95 percent confidence interval, however, suggests that income may be reduced by as much as $\$ 1.71$ and or increased as much as $\$ 1.98$ for every dollar of UI transferred. ${ }^{39}$ We will return to this number in the next section, when we estimate the same quantity for the weekly benefit level policy.

\subsection{Estimates from the Regression Kink Design}

This section reports the regression kink estimates of the fiscal externality associated with a marginal increase in the weekly benefit level $(w b a)$. As with the analysis of the experiment, we need to estimate the impact of $w b a$ on UI payments and tax receipts, but in this section, we will use the quasi-experimental variation in benefits generated by the UI benefits cap. We first present graphical evidence of the design's validity and impacts on the behavioral and mechanical components of UI payments and earnings before proceeding to our main estimates. After verifying the robustness of our estimates to various estimating specifications, we turn to estimates of the fiscal externality parameters of interest.

\footnotetext{
${ }^{39}$ This confidence interval accounts for the estimated impact on UI payments.
} 
Figure 4 shows the RK first stage, plotting the weekly benefit amount wba against the normalized two highest quarter earnings variable, i.e. the running variable $X$. Each solid circle represents the average of $w b a$ (left y-axis) within a $X$-bin of width $\$ 400$. The empirical relationship between $X$ and $w b a$ tracks closely the statutory benefit formula described in Section 3, in the range where $X$ is above $-\$ 14,000$. We do see some modest departure from the benefit formula, which is common in RK analyses, most likely due to measurement error in $X$ as discussed in Appendix C. ${ }^{40}$ Therefore, we apply a fuzzy regression discontinuity design as described in Card et al. (2015b).

To confirm our understanding of the UI benefit formula, we also plot the maximum benefit payable $m b p$ (right y-axis) against $X$ in Figure 4 separately for workers with $R>0.8$ (hollow circles) and $R \leqslant 0.8$ (hollow triangles), where $R=\frac{Q_{3}+Q_{4}}{Q_{1}+Q_{2}}$ and $Q_{i}$ is the earnings from the $i^{\text {th }}$ highest paid quarter in the base period. As discussed in Section 3, the relation between $X$ and $m b p$ differs depending on whether the ratio $R$ is above or below 0.8 . When $R>0.8$, the rules imply a kink in $m b p$ because $\frac{m b p}{w b a}$, the maximum number of weeks of UI at the full benefit amount, is exactly 30 throughout. When $R \leqslant 0.8$, we would not expect a kink in the relationship between $m b p$ and $X$. We see both of these features in the empirical relationship when viewing them separately for individuals who have an $R$ above or below 0.8 . In our main analysis, we pool observations from both sub-groups to maximize statistical power. We note that any estimated kink from the pooled sample will include the marginal effect of both the marginal effects of wba and $m b p$ for those with $R>0.8$. That said, the estimates when only using 72 percent of the sample that has $R \leqslant 0.8$ are similar.

Following Card et al. (2015b), a valid regression kink design requires that, conditional on unobservables, the density of $X$ is continuously differentiable at the kink threshold. The first way to test this identifying assumption is to examine the empirical density of $X$, to determine if there is evidence of "sorting" around the threshold - this is the RKD analogue to the test of McCrary (2008). We plot the frequency distribution of the running variable $X$ in Figure 5. Finding a kink in the density at the threshold would indicate a rejection of the identifying smooth density assumption at the individual level. The frequencies do not reveal any large kinks in the histogram. It is also clear that the observations in the left tail of the $X$ distribution causing the most deviations in Figure 4 are relatively few in number. In subsequent graphical presentations, we will restrict to the range of $X \in[-14000,14000]$.

A second method of assessing the validity of the identifying smoothness assumptions is to examine whether or not there are kinks in the relationship between the baseline characteristics and $X$. Column (5)

\footnotetext{
${ }^{40}$ The recorded $w b a$ is within 1 dollar of the nominal $w b a$ using $X$ for 93.8 percent of the sample.
} 
of Table 1 presents evidence showing that a global parametric regression does not reveal significant kinks in those characteristics. In principle, one can perform an in-depth examination of those estimates and their sensitivity to different functional forms and bandwidths, for each variable. As an alternative, we adopt the approach taken in Card et al. (2015a) and Card et al. (2017) and examine a "covariate index" for each outcome that we consider. The index is simply a linear combination of the baseline characteristics, where the coefficients are those from a regression of the outcome on the covariates. ${ }^{41}$ This constructed index is measured in the same units as the outcome variable, and so we can directly compare the covariate index to the actual outcome of interest in our plots.

We now present graphical evidence on the key outcomes in our analysis before turning to estimation and inference. When indicated, we "de-trend" both the outcome and the covariate index from a linear regression of the outcome (or covariate index) on the running variable $X$ in order to facilitate the visual detection of a kink in the relationship. We hypothesize that it can be difficult to recognize a kink when the slope of the function is steep. Residualizing the outcome (and covariate index) from a linear prediction using $X$ effectively rotates the relationship around the threshold, which may improve the ability to see a feature such as a kink near the threshold. Using this method, Figure 6 plots total UI payments against $X$ in the four time periods. Each dot represents an average payment amount within a bin that is $\$ 400$ wide. In all four graphs, there is a visible break in the slope of the relationship, with the magnitude of the kink growing as the time frame expands, and as more benefits are received. By contrast, the comparable plots for the covariate index are quite flat with respect to $X$.

Figure 7 plots the empirical relation between $X$ and the mechanical increase in UI payments from a dollar increase in $w b a$ within the four time periods. The mechanical effect is the additional benefits that claimants would receive if their weekly benefit amounts were $\$ 1$ higher and if they did not change their UI take-up or labor supply behavior. To compute this amount, we add a dollar to the benefits that claimants receive each week that they claim, and then restrict their cumulative payments to be no more than their $m b p$, accounting also for the fact that $m b p$ increases by $\$ 30$ for individuals with $R>0.8$. The difference between the simulated UI payments and the actual UI payments is the mechanical increase in UI payments from a marginal increase in wba. For many claimants, this mechanical effect is equal to the number of weeks that they claim UI benefits, because absent any behavioral response, a dollar increase in $w b a$ simply translates to

\footnotetext{
${ }^{41}$ The covariates are age, age-squared, sex, ethnicity, years of schooling, veteran status, job center location, occupation, industry, self-employment, week in quarter of initial UI claim, and the earnings and hours in each quarter of the base year.
} 
an additional dollar per week claimed. However, since individuals cannot receive more benefits than their $m b p$, some claimants' mechanical effects are less than the number of weeks that they claim UI payments. We do not de-trend the graphs in Figure 7 in order to show our estimate of the graphs' intercepts, which is the mechanical effect of a marginal increase in $w b a$ for individuals at the kink. Thus, for example, in the Q1 to Q4 period, the pure mechanical effect of a dollar increase in the $w b a$ is about 11.

Figure 8 displays the relationship between cumulative earnings and $X$ for each follow-up period. In this case, there are no visible kinks in either the actual outcome or the covariate index for this outcome, although for the Q1 to Q4 period, the variability in the binned averages could potentially be masking kinks in either direction. The covariate index appears to have much less variability and does not appear to show any kinks in the relationship with $X$. Based on the visual evidence for earnings, unlike the previous figures, we might expect to see statistically insignificant effects of $w b a$ on earnings.

To estimate the magnitudes of these kinks, we follow the approach in Card et al. (2015b) and estimate the fuzzy RKD estimand by taking the ratio of estimated kinks in the outcome and observed $w b a$ with respect to $X$, where each kink is estimated by a local polynomial estimator of the change in the derivative at $X=0$. Numerically, this is equivalent to restricting the data within a bandwidth of the threshold, and regressing the outcome on $w b a$, instrumenting with $A \cdot X$, using as controls polynomial terms $X^{k}$ and $A \cdot X^{k}$ (excluding the linear $A \cdot X$ term) for $k$ up to order $p$, where $A=\mathbf{1}[X \geq 0]$ indicates that a worker has base period earnings above the threshold.

Two tuning parameters are required for RK estimation: the bandwidth $h$ and polynomial order $p$. For $h$, we use the mean squared error (MSE) optimal bandwidth from the rdrobust Stata package by Calonico et al., 2017 (henceforth CCT bandwidth). ${ }^{42}$ For polynomial order $p$, we choose the order from the set $\{1,2,3\}$ that delivers the lowest estimated MSE as per Pei et al. (2018) by using the accompanying rdmse Stata package. We also present evidence that the RK estimates of our key outcomes are generally robust with respect to these tuning parameters.

Table 4 presents the fuzzy RK estimation results for the same outcomes as in Table 2. The first two columns report the tuning parameters used in estimation: column (1) reports the polynomial order $p$ that

\footnotetext{
${ }^{42}$ When using the default CCT bandwidth, which includes a regularization term, we find that our estimates in many cases suffer from low precision. This is the case, for example, with the estimate of cumulative UI payments from Q1 to Q4, despite the visually striking and institutionally grounded kink in the lower right panel of Figure 6. Therefore, our results reflect estimates without the regularization term. Consistent with the findings in Card et al. (2017), the regularization term, while asymptotically negligible, greatly impacts the computed value of the RK optimal bandwidth. Following Card et al. (2015b), we use the fuzzy CCT bandwidth without regularization as our specification to estimate the various RK effects, but explore the sensitivity of our estimates to bandwidth choices in Figures 9, 10, A.3, and A.4.
} 
minimizes estimated MSE, and column (2) the CCT bandwidth $h$ for the selected $p$. A quadratic or linear specification is chosen for the vast majority of outcomes, though in a handful of cases, a cubic polynomial is estimated. In terms of our main outcomes, the effects on UI payments are estimated with a linear specification, while the effects on earnings are generally estimated with a quadratic specification. In general, the optimal bandwidth for linear specifications (ranging from 1,453 to 7,817) is smaller than that for higher order polynomials (ranging from 2,991 to 12,208 for quadratic). As reported in column (3), the corresponding effective sample size, i.e., the number of observations within bandwidth $h$, ranges from 20,164 to 127,864 for local linear and from 41,164 to 225,983 for local quadratic.

The first stage estimates in column (4) confirm the formulaic relationship graphically presented in Figure 4 between the treatment variable $w b a$ and the running variable $X$. In rows where the level of $w b a$ is the treatment variable - every row except for the last row, for which $\log (w b a)$ is the treatment variable the first stage estimate almost always falls between -0.019 and -0.020 (recall that -0.02 is the exact slope change implied by the formula). ${ }^{43}$ The first stage is also precisely estimated, and the associated $F$-statistic is above 1,000 for every outcome.

We present the fuzzy RK estimate in column (5). In all rows but the last, the estimate represents the average marginal change in the outcome in response to a one dollar increase in the $w b a$, and in the last row, we report the elasticity of initial claim duration with respect to $w b a$ in order to connect our estimate to the UI literature. Looking down the first four rows, we see that a dollar increase in $w b a$ is estimated to increase total UI payments by 4.7 dollars in Q1 and 15.9 dollars in Q1-Q4. These cumulative UI payment estimates are statistically significant and encompass both the mechanical effect and the behavioral response. The next four rows report the fuzzy RK estimates for cumulative earnings within the four time periods. The effects are statistically insignificant except for that of Q1, and a closer inspection, which we describe below, indicates that the Q1 estimate is likely an outlier. Consistent with the insignificant cumulative earnings result, the RK estimates for the next sets of outcomes-cumulative hours, whether a worker has positive cumulative earnings/hours, and $\log$ (cumulative earnings/hours)—are generally statistically insignificant as well.

In the final rows of Table 4, we present our estimates of $w b a$ on the initial benefit duration, defined as the number of consecutive weeks of UI payments with a gap of no longer than three weeks. To compare with the literature, we redefine the treatment variable (in the last row) to $\log (w b a)$ so that the estimate is close to a

\footnotetext{
${ }^{43}$ The only exception is $\log$ (cumulative hours), for which a cubic polynomial with bandwidth 14,647 is selected with a resulting first stage estimate of -0.014 . This is one of the few cases where the bandwidth seems too large, resulting from the lack of regularization.
} 
duration elasticity. ${ }^{44}$ We find an estimate of 1.06 , implying an elasticity of 1.15 , with a 95 percent confidence interval that allows us to rule out elasticities below 0.28 . This point estimate is larger than the elasticity of 0.88 recently found in Card et al. (2015a), which uses the same methodology and similar administrative data from Missouri. As a visual aid for comparison, we plot in Figure 11 the empirical relation between the logarithm of the initial UI spell duration and base earnings, using the same running variable scale and range as Card et al. (2015a). ${ }^{45}$ While the figure does show a visible break at the discontinuity threshold, variability in the binned averages appears to be larger in Washington compared to Missouri. ${ }^{46}$

Figures 9 and 10 show graphically the sensitivity of our estimates to alternative regression specifications for our two main sets of outcomes. Figure 9 plots the estimated RK effects of $w b a$ on total UI payments Q1-Q4 (row 4 of Table 4) using different bandwidths and a different polynomial order. The solid black curve plots quadratic estimates for bandwidths ranging from 2,000 to 14,000 in 500 increments, and the short dashed black lines plot the upper and lower end of the pointwise 95 percent confidence intervals. In gray, we generate the analogous series of estimates using a linear specification. Our point estimate of about $\$ 16$ for total UI payments over four quarters is consistent with those estimated using a number of alternative bandwidths in the stable range for both linear and quadratic specifications, though the standard errors are smaller for the linear estimates. Figure 10 shows that the negligible effect for earnings are robust to both specifications and for a wide range of bandwidth choices. Appendix Figures A.3 and A.4 show the analogous graphs for UI payments and earnings in all quarters (the lower right corners of the two figures replicate Figures 9 and 10, respectively). Although we find statistically significant and positive quadratic RK estimate for earnings effects in Q1 in Table 4, it is only attained for a set of very large bandwidths, and the unregularized CCT bandwidth happens to fall into this range. Therefore, while we report the positive effect using the unregularized quadratic CCT bandwidth in Table 4, we will focus on the more robust Q1-Q4 estimate on cumulative earnings in our discussion.

Table 5 shows our estimates of the fiscal externality $\beta+\gamma$. We first reproduce the estimates on UI payments from Table 4 in the first column. The mechanical effects (column 2) are the estimated intercepts in

\footnotetext{
${ }^{44}$ Since the numerator is one plus the claim duration, the estimate needs to be scaled by $\frac{1+\text { claim duration }}{\text { claim duration }}$ to be interpreted as an elasticity.

${ }^{45} \mathrm{We}$ adjust for inflation and the fact that the running variable in Card et al. (2015a) was measured in terms of one quarter of earnings.

${ }^{46} \mathrm{~A}$ key difference between the two contexts is that the threshold in Washington State is much higher than in Missouri in an absolute (inflation-adjusted) and relative (position in the base earnings distribution) sense. When we look at approximately the same range around the threshold, we have much fewer observations in our analysis compared to the pre-recession Missouri sample in Card et al. (2015a).
} 
Figure 7, which we obtain from a regression of the simulated mechanical increase in UI payments on quintic polynomials in $X$ and $A \cdot X$, and the behavioral effects on UI payments are the differences between total and mechanical effects. Column (4) shows the fuzzy RKD estimates of the increase in $w b a$ on tax receipts, which are calculated by applying the average payroll tax schedule on earnings. We find economically small estimates of $w b a$ on tax receipts, which is consistent with the negligible estimates earnings effects of Table 4. The Q1-Q4 estimate of the fiscal externality suggests that to transfer one mechanical dollar via an increase in the weekly benefit amount, it costs an extra 53 cents (with a confidence interval of 27 cents to 78 cents) to pay for the behavioral claiming response and the lost UI tax revenue due to changes in labor earnings. In comparison, recall that the fiscal externality of decreasing the implicit tax rate that we estimated earlier is in the range of 49 cents to $\$ 2.26$ with a point estimate of $\$ 1.38$. Unsurprisingly, due to the low tax rates, we find that the fiscal externality is driven mostly by the increased benefit payments when we break the estimates down into components due to UI payments and tax receipts (columns 6 and 7). ${ }^{47,48}$

While the fiscal externality estimates are useful for quantifying the behavioral impacts of a policy, one may also look beyond the standard welfare framework to another economically meaningful metric of how the policy affects overall income of its intended recipients. As before, we estimate the dollar increase in total income, where total income includes UI payments and wages, associated with a dollar transferred to recipients in the form of UI payments. To compute this, we estimate a fuzzy RK specification using income as the outcome and UI payments (instead of $w b a$ ) as a first stage. ${ }^{49}$ The resulting estimate suggests that a one dollar transfer of UI payments increases income by 96 cents, with a 95 percent confidence interval suggesting an income increase by at least 66 cents. In contrast with the implicit tax rate policy, which increases total incomes by (a statistically insignificant) 13 cents per dollar transferred, an increase in the weekly benefit level is therefore more effective at increasing recipient income. We note again, however, that the fiscal externality and associated concepts do not capture potential benefits such as consumption smoothing. A complete welfare analysis requires measurement of these benefits along with the cost measures presented in this study.

\footnotetext{
${ }^{47}$ Due to the small earnings effects, when we use the "full tax wedge" tax rate of 31.54 percent (Schmieder and von Wachter 2016), we obtain a similar estimated $\gamma$ of -0.02 and a total fiscal externality of 0.53 over four quarters. See Appendix Table A.2 for details.

${ }^{48}$ We use the same bandwidths and specifications, which minimize estimated MSE when UI payments are the outcomes, to estimate the different components of the fiscal externality.

${ }^{49}$ Bandwidth and polynomial orders are chosen to minimize estimated MSE when the outcome is total income.
} 


\subsection{Fiscal Externality Measures: Decomposition versus Sufficient Statistics Estimates}

In this section, we directly compare our decomposition estimate (0.53) of the fiscal externality for an increase in the weekly benefit level to the estimate that one would obtain from employing a standard sufficient statistics approach. Specifically, we directly use the sufficient statistics formula of Schmieder and von Wachter (2016) which relates the fiscal externality to behavioral elasticities and other program parameters and quantities. The bottom row of Table 6 shows the formula they use: the fiscal externality is proportional to $\varepsilon$, the elasticity of UI claim duration with respect to the benefit amount, where the factor of proportionality is dependent on the tax rate and the UI replacement rate. We estimate the elasticity $\varepsilon$ using the fuzzy RKD estimate of 1.15 referred to in the previous section. ${ }^{50}$ The resulting fiscal externality estimate of 1.21 is reported in the last row of 6.51

What explains the difference in the magnitudes from these two different approaches applied to the same data, and essentially the same research design for estimating behavioral responses? We identify the source of these differences in Table 6. Starting with the first row of the table, which reproduces our decomposition estimate from Table 5, in each subsequent row, we consider the magnitude that would be obtained by adopting more of the modeling assumptions implicit in a simple implementation of Schmieder and von Wachter (2016)'s formula, until we employ all of the modeling assumptions assumptions in the final row.

The second row of Table 6 adopts the simplification that total benefits paid out is equal to the number of weeks claimed times the weekly benefit amount. This simplification allows one to use weeks claimed as a dependent variable rather than benefits paid, and it leads to a different measure of the mechanical effect: an estimate of $E$ [weeks claimed] at the threshold. Note, however, that this is a simplification of actual benefits because it does not account for the possibility of partial benefits (i.e., the actual weekly benefit may be lower than the assigned weekly benefit amount), and more subtly, that the total UI benefits available over the benefit year is capped. ${ }^{52}$ The latter simplification is consequential for calculating the mechanical impact of increasing the weekly benefit amount because some workers already claim at or close to their maximum entitlement and an increase in the weekly benefit amount (with no corresponding change to the formula for the maximum total UI benefits over the benefit year) will have a smaller actual mechanical impact than under the simplified formula. Indeed, under this simplified benefits assumption, the resulting

\footnotetext{
${ }^{50}$ This estimate is constructed in the same way as Card et al. (2015a)'s 0.78 elasticity estimate that was used in Schmieder and von Wachter (2016)'s Table 2.

${ }^{51}$ We thank Johannes Schmieder for providing the code for the Schmieder and von Wachter (2016) calculations for this exercise.

${ }^{52}$ The maximum benefit entitlement is equal to the minimum of 30 times the weekly benefit and a third of the base period wages.
} 
fiscal externality shrinks to 0.31 , much of it due to a larger estimated mechanical effect.

The third row of Table 6 makes the additional set of assumptions from Schmieder and von Wachter (2016) that allow the researcher to obtain an estimate of the lost tax revenues from the estimated impact on weeks of UI claimed. These assumptions are: 1) a constant weekly hazard from unemployment, 2) the pre-layoff and post-reemployment wages are equal, and 3) a linear tax schedule. Under these assumptions, the fiscal externality can be expressed as being proportional to the RKD estimate of the average marginal effect of $\theta$ weeks claimed. This additional set of simplifications result in a slight increase (to 0.34 ) in the fiscal externality estimate relative to the second row. ${ }^{53}$

The fourth row employs the simplification of focusing on the initial (and only) spell of unemployment. With this simplification "weeks claimed" in the formula is replaced with "(initial) claim duration". ${ }^{54}$ In our data, the RKD estimate of the impact of $\theta$ on initial claim duration (from Table 4) is small enough to drive down the fiscal externality estimate to 0.08 .

The last assumption, which fully reconciles the differences between the first and last row, is the most consequential. The Schmieder and von Wachter (2016) formula, which is derived using a representative agent model, simply requires an estimate of the elasticity of UI duration with respect to $\theta$. Following their calculation of the fiscal externality for Card et al. (2015a), we plug in our estimated average elasticity of claim duration with respect to $\theta$ (1.15). Note that this amounts to using $\varepsilon=E\left[\frac{\partial \text { claim duration }}{\partial \theta} \frac{\theta}{\text { claim duration }}\right]$, instead of a scaled average marginal response of claim duration, $\frac{\theta E\left[\frac{\partial \text { claim duration }}{\partial \theta}\right]}{E[\text { claim duration }]}$. In the context of heterogeneity in responses across individuals, the use of average elasticity $\varepsilon$ requires the assumption that individual claim duration elasticities are (mean) independent of initial claim durations, which implies

$$
\begin{aligned}
\theta E\left[\frac{\partial \text { claim duration }}{\partial \theta}\right] & =E\left[\frac{\partial \text { claim duration }}{\partial \theta} \frac{\theta}{\text { claim duration }} \cdot \text { claim duration }\right] \\
& =\varepsilon \cdot E[\text { claim duration }]
\end{aligned}
$$

Put another way, this assumes that the elasticity of the average duration with respect to the weekly benefit is equal to the average elasticity across individuals. Of course, in the absence of heterogeneity in elasticities, this assumption is trivially satisfied. A homogeneity assumption in this context turns out to be the most

\footnotetext{
${ }^{53}$ The weekly hazard is estimated as in Schmieder and von Wachter (2016) as $\frac{1}{\text { claim duration }}$, where "claim duration" is the average initial duration at the threshold.

${ }^{54}$ As in common empirical practice, we define the initial benefit duration as the observed number of consecutive weeks of benefit receipts before a three-week period of non-payment. This definition implicitly assumes that claimants have full take-up for every week of their unemployment spell, even when the data shows a lapse of one or two weeks in claims.
} 
consequential assumption in Table 6 , increasing the fiscal externality from 0.08 to 1.21 .55

In summary, the decomposition approach invokes a strict subset of the assumptions that would be needed for the sufficient statistics calculation using the formula in Schmieder and von Wachter (2016), which adopts the necessary modeling assumptions that are similar to the kinds of simplifications used in the UI literature to infer fiscal externalities from elasticity estimates. Therefore, by computing the fiscal externality both ways, one can conclude that substantial differences in the magnitudes must be due to the assumptions made by the latter approach that are not needed for the former approach. In our particular application, the assumption that appears to be most inconsistent with the data is that of the assumption of homogeneity. More broadly, this exercise illustrates how the decomposition approach we have discussed can help critically evaluate modeling assumptions when conducting welfare analyses, whether one uses a "sufficient statistics" or fully structural approach.

\section{Implications and Conclusions}

This paper proposes a "decomposition" method of estimating fiscal externalities associated with government income transfer policies as a complement to the prevailing sufficient statistics approach. By employing a simple accounting identity, the behavioral component of the effect of a policy on the government budget can be estimated from the microdata as the difference between the estimated total effect and the mechanical effect that can be calculated using knowledge of the income transfer formula. This allows one to compute a fiscal externality quantity that is consistent with a very large class of behavioral models, and therefore can serve as a complementary benchmark to approaches that require more modeling assumptions. While it follows quite naturally from well-known public economics principles, this method of estimation does not appear to have been employed in the empirical analysis of UI or other income transfer programs.

We use this decomposition framework to evaluate the efficiency of two policy experiments in the Washington State UI system. First, we examine a large randomized experiment that reduced the implicit tax rate on the earnings of UI claimants. While the hope was that the enhanced work incentive could have generated a positive labor supply response and hence reduced the cost to the government, instead we find that for each dollar of inframarginal transfer, the government must pay at least an extra 49 cents to cover the increased benefit expenditure, with a point estimate of $\$ 1.38$.

\footnotetext{
${ }^{55}$ This suggests that initial claim duration is negatively correlated with responsiveness (elasticity) of durations with respect to the benefit level, which is likely if benefit durations are capped as in our setting.
} 
By contrast, our confidence interval for the fiscal externality from increasing the maximum weekly benefit amount ranges from $\$ 0.27$ to $\$ 0.79$ with a point estimate of $\$ 0.53$ for each dollar of mechanical transfer. As a point of comparison, Schmieder and von Wachter (2016) survey the US literature, using elasticities (typically the UI spell duration with respect to the benefit level) estimated in the literature to compute the fiscal externality, and find a range of $\$ 0.08$ to $\$ 0.95$, with a median of $\$ 0.26$, per dollar of mechanical transfer. Our estimate is thus on the high side of this range.

Comparing the fiscal externality quantities for the above two policies suggests that, despite the intent of increasing work incentives through a lower implicit tax rate, increasing the weekly benefit is a relatively more efficient way of transferring income to UI recipients. The fiscal externality of a lower implicit tax rate in UI has a point estimate of $\$ 1.38$, which is more than double the corresponding measure of increasing the weekly benefit amount of $\$ 0.53$. The two fiscal externalities are statistically significantly different at the 10 percent level. ${ }^{56}$ Therefore, in a standard welfare analytic framework, the social benefits of lowering the implicit tax rate must exceed those of increasing the weekly benefit level in order for the former to be more welfare-enhancing.

We believe that there are a number of avenues of research that may be promising, based on the decomposition approach that we employ. First, our analysis focuses on the margins of increasing the weekly benefit and reducing the implicit tax rate on earnings. But there is little reason why the same approach for estimating the fiscal externality could not be similarly employed to estimate the impact of a policy that lengthened the maximum duration of UI benefits. As suggested by Schmieder and von Wachter (2016), the side-by-side comparison between the fiscal externalities associated with the benefit margin and the maximum duration margin can suggest the margin along which UI transfers can be made with minimal distortionary burden.

Second, although we find that our direct estimate of the fiscal externality of an increase in the benefit amount is somewhat smaller than that computed using the modeling framework and formula of Schmieder

\footnotetext{
${ }^{56}$ Another way to compare the two fiscal externalities while accounting for the sampling errors in both estimates is to consider the following thought experiment. Suppose a policymaker intends to transfer a portion $\xi$ of benefits by increasing $w b a$ and the remainder $1-\xi$ by decreasing $\rho$. With our estimates of the fiscal externality of increasing $w b a$ and decreasing $\rho$ in hand denoted by $(\hat{\beta}+\hat{\gamma})_{w b a}$ and $(\hat{\beta}+\hat{\gamma})_{\rho}$, respectively — the policy maker can forecast the fiscal externality by using the estimates from this paper:

$$
(\hat{\beta}+\hat{\gamma})_{\xi}=\xi(\hat{\beta}+\hat{\gamma})_{w b a}+(1-\xi)(\hat{\beta}+\hat{\gamma})_{\rho}
$$

She knows that she should set $\xi=1$ to minimize $(\hat{\beta}+\hat{\gamma})_{\xi}$. But given the uncertainty of the estimates, she also wants to minimize the "5 percent worst case" level of fiscal externality. That is, she would like to choose $\xi$ to minimize the upper bound of the one-sided 95 percent confidence interval:

$$
(\hat{\beta}+\hat{\gamma})_{\xi}+1.64 * S E[(\hat{\beta}+\hat{\gamma}) \xi] .
$$

Because $S E\left[(\hat{\beta}+\hat{\gamma})_{w b a}\right]=\$ 0.13$ is also substantially smaller than $S E\left[(\hat{\beta}+\hat{\gamma})_{\rho}\right]=\$ 0.45$ and that the estimated correlation between the two fiscal externalities is very close to zero, the policy maker's choice is again $\xi=1$.
} 
and von Wachter (2016), it is still an open question whether the size of this discrepancy is an outlier or a magnitude that could be expected. In principle, our proposed decomposition approach can also be used to calculate the fiscal externality of other UI policies which have been studied in previous empirical studies of UI (e.g., of extending the potential benefit duration). The systematic comparison between the nonparametric decomposition-based benchmark and estimates using parametric formulae can be informative in assessing the ability of parametric modeling approaches, including "sufficient statistic" approaches, to accurately forecast the fiscal externalities of new policies.

Finally, as is evident from the framework in Section 2, there is virtually nothing in the empirical strategy that is specific or unique to UI. In principle, it is also possible to compute the fiscal externality parameter for other income transfer programs, as long as one has relatively complete microdata on benefits and taxes and the inputs needed to simulate a mechanical effect. It would be useful to compare the relative efficiency of transfers across different programs as in Hendren (2016) and Hendren and Sprung-Keyser (2019), but using a similar decomposition strategy as proposed in this paper. 


\section{References}

Anderson, Patricia M., and Bruce D. Meyer. 1997. "Unemployment Insurance Takeup Rates and the After-Tax Value of Benefits." The Quarterly Journal of Economics, 112(3): 913-937.

Ashenfelter, Orley, and Mark W. Plant. 1990. "Nonparametric Estimates of the Labor-Supply Effects of Negative Income Tax Programs.” Journal of Labor Economics, 8(1): 396-415.

Auerbach, Alan J. 1985. "The Theory of Excess Burden and Optimal Taxation.” In Handbook of Public Economics. Vol. 1, , ed. Alan J. Auerbach and Martin Feldstein, Chapter 2, 61-127. Elsevier Science Publishers B.V. (North-Holland).

Baily, Martin Neil. 1978. "Some Aspects of Optimal Unemployment Insurance." Journal of Public Economics, 10(3): 379-402.

Blank, Rebecca, and David Card. 1991. "Recent Trends in Insured and Uninsured Unemployment: Is There an Explanation?" The Quarterly Journal of Economics, 106(4): 1157-1189.

Bockerman, Petri, Ohto Kanninen, and Ilpo Suoniemi. 2015. "A Kink that Makes You Sick: the Effect of Sick Pay on Absence in a Social Insurance System.” Labour Institute for Economic Research Working Paper 297.

Bronchetti, Erin Todd. 2012. "Workers' Compensation and Consumption Smoothing." Journal of Public Economics, 96(5-6): 495-508.

Calonico, Sebastian, Matias D. Cattaneo, and Rocio Titiunik. 2014. "Robust Nonparametric Confidence Intervals for Regression-Discontinuity Designs.” Econometrica, 82(6): 2295-2326.

Calonico, Sebastian, Matias D. Cattaneo, Max H. Farrell, and Rocio Titiunik. 2017. "rdrobust: Software for Regression Discontinuity Designs.” Stata Journal, 2: 372-404.

Card, David, Andrew Johnston, Pauline Leung, Alexandre Mas, and Zhuan Pei. 2015a. "The Effect of Unemployment Benefits on the Duration of Unemployment Insurance Receipt: New Evidence from a Regression Kink Design in Missouri, 2003-2013." American Economic Review: Papers \& Proceedings, 105(5): 126-130.

Card, David, David S. Lee, and Zhuan Pei. 2009. "Quasi-Experimental Identification and Estimation in the Regression Kink Design.” Princeton University Industrial Relations Section Working Paper 553.

Card, David, David S. Lee, Zhuan Pei, and Andrea Weber. 2015b. "Inference on Causal Effects in a Generalized Regression Kink Design.” Econometrica, 83(6): 2453-2483.

Card, David, David S. Lee, Zhuan Pei, and Andrea Weber. 2017. "Regression Kink Design: Theory and Practice." In Regression Discontinuity Designs: Theory and Applications. Vol. 38 of Advances in Econometrics, , ed. Matias D. Cattaneo and Juan Carlos Escanciano, 341-382. Emerald Publishing Limited.

Chetty, Raj. 2008. "Moral Hazard versus Liquidity and Optimal Unemployment Insurance." Journal of Political Economy, 116(2): 173-234.

Chetty, Raj. 2009a. "Is the Taxable Income Elasticity Sufficient to Calculate Deadweight Loss? The Implications of Evasion and Avoidance." American Economic Journal: Economic Policy.

Chetty, Raj. 2009b. "Sufficient Statistics for Welfare Analysis: A Bridge Between Structural and ReducedForm Methods." Annual Review of Economics, 1(1): 451-488. 
DellaVigna, Stefano, Attila Lindner, Balázs Reizer, and Johannes F. Schmieder. 2017. "ReferenceDependent Job Search: Evidence from Hungary." The Quarterly Journal of Economics, 132(4): 19692018.

Denning, Jeffrey T., Benjamin M. Marx, and Lesley J. Turner. 2017. "ProPelled: The Effects of Grants on Graduation, Earnings, and Welfare.” National Bureau of Economic Research Working Paper 23860.

Feldstein, Martin. 1999. "Tax Avoidance and the Deadweight Loss of the Income Tax." Review of Economics and Statistics, 81(4): 674-680.

Gruber, Jonathan. 1997. “The Consumption Smoothing Benefits of Unemployment Insurance." The American Economic Review, 87(1): 192-205.

Hendren, Nathaniel. 2016. “The Policy Elasticity.” Tax Policy and the Economy, 30(1): 51-89.

Hendren, Nathaniel, and Ben Sprung-Keyser. 2019. "A Unified Welfare Analysis of Government Policies.” National Bureau of Economic Research Working Paper 26144.

Kleven, Henrik Jacobsen. 2018. "Sufficient Statistics Revisited.” Working Paper.

Kleven, Henrik Jacobsen, and Claus Thustrup Kreiner. 2005. "Labor Supply Behavior and the Design of Tax and Transfer Policy.” Danish Journal of Economics, 143(2005): 321-358.

Kolsrud, Jonas, Camille Landais, Peter Nilsson, and Johannes Spinnewijn. 2018. "The Optimal Timing of Unemployment Benefits: Theory and Evidence from Sweden.” American Economic Review, 108(45): $985-1033$.

Kroft, Kory. 2008. "Takeup, Social Multipliers and Optimal Social Insurance.” Journal of Public Economics, 92(3): 722-737.

Kroft, Kory, and Matthew J. Notowidigdo. 2016. "Should Unemployment Insurance Vary with the Unemployment Rate? Theory and Evidence.” The Review of Economic Studies, 83(3): 1092-1124.

Krueger, Alan B., and Bruce D. Meyer. 2002. "Labor Supply Effects of Social Insurance." In Handbook of Public Economics. Vol. 4 of Handbook of Public Economics, 2327-2392. Elsevier.

Lalive, Rafael, Jan C. van Ours, and Josef Zweimüller. 2006. "How Changes in Financial Incentives Affect the Duration of Unemployment." Review of Economic Studies, 73(4): 1009-1038.

Landais, Camille. 2015. "Assessing the Welfare Effects of Unemployment Benefits Using the Regression Kink Design.” American Economic Journal: Economic Policy, 7(4): 243-278.

Landais, Camille, Pascal Michaillat, and Emmanuel Saez. 2018. "A Macroeconomic Approach to Optimal Unemployment Insurance: Theory." American Economic Journal: Economic Policy, 10(2): 152-181.

Lawson, Nicholas. 2015. “Social Program Substitution and Optimal Policy.” Labour Economics, 37: 13-27.

Lawson, Nicholas. 2017. "Fiscal Externalities and Optimal Unemployment Insurance." American Economic Journal: Economic Policy, 9(4): 281-312.

Le Barbanchon, Thomas. 2016. “Partial Unemployment Insurance.” Working Paper.

Lee, David S. 2008. "Randomized Experiments from Non-random Selection in U.S. House Elections." Journal of Econometrics, 142(2): 675-697. 
Lee, David S. 2009. "Training, Wages, and Sample Selection: Estimating Sharp Bounds on Treatment Effects." The Review of Economic Studies, 76(3): 1071-1102.

Lee, David S., and Thomas Lemieux. 2010. "Regression Discontinuity Designs in Economics." Journal of Economic Literature, 48(2): 281-355.

Leung, Pauline, and Christopher O'Leary. Forthcoming. "Unemployment Insurance and Means-Tested Program Interactions: Evidence from Administrative Data." American Economic Journal: Economic Policy.

McCall, Brian P. 1996. "Unemployment Insurance Rules, Joblessness, and Part-Time Work.” Econometrica, 64(3): 647-682.

McCrary, Justin. 2008. "Manipulation of the Running Variable in the Regression Discontinuity Design: A Density Test." Journal of Econometrics, 142(2): 698-714.

Meyer, Bruce D. 1990. “Unemployment Insurance and Unemployment Spells.” Econometrica, 58(4): 757782.

Moffitt, Robert. 1985. "Unemployment Insurance and the Distribution of Unemployment Spells.” Journal of Econometrics, 28(1): 85-101.

Nekoei, Arash, and Andrea Weber. 2017. "Does Extending Unemployment Benefits Improve Job Quality?" American Economic Review, 107(2): 527-561.

O'Leary, Christopher. 1997. "An Evaluation of the Washington State Unemployment Insurance Earnings Deduction Experiment." W.E. Upjohn Institute Report prepared for UI Program analysis, Washington State Employment Security Department.

Pei, Zhuan. 2017. "Eligibility Recertification and Dynamic Opt-In Incentives in Income-Tested Social Programs: Evidence from Medicaid/CHIP." American Economic Journal: Economic Policy, 9(1): 241-76.

Pei, Zhuan, David S. Lee, David Card, and Andrea Weber. 2018. "Local Polynomial Order in Regression Discontinuity Designs.” IRS Working Papers http://arks.princeton.edu/ark:/88435/dsp01v118rh27h.

Pei, Zhuan, Jörn-Steffen Pischke, and Hannes Schwandt. forthcoming. "Poorly Measured Confounders Are More Useful on the Left Than on the Right." Journal of Business and Economic Statistics.

Saez, Emmanuel. 2004. "Reported Incomes and Marginal Tax Rates, 1960-2000: Evidence and Policy Implications." Tax Policy and the Economy, 18: 117-173.

Saez, Emmanuel, Joel Slemrod, and Seth H. Giertz. 2012. "The Elasticity of Taxable Income with Respect to Marginal Tax Rates: a Critical Review." Journal of Economic Literature, 50(1): 3-50.

Schmieder, Johannes F., and Till von Wachter. 2016. "The Effects of Unemployment Insurance Benefits: New Evidence and Interpretation.” Annual Review of Economics, 8(1): 547-581.

Schmieder, Johannes F., Till von Wachter, and Stefan Bender. 2012. "The Effects of Extended Unemployment Insurance Over the Business Cycle: Evidence from Regression Discontinuity Estimates Over 20 Years.” The Quarterly Journal of Economics, 127(2): 701-752.

Schmieder, Johannes F., Till von Wachter, and Stefan Bender. 2016. "The Effect of Unemployment Benefits and Nonemployment Durations on Wages." American Economic Review, 106(3): 739-777. 
Shimer, Robert, and Iván Werning. 2007. "Reservation Wages and Unemployment Insurance.” The Quarterly Journal of Economics, 122(3): 1145-1185.

Slemrod, Joel. 1998. "Methodological Issues in Measuring and Interpreting Taxable Income Elasticities." National Tax Journal, 51(4): 773-788.

Spinnewijn, Johannes. 2014. "Unemployed but Optimistic: Optimal Insurance Design with Biased Beliefs." Journal of the European Economic Association, 13(1): 130-167.

Vroman, Wayne. 2009. "Unemployment Insurance Recipients and Nonrecipients in the CPS." Monthly Labor Review. 
Figure 1: Regression Kink Design: Weekly Benefit Amount wba and Normalized Running Variable $X$
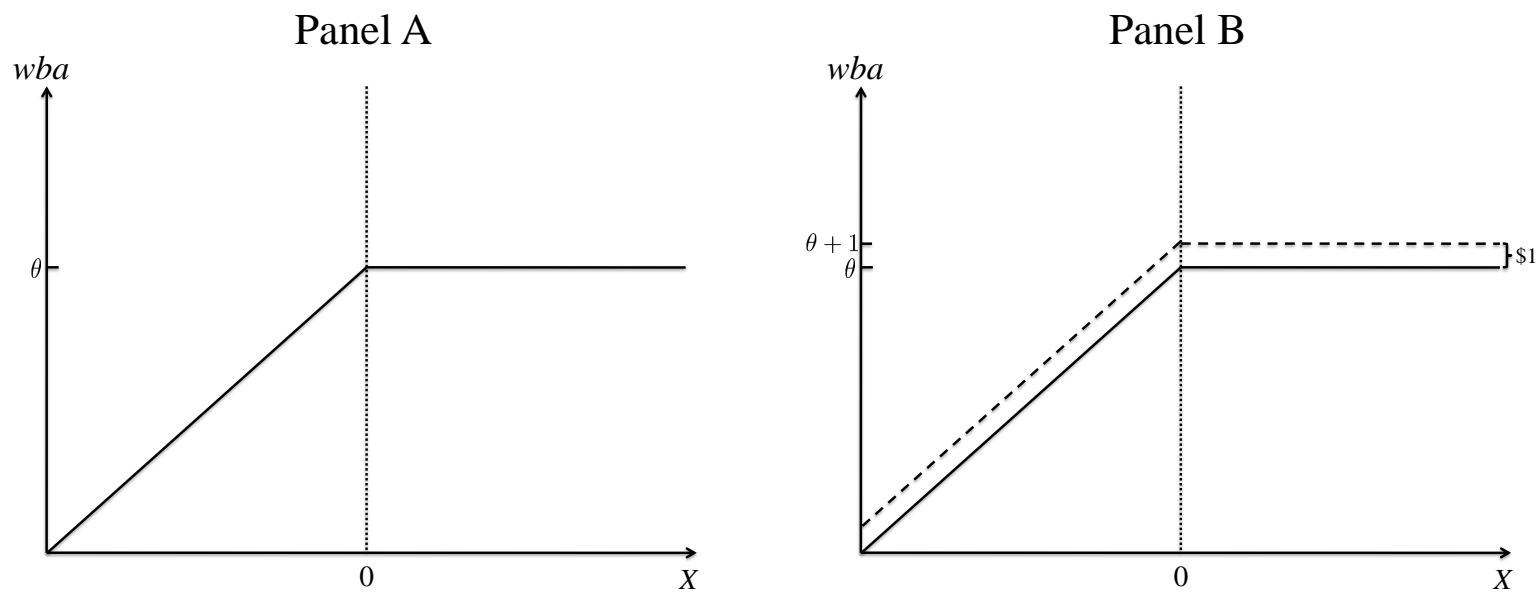

Note: Panel A graphically represents the statutory relationship between $w b a$ and $X$. Panel B represents the policy reform where we raise $w b a$, or equivalently $\theta$, by $\$ 1$. By applying a regression kink design, we can identify the fiscal externality of this policy reform. 
Figure 2: The Relationship Between UI Benefit Parameters and Earnings in the Base Year

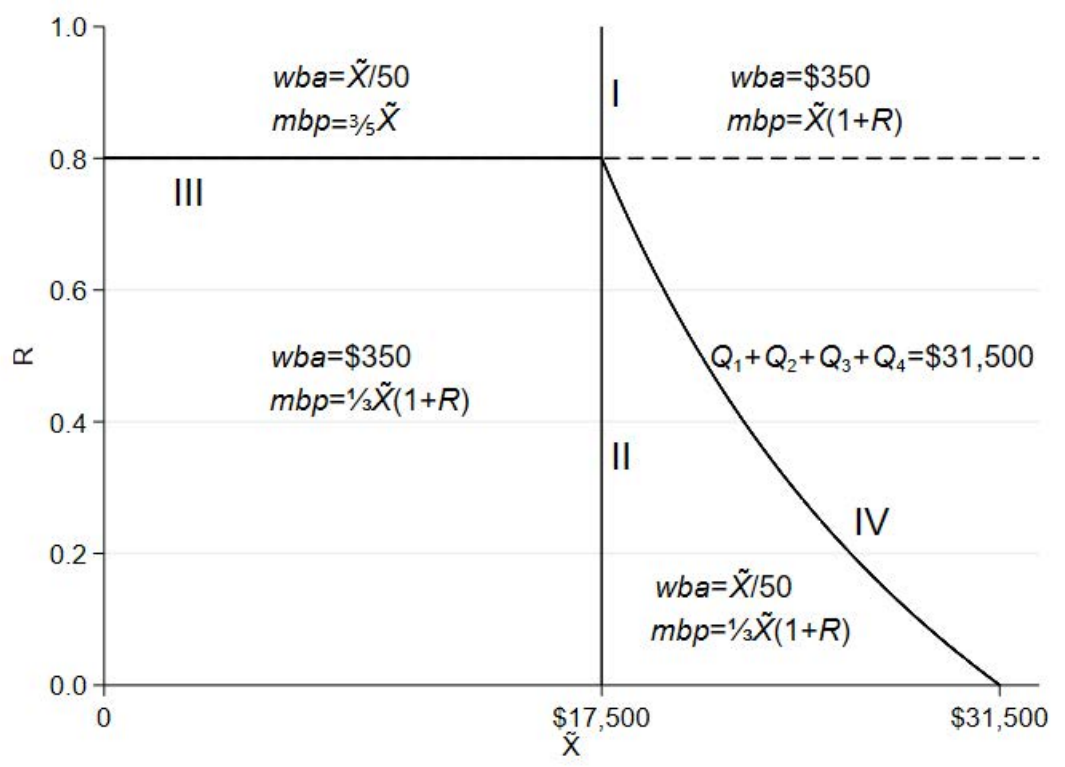

Note: $\tilde{X}=Q_{1}+Q_{2}$ is the sum of the two highest earning quarters in the base year. $R=\frac{Q_{3}+Q_{4}}{Q_{1}+Q_{2}}$ is the ratio of the two lowest earning quarters in the base year to the two highest earnings quarters in the base year. The slope of weekly benefit amount ( $w b a$ ) with respect to $\tilde{X}$ changes sharply at $\tilde{X}=\$ 17,500$ (boundaries I and II). If $R>0.8$, then the slope of maximum benefits payable ( $m b p)$ also changes at $\tilde{X}=\$ 17,500$ (I). The slope of $m b p$ with respect to $R$ changes at $R=0.8$ (III). The slope of $m b p$ with respect to $\tilde{X}(1+R)$ changes at $\tilde{X}(1+R)=\$ 31,500(\mathrm{IV})$. 
Figure 3: The Relationship Between Weekly Net Income and Earnings, by Treatment and Control Group of the Unemployment Insurance Earnings Deduction Experiment

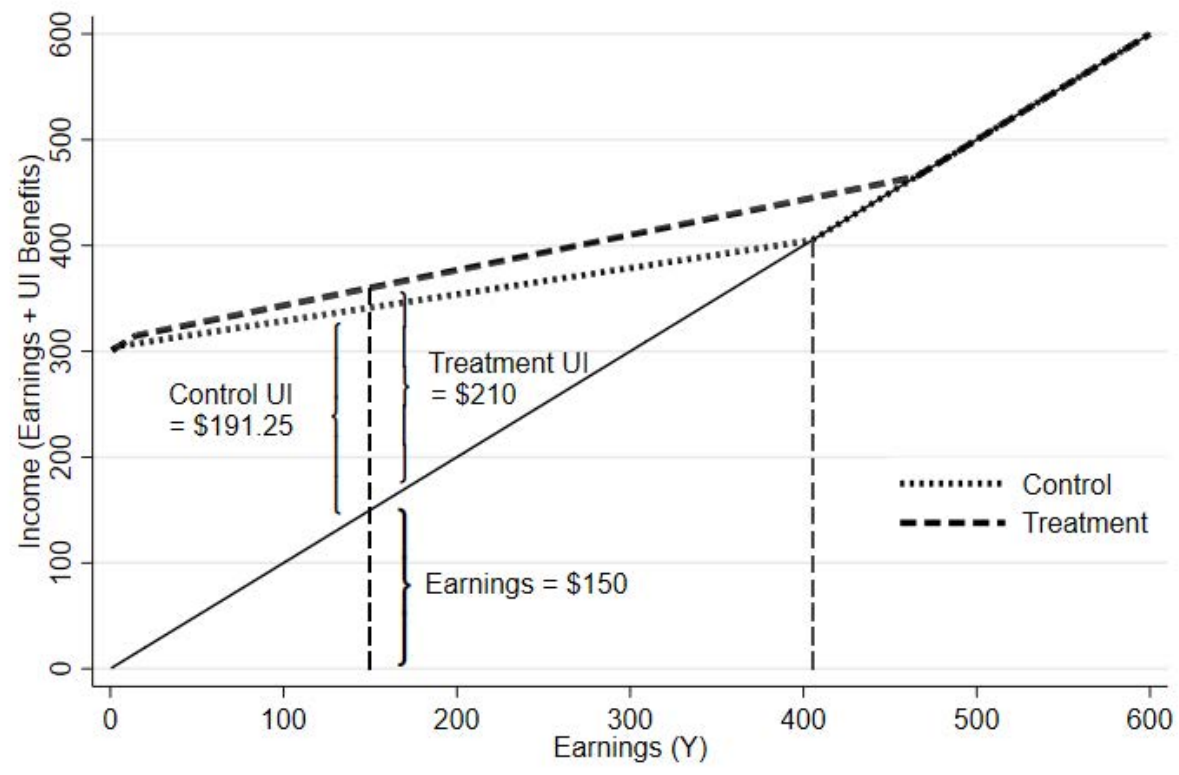

Note: This graph shows the weekly UI benefits and income for a worker with a weekly benefit amount of $\$ 300$, under control and treatment regimes. The example marked on the graph shows that if a worker has $\$ 150$ in earnings, she would receive $\$ 191.25$ of UI if she were assigned to the control group and $\$ 210$ if assigned to the treatment group. Adapted from O'Leary (1997). 
Figure 4: Weekly Benefit Amount and Maximum Benefits Payable versus Base Year Earnings

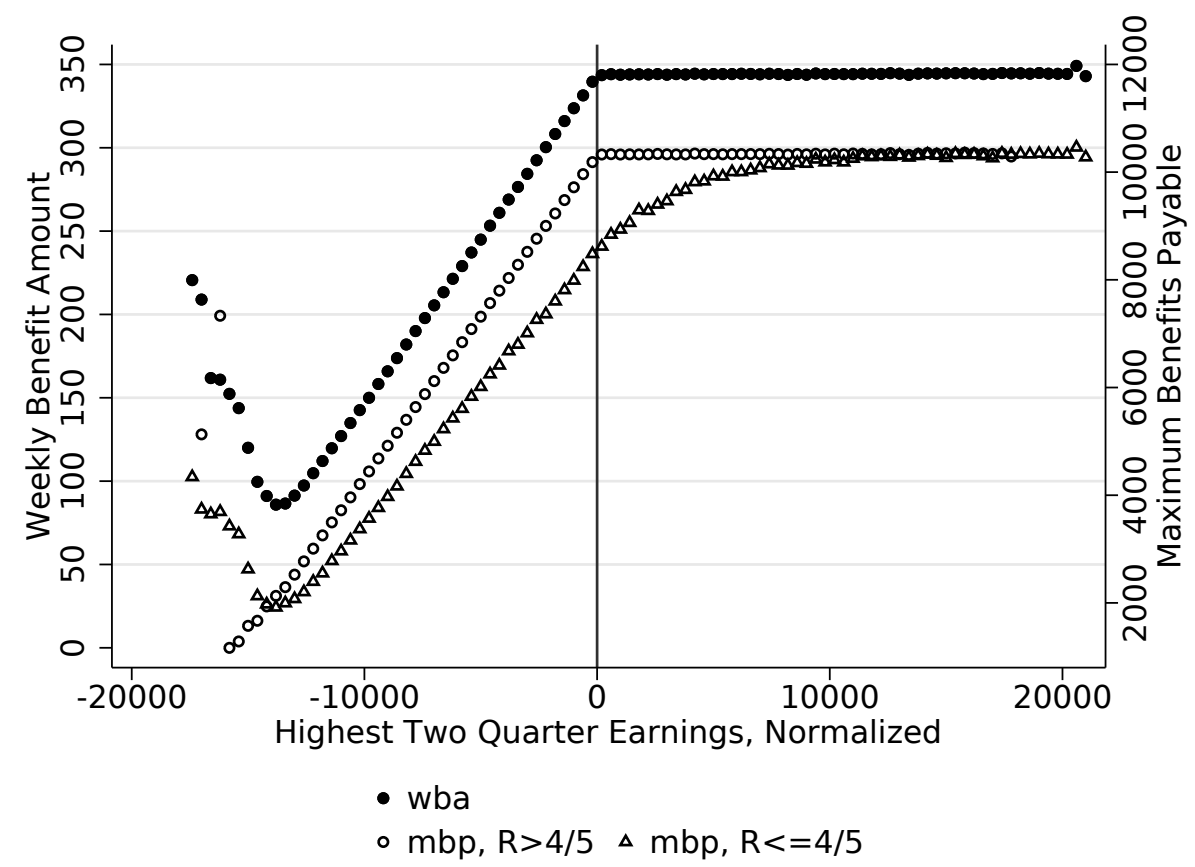

Note: $R=\frac{Q_{3}+Q_{4}}{Q_{1}+Q_{2}}$ is the ratio of the two lowest earning quarters in the base year to the two highest earnings quarters in the base year. There are 74,817 claimants in our sample with $R>4 / 5$ and 195,444 with $R \leq 4 / 5$ (2,475 claimants had no earnings in the two lowest earning quarters). There are 97 bins ( 87 bins for $R>4 / 5)$, each $\$ 400$ wide. 
Figure 5: Frequency Distribution of Base Year Earnings

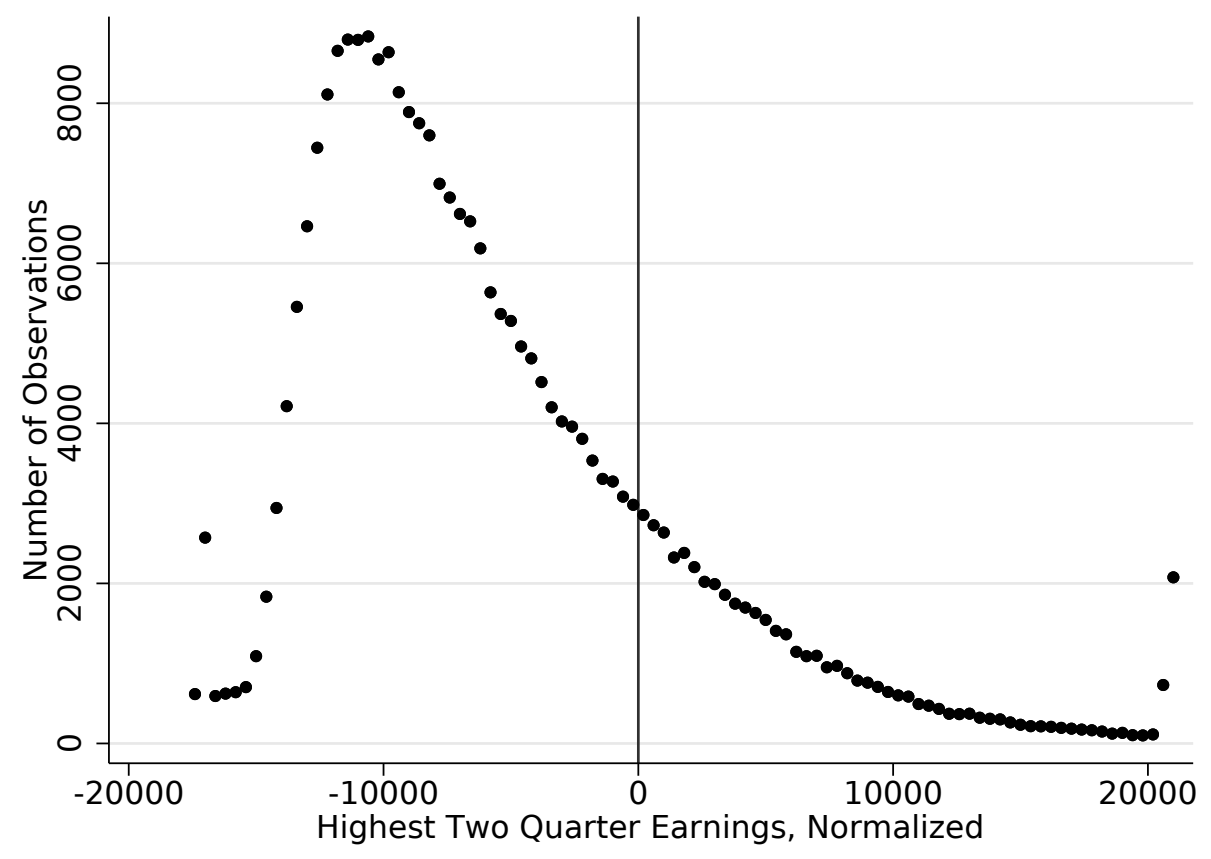

Note: This graph shows the number of observations in each $\$ 400$ bins of the running variable, the highest two quarters of earnings in the base year. The running variable is normalized relative to the kink threshold ( $\$ 17,150$ before July 1995 and $\$ 17,500$ after July 1995). There are 97 bins in total. 
Figure 6: Cumulative UI Payments versus Base Year Earnings, by Quarter
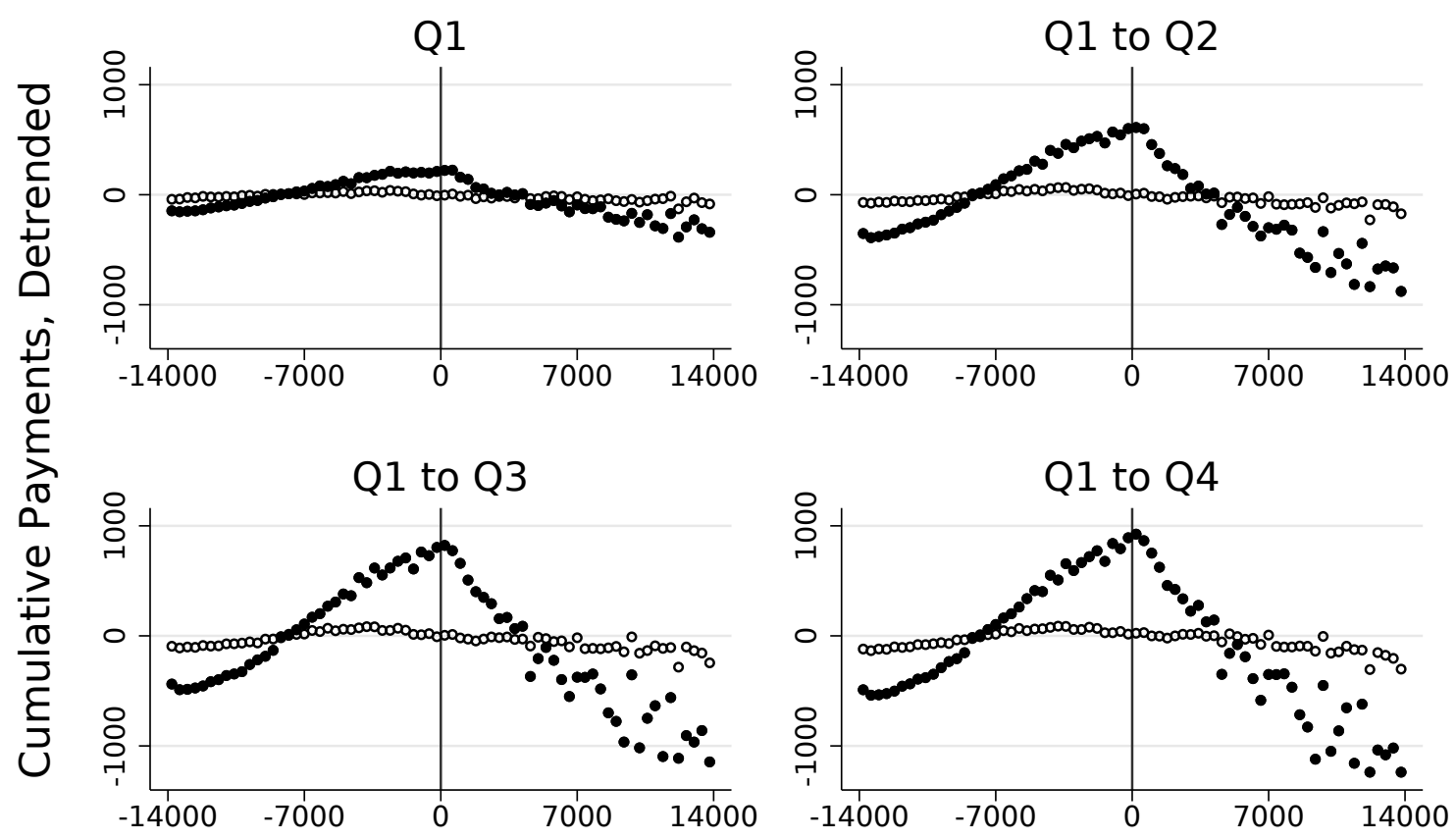

Highest Two Quarter Earnings, Normalized

- Outcome o Covariate Index

Note: Each graph shows the averages, within bins of highest two quarter earnings, of total UI payments accumulated since the quarter in which the first UI claim was filed. Covariate index is a linear combination of baseline characteristics (details in text). Both dependent variables are deviated from a linear regression fit of the running variable. Only data within $\$ 14,000$ of the threshold are shown. There are 70 bins, each $\$ 400$ wide. 
Figure 7: Mechanical Increase in Cumulative UI Payments from a Dollar Increase in the Weekly Benefit Amount versus Base Year Earnings, by Quarter
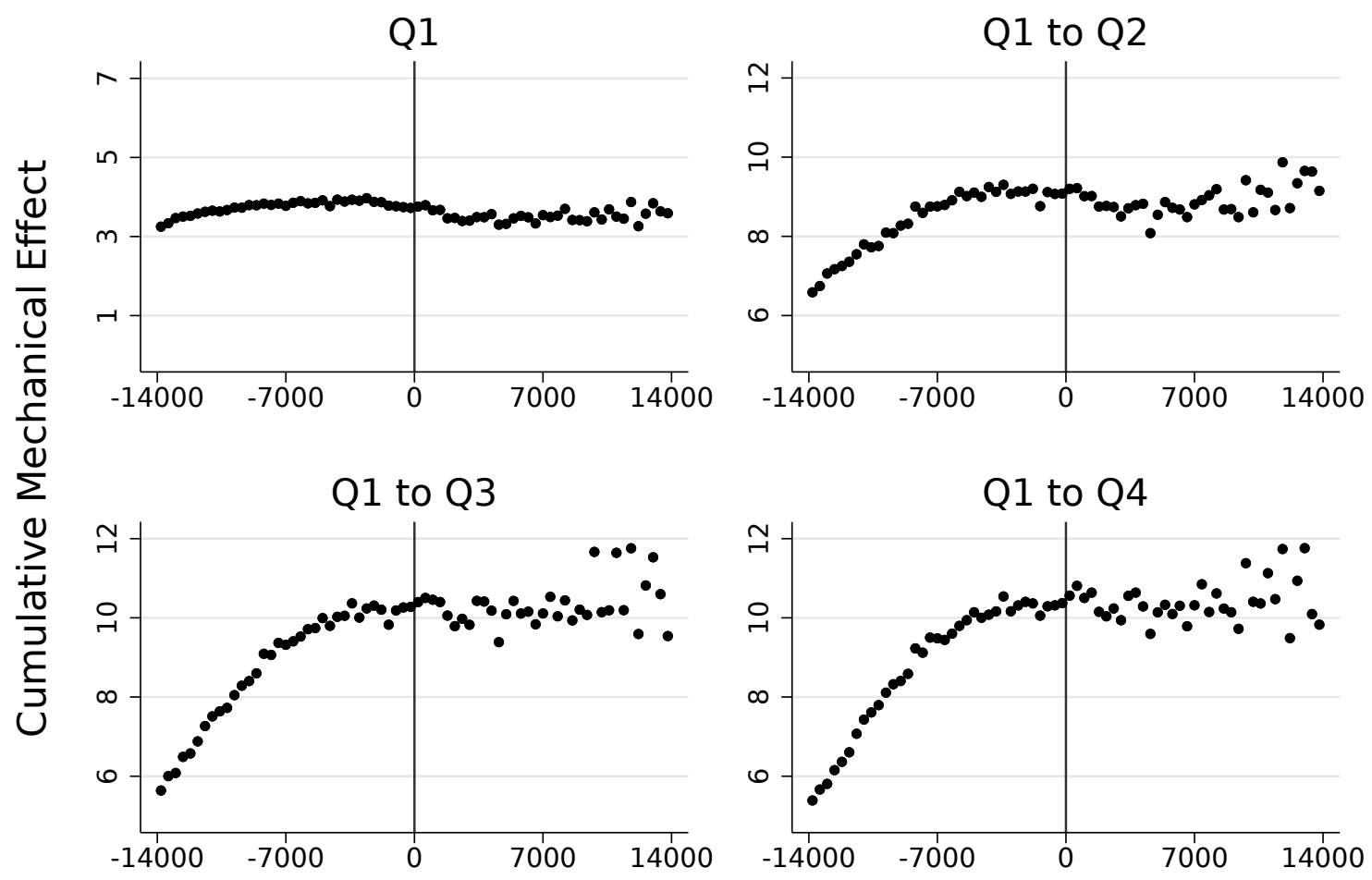

Highest Two Quarter Earnings, Normalized

Note: Each graph shows the averages, within bins of highest two quarter earnings, of the mechanical increase in UI benefits that claimants receive since the quarter in which the first UI claim was filed. Only data within $\$ 14,000$ of the threshold are shown. There are 70 bins, each $\$ 400$ wide. 
Figure 8: Cumulative Earnings versus Base Year Earnings, by Quarter
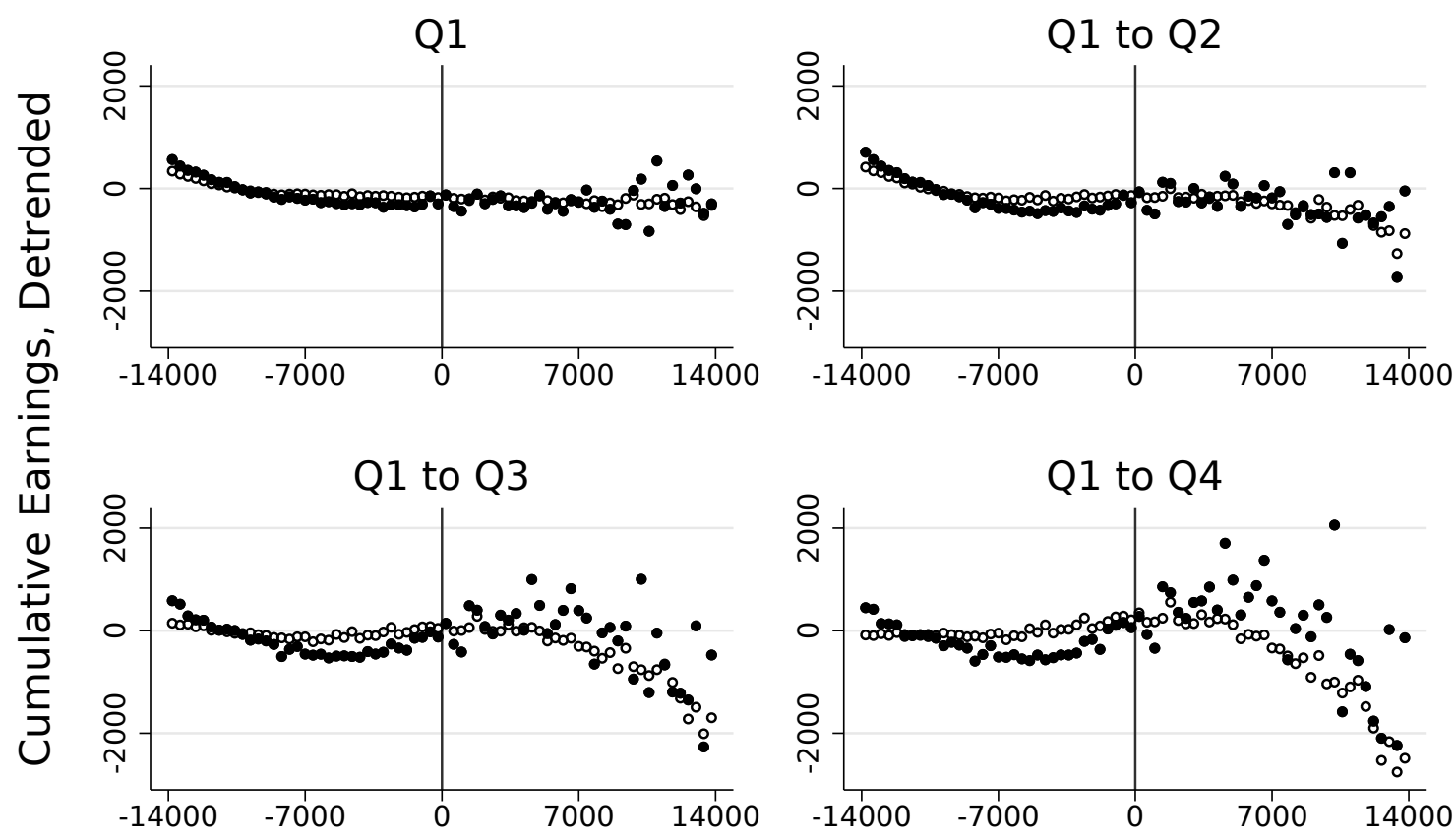

Highest Two Quarter Earnings, Normalized

- Outcome o Covariate Index

Note: Each graph shows the averages, within bins of highest two quarter earnings, of the expected total administrative earnings accumulated since the quarter in which the first UI claim was filed. Covariate index is a linear combination of baseline characteristics (details in text). Both dependent variables are deviated from a linear regression fit of the running variable. Only data within $\$ 14,000$ of the threshold are shown. There are 70 bins, each $\$ 400$ wide. 
Figure 9: RK Estimates versus Bandwidths: Cumulative UI Payments Q1-Q4

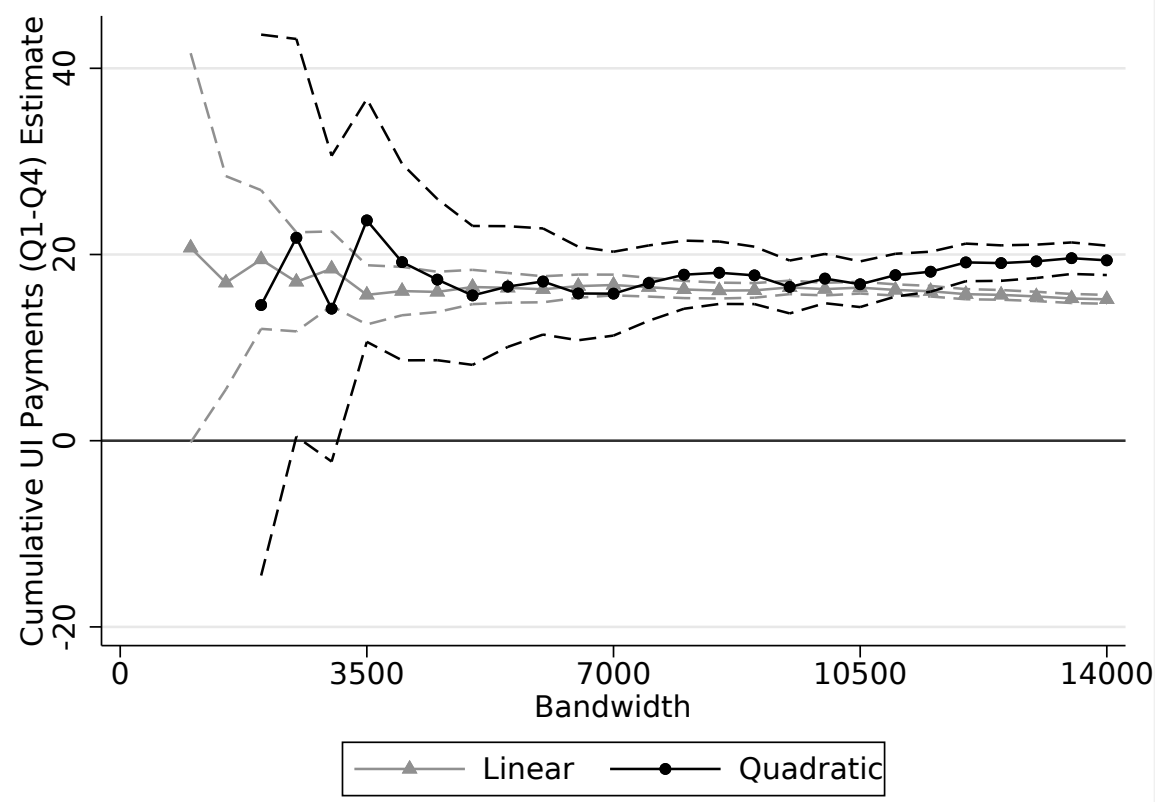

Note: This graph shows the estimated effects of $w b a$ on cumulative UI payments in Q1-Q4 (corresponding to row 4 of Table 4), when using different bandwidths and an alternative polynomial order. The black and gray series represent quadratic and linear estimates, respectively. The dashed short dashed lines represent the upper and lower end of the pointwise 95 percent confidence intervals. 
Figure 10: RK Estimates versus Bandwidths: Cumulative Earnings Q1-Q4

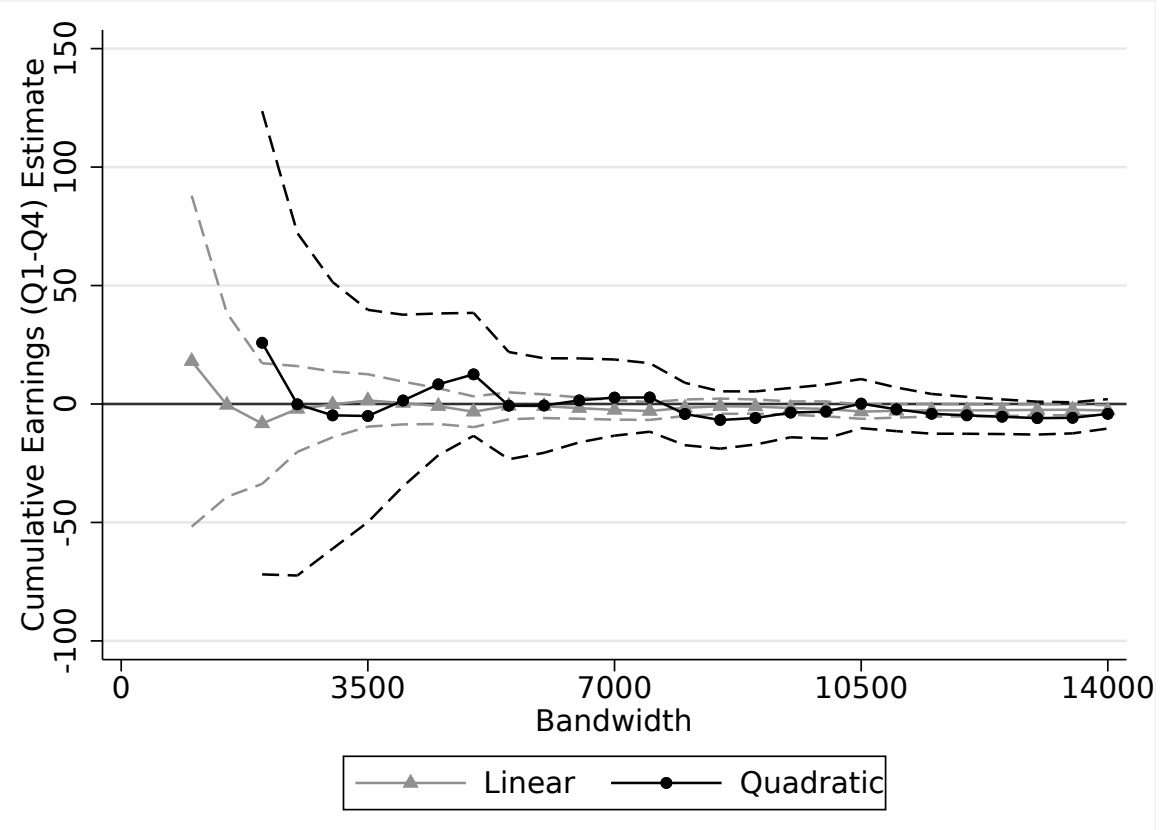

Note: This graph shows the estimated effects of $w b a$ on cumulative earnings in Q1-Q4 (corresponding to row 8 of Table 4), when using different bandwidths and an alternative polynomial order. The black and gray series represent quadratic and linear estimates, respectively. The short dashed lines represent the upper and lower end of the pointwise 95 percent confidence intervals. 
Figure 11: Log Paid Duration versus Base Year Earnings

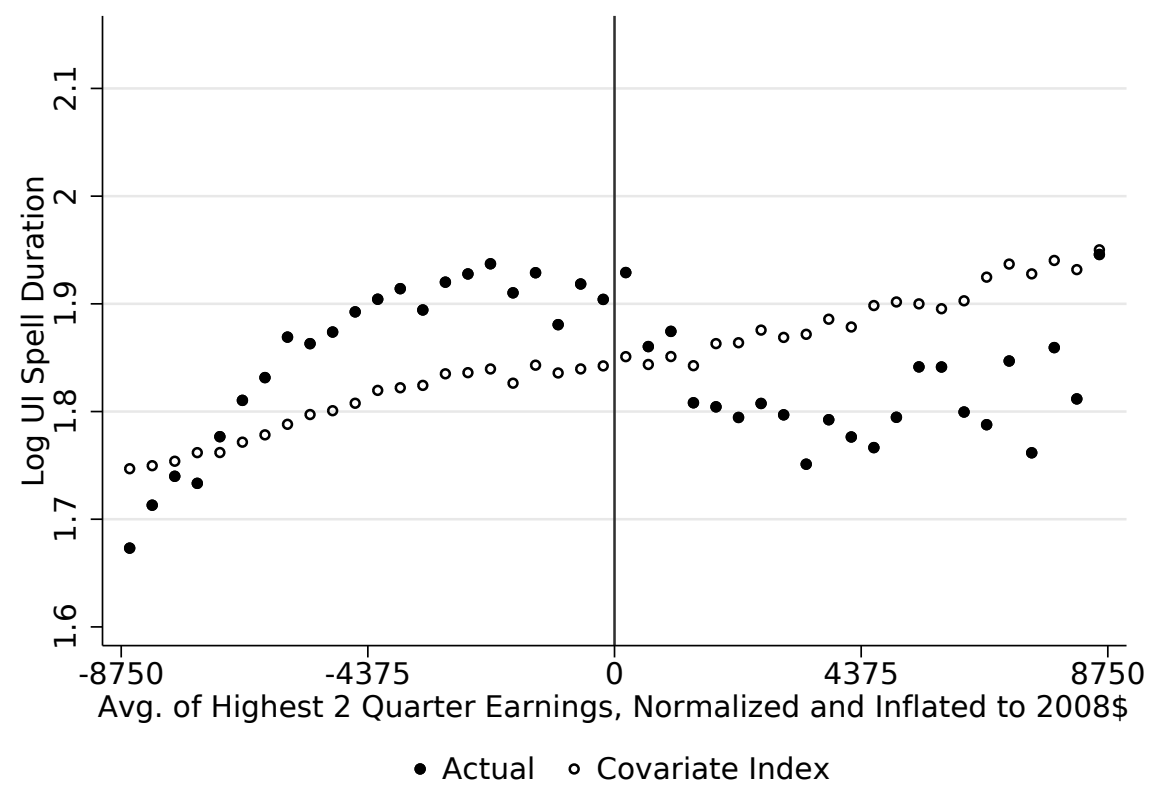

Note: The scale has been adjusted to be comparable to Card et al. (2015a). Paid duration is defined as one plus the number of weeks for which a claimant receives a UI payment before a gap of three or more weeks with no payments. Covariate index is a linear combination of baseline characteristics (details in text). There are 44 bins, each $\$ 400$ wide. 


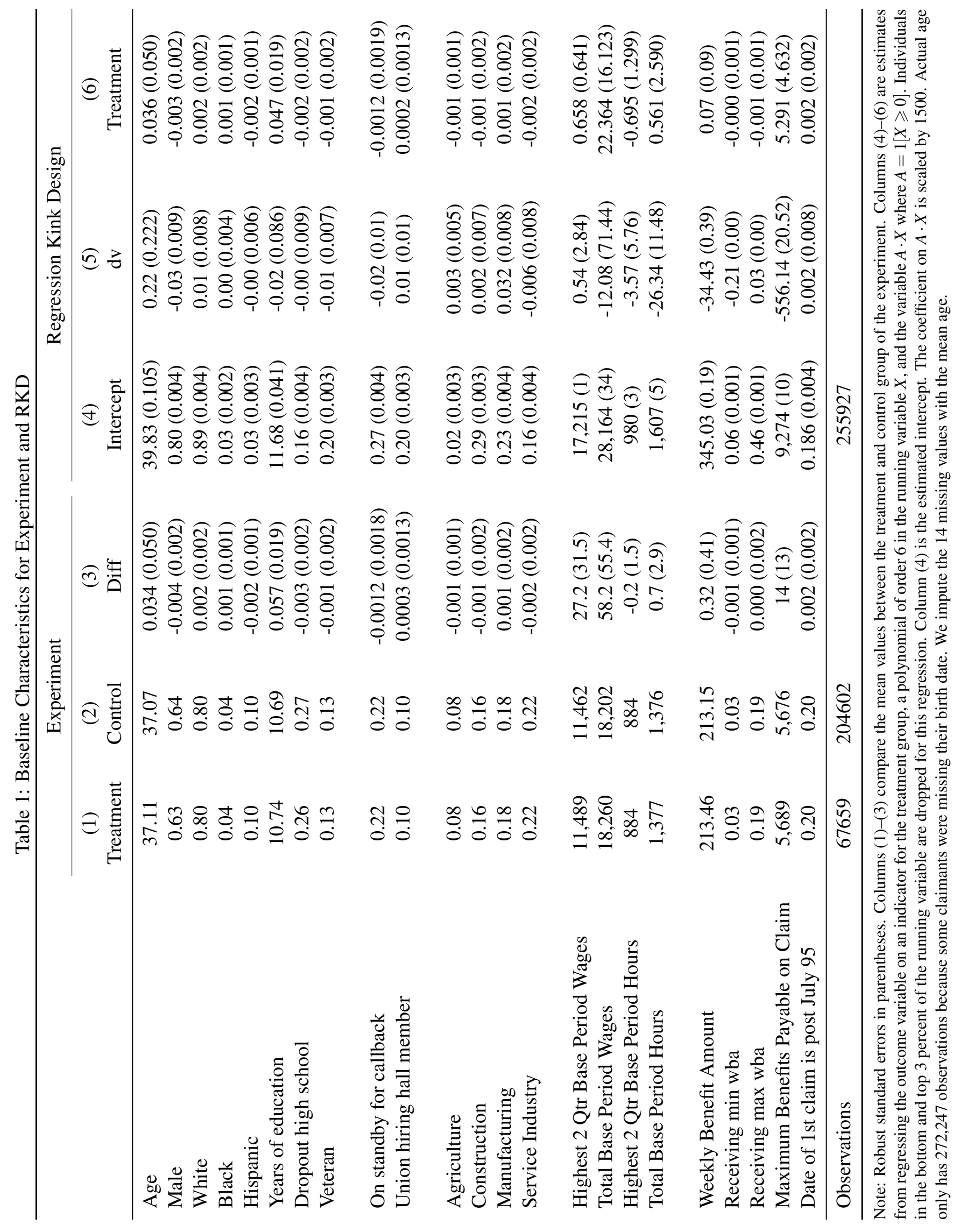


Table 2: Estimated Impacts from Earnings Deduction Experiment

\begin{tabular}{|c|c|c|c|}
\hline & $\begin{array}{c}(1) \\
\text { Treatment }\end{array}$ & $\begin{array}{c}(2) \\
\text { Control }\end{array}$ & $\begin{array}{c}(3) \\
\text { Difference }\end{array}$ \\
\hline \multicolumn{4}{|l|}{-Cumulative UI Payments } \\
\hline Q1 & 757.4 & 741.9 & $15.5(4.04)$ \\
\hline $\mathrm{Q} 1$ to $\mathrm{Q} 2$ & $1,899.9$ & $1,855.2$ & $44.7(8.79)$ \\
\hline Q1 to Q3 & $2,508.8$ & $2,446.5$ & $62.3(11.92)$ \\
\hline Q1 to Q4 & $2,756.3$ & $2,689.3$ & $66.9(12.60)$ \\
\hline \multicolumn{4}{|l|}{-Cumulative Earnings } \\
\hline Q1 & $3,649.0$ & $3,677.9$ & $-28.9(24.6)$ \\
\hline Q1 to Q2 & $6,377.2$ & $6,447.2$ & $-70.0(39.1)$ \\
\hline Q1 to Q3 & $9,762.8$ & $9,837.5$ & $-74.6(49.5)$ \\
\hline Q1 to Q4 & $13,329.6$ & $13,387.7$ & $-58.1(62.8)$ \\
\hline \multicolumn{4}{|l|}{-Cumulative Hours } \\
\hline Q1 & 237.2 & 237.9 & $-0.74(0.86)$ \\
\hline Q1 to $\mathrm{Q} 2$ & 435.9 & 436.8 & $-0.85(1.49)$ \\
\hline Q1 to Q3 & 685.6 & 686.5 & $-0.94(2.25)$ \\
\hline Q1 to Q4 & 944.9 & 945.6 & $-0.71(3.01)$ \\
\hline \multicolumn{4}{|c|}{-Have Positive Cumulative Earnings } \\
\hline Q1 & 0.86 & 0.86 & $0.00097(0.0015)$ \\
\hline Q1 to Q2 & 0.91 & 0.91 & $-0.00043(0.0013)$ \\
\hline Q1 to Q3 & 0.94 & 0.94 & $-0.00049(0.0011)$ \\
\hline Q1 to Q4 & 0.95 & 0.95 & $-0.00077(0.0010)$ \\
\hline \multicolumn{4}{|c|}{-Have Positive Cumulative Hours } \\
\hline Q1 & 0.80 & 0.80 & $-0.00055(0.0018)$ \\
\hline Q1 to $\mathrm{Q} 2$ & 0.87 & 0.87 & $-0.00053(0.0015)$ \\
\hline Q1 to Q3 & 0.90 & 0.90 & $-0.00031(0.0013)$ \\
\hline Q1 to Q4 & 0.92 & 0.92 & $-0.00077(0.0012)$ \\
\hline \multicolumn{4}{|l|}{-Log Cumulative Earnings } \\
\hline Q1 $\quad(\mathrm{N}=233959)$ & 7.91 & 7.91 & $-.0031(0.0050)$ \\
\hline Q1 to Q2 $(\mathrm{N}=248455)$ & 8.41 & 8.41 & $.00042(0.0050)$ \\
\hline Q1 to Q3 (N=255067) & 8.81 & 8.81 & $-.000013(0.0050)$ \\
\hline Q1 to Q4 $(\mathrm{N}=258283)$ & 9.10 & 9.10 & $-.00043(0.0051)$ \\
\hline \multicolumn{4}{|l|}{-Log Cumulative Hours } \\
\hline $\mathrm{Q} 1 \quad(\mathrm{~N}=218600)$ & 5.43 & 5.43 & $-.0036(0.0043)$ \\
\hline Q1 to Q2 $(\mathrm{N}=236845)$ & 5.93 & 5.93 & $-.00075(0.0044)$ \\
\hline Q1 to Q3 (N=245783) & 6.32 & 6.32 & $-.0026(0.0045)$ \\
\hline Q1 to Q4 $(\mathrm{N}=250705)$ & 6.61 & 6.61 & $-.0015(0.0046)$ \\
\hline \multicolumn{4}{|c|}{-Number of Weeks with UI Payments } \\
\hline Q1 & 3.77 & 3.66 & $0.11(0.017)$ \\
\hline Q1 to $\mathrm{Q} 2$ & 9.44 & 9.12 & $0.32(0.035)$ \\
\hline Q1 to Q3 & 12.44 & 11.98 & $0.46(0.046)$ \\
\hline Q1 to Q4 & 13.76 & 13.23 & $0.53(0.050)$ \\
\hline Claim Duration (Weeks) & 11.50 & 10.91 & $0.60(0.051)$ \\
\hline Log Claim Duration & 1.85 & 1.79 & $0.06(0.006)$ \\
\hline
\end{tabular}

Note: The variable claim duration is the number of weeks of received UI payments prior to the first 3 weeks of no payments. $\log$ claim duration is the natural logarithm of one plus claim duration. All remaining variables are averaged over cumulative calendar quarters, where Q1 refers to the quarter of the initial UI claim. Unless stated in brackets next to the quarters of accumulation, the number of observations is 272,261 . 
Table 3: Earnings Deduction Experiment: Separating the Mechanical and Behavioral Effects

\begin{tabular}{|c|c|c|c|c|c|c|c|}
\hline & (1) & (2) & (3) & (4) & $(5)$ & (6) & (7) \\
\hline & \multicolumn{3}{|c|}{ UI Payments } & \multirow[b]{2}{*}{ Tax Receipts } & \multicolumn{3}{|c|}{ Fiscal Externality } \\
\hline & Total & Mechanical & Behavioral & & $\beta+\gamma$ & $\beta$ & $\gamma$ \\
\hline Q1 & $\begin{array}{l}15.52 \\
(4.04)\end{array}$ & $\begin{array}{c}7.73 \\
(0.05)\end{array}$ & $\begin{array}{c}7.79 \\
(4.04)\end{array}$ & $\begin{array}{l}-0.05 \\
(0.31)\end{array}$ & $\begin{array}{c}1.02 \\
(0.53)\end{array}$ & $\begin{array}{c}1.01 \\
(0.52)\end{array}$ & $\begin{array}{c}0.01 \\
(0.04)\end{array}$ \\
\hline $\mathrm{Q} 1$ to $\mathrm{Q} 2$ & $\begin{array}{l}44.66 \\
(8.79)\end{array}$ & $\begin{array}{c}19.83 \\
(0.12)\end{array}$ & $\begin{array}{l}24.84 \\
(8.79)\end{array}$ & $\begin{array}{l}-0.26 \\
(0.47)\end{array}$ & $\begin{array}{c}1.27 \\
(0.45)\end{array}$ & $\begin{array}{c}1.25 \\
(0.44)\end{array}$ & $\begin{array}{c}0.01 \\
(0.02)\end{array}$ \\
\hline Q1 to Q3 & $\begin{array}{c}62.29 \\
(11.92)\end{array}$ & $\begin{array}{l}26.37 \\
(0.17)\end{array}$ & $\begin{array}{c}35.92 \\
(11.92)\end{array}$ & $\begin{array}{l}-0.25 \\
(0.62)\end{array}$ & $\begin{array}{c}1.37 \\
(0.46)\end{array}$ & $\begin{array}{c}1.36 \\
(0.45)\end{array}$ & $\begin{array}{c}0.01 \\
(0.02)\end{array}$ \\
\hline $\mathrm{Q} 1$ to $\mathrm{Q} 4$ & $\begin{array}{c}66.92 \\
(12.60)\end{array}$ & $\begin{array}{l}28.15 \\
(0.20)\end{array}$ & $\begin{array}{c}38.77 \\
(12.61)\end{array}$ & $\begin{array}{l}-0.11 \\
(0.75)\end{array}$ & $\begin{array}{c}1.38 \\
(0.45)\end{array}$ & $\begin{array}{c}1.38 \\
(0.45)\end{array}$ & $\begin{array}{c}0.00 \\
(0.03)\end{array}$ \\
\hline
\end{tabular}

Note: Column (1) are the estimates from the first four rows of Table 2. Column (2) is the cumulative UI payments that the control group would gain if it was mechanically subject to the treatment group's earnings deduction schedule. Column (3) is (1) minus (2). Column (4) is the experimental impact on tax receipts. Column (5) is equal to the estimate from a regression of tax receipts on the treatment indicator, then divided by column (2). Column (6) is (3) divided by (2). Column (7) is (5) minus (6). 
Table 4: RKD Estimates: Effects of an Increase in the Weekly Benefit Amount

\begin{tabular}{|c|c|c|c|c|c|}
\hline & $\begin{array}{l}(1) \\
p\end{array}$ & $\begin{array}{c}(2) \\
h\end{array}$ & $\begin{array}{l}(3) \\
\mathrm{n}\end{array}$ & $\begin{array}{c}(4) \\
\text { First Stage }\end{array}$ & $\begin{array}{c}(5) \\
\text { Fuzzy RKD Estimate }\end{array}$ \\
\hline \multicolumn{6}{|l|}{-Cumulative UI Payments } \\
\hline Q1 & 1 & 2,171 & 31,747 & $-0.019(0.0001)$ & $4.7(1.12)$ \\
\hline $\mathrm{Q} 1$ to $\mathrm{Q} 2$ & 1 & 2,130 & 31,019 & $-0.019(0.0001)$ & $13.3(2.45)$ \\
\hline Q1 to Q3 & 1 & 7,817 & 127,864 & $-0.020(0.0000)$ & $15.1(0.47)$ \\
\hline Q1 to Q4 & 1 & 3,932 & 58,333 & $-0.020(0.0001)$ & $15.9(1.36)$ \\
\hline \multicolumn{6}{|l|}{-Cumulative Earnings } \\
\hline Q1 & 2 & 12,208 & 225,983 & $-0.020(0.0001)$ & $4.1(1.42)$ \\
\hline $\mathrm{Q} 1$ to $\mathrm{Q} 2$ & 1 & 3,392 & 50,010 & $-0.020(0.0001)$ & $1.1(3.11)$ \\
\hline Q1 to Q3 & 2 & 9,041 & 153,672 & $-0.019(0.0001)$ & $-0.8(4.29)$ \\
\hline Q1 to Q4 & 2 & 11,016 & 198,899 & $-0.020(0.0001)$ & $-2.4(4.68)$ \\
\hline \multicolumn{6}{|l|}{-Cumulative Hours } \\
\hline Q1 & 3 & 10,598 & 189,040 & $-0.019(0.0002)$ & $0.16(0.18)$ \\
\hline Q1 to $\mathrm{Q} 2$ & 1 & 5,172 & 78,889 & $-0.020(0.0000)$ & $0.04(0.09)$ \\
\hline Q1 to Q3 & 1 & 3,412 & 50,299 & $-0.020(0.0001)$ & $0.04(0.25)$ \\
\hline Q1 to Q4 & 3 & 8,878 & 150,225 & $-0.019(0.0002)$ & $0.57(0.82)$ \\
\hline \multicolumn{6}{|c|}{-Have Positive Cumulative Earnings } \\
\hline Q1 & 2 & 7,633 & 124,202 & $-0.019(0.0001)$ & $0.00002(0.0002)$ \\
\hline $\mathrm{Q} 1$ to $\mathrm{Q} 2$ & 1 & 3,133 & 46,056 & $-0.020(0.0001)$ & $0.00005(0.0001)$ \\
\hline Q1 to Q3 & 2 & 7,944 & 130,441 & $-0.019(0.0001)$ & $0.00012(0.0001)$ \\
\hline Q1 to Q4 & 2 & 5,389 & 82,519 & $-0.019(0.0001)$ & $-0.00001(0.0002)$ \\
\hline \multicolumn{6}{|c|}{-Have Positive Cumulative Hours } \\
\hline Q1 & 2 & 6,193 & 96,660 & $-0.019(0.0001)$ & $-0.00024(0.0003)$ \\
\hline Q1 to $\mathrm{Q} 2$ & 2 & 8,851 & 149,679 & $-0.019(0.0001)$ & $-0.00023(0.0001)$ \\
\hline Q1 to Q3 & 2 & 6,597 & 104,213 & $-0.019(0.0001)$ & $-0.00007(0.0002)$ \\
\hline Q1 to Q4 & 2 & 4,877 & 73,740 & $-0.019(0.0002)$ & $-0.00005(0.0003)$ \\
\hline \multicolumn{6}{|l|}{-Log Cumulative Earnings } \\
\hline Q1 $\quad(\mathrm{N}=233959)$ & 3 & 5,040 & 68,272 & $-0.019(0.0004)$ & $0.0002(0.0023)$ \\
\hline Q1 to Q2 (N=248455) & 2 & 2,991 & 41,164 & $-0.019(0.0003)$ & $-0.0021(0.0021)$ \\
\hline Q1 to Q3 (N=255067) & 1 & 1,453 & 20,164 & $-0.019(0.0003)$ & $-0.0011(0.0016)$ \\
\hline Q1 to Q4 (N=258283) & 2 & 4,361 & 62,802 & $-0.019(0.0002)$ & $0.0005(0.0013)$ \\
\hline \multicolumn{6}{|l|}{-Log Cumulative Hours } \\
\hline $\mathrm{Q} 1 \quad(\mathrm{~N}=218600)$ & 3 & 14,667 & 211,349 & $-0.014(0.0002)$ & $0.0014(0.0007)$ \\
\hline Q1 to Q2 (N=236845) & 1 & 2,628 & 34,028 & $-0.019(0.0001)$ & $0.0005(0.0006)$ \\
\hline Q1 to Q3 (N=245783) & 1 & 5,595 & 78,581 & $-0.020(0.0000)$ & $-0.0002(0.0002)$ \\
\hline $\mathrm{Q} 1$ to $\mathrm{Q} 4(\mathrm{~N}=250705)$ & 1 & 1,767 & 23,793 & $-0.019(0.0002)$ & $0.0008(0.0012)$ \\
\hline \multicolumn{6}{|c|}{-Number of Weeks with UI Payments } \\
\hline Q1 & 2 & 6,660 & 105,447 & $-0.019(0.0001)$ & $0.0039(0.0026)$ \\
\hline Q1 to Q2 & 2 & 6,942 & 110,758 & $-0.019(0.0001)$ & $0.0137(0.0051)$ \\
\hline Q1 to Q3 & 1 & 3,871 & 57,402 & $-0.020(0.0001)$ & $0.0112(0.0042)$ \\
\hline Q1 to Q4 & 2 & 8,900 & 150,699 & $-0.019(0.0001)$ & $0.0140(0.0053)$ \\
\hline Claim Duration (Weeks) & 2 & 9,607 & 166,186 & $-0.019(0.0001)$ & $0.0026(0.0049)$ \\
\hline Claim Duration (Elasticity) & 3 & 10,072 & 176,894 & $-0.00006(0.000001)$ & $1.06(0.41)$ \\
\hline
\end{tabular}

Note: Robust standard errors in parentheses. The variable claim duration is the number of weeks of received UI payments prior to the first 3 weeks of no payments. Claim duration (elasticity) is a fuzzy RK estimate with $\log (w b a)$ as the regressor and $\log (1+$ claim duration) as the outcome. All remaining variables are averaged over cumulative calendar quarters, where Q1 refers to the quarter of the initial UI claim. Columns (1) and (2) show the polynomial order (chosen between 1 and 3) and CCT bandwidth that minimize estimated MSE. Column (3) reports the effective number of observations within the CCT bandwidth that is computed without regularization. Column (4) reports the first stage estimates and Column (5) the fuzzy RK estimates. Unless stated in brackets next to the quarters of accumulation, the total number of observations in the analysis sample is 272,261 . 
Table 5: RK Estimates: Separating the Mechanical and Behavioral Effects

\begin{tabular}{|c|c|c|c|c|c|c|c|}
\hline & (1) & (2) & (3) & \multirow[b]{3}{*}{ Tax Receipts } & (5) & $(6)$ & (7) \\
\hline & \multicolumn{3}{|c|}{ UI Payments } & & \multicolumn{3}{|c|}{ Fiscal Externality } \\
\hline & Total & Mechanical & Behavioral & & $\beta+\gamma$ & $\beta$ & $\gamma$ \\
\hline Q1 & $\begin{array}{c}4.67 \\
(1.12)\end{array}$ & $\begin{array}{c}3.75 \\
(0.04)\end{array}$ & $\begin{array}{c}0.92 \\
(1.09)\end{array}$ & $\begin{array}{c}0.06 \\
(0.04)\end{array}$ & $\begin{array}{c}0.23 \\
(0.30)\end{array}$ & $\begin{array}{c}0.24 \\
(0.29)\end{array}$ & $\begin{array}{l}-0.01 \\
(0.02)\end{array}$ \\
\hline Q1 to Q2 & $\begin{array}{l}13.31 \\
(2.45)\end{array}$ & $\begin{array}{c}9.06 \\
(0.09)\end{array}$ & $\begin{array}{c}4.25 \\
(2.40)\end{array}$ & $\begin{array}{c}0.08 \\
(0.03)\end{array}$ & $\begin{array}{c}0.46 \\
(0.27)\end{array}$ & $\begin{array}{c}0.47 \\
(0.26)\end{array}$ & $\begin{array}{c}-0.01 \\
(0.01)\end{array}$ \\
\hline Q1 to Q3 & $\begin{array}{l}15.11 \\
(0.47)\end{array}$ & $\begin{array}{l}10.13 \\
(0.12)\end{array}$ & $\begin{array}{c}4.98 \\
(0.44)\end{array}$ & $\begin{array}{c}0.20 \\
(0.05)\end{array}$ & $\begin{array}{c}0.47 \\
(0.05)\end{array}$ & $\begin{array}{c}0.49 \\
(0.04)\end{array}$ & $\begin{array}{l}-0.02 \\
(0.00)\end{array}$ \\
\hline Q1 to Q4 & $\begin{array}{l}15.88 \\
(1.36)\end{array}$ & $\begin{array}{l}10.23 \\
(0.13)\end{array}$ & $\begin{array}{c}5.66 \\
(1.30)\end{array}$ & $\begin{array}{c}0.23 \\
(0.16)\end{array}$ & $\begin{array}{c}0.53 \\
(0.13)\end{array}$ & $\begin{array}{c}0.55 \\
(0.12)\end{array}$ & $\begin{array}{l}-0.02 \\
(0.01)\end{array}$ \\
\hline
\end{tabular}

Note: Robust standard errors in parentheses. Column (1) shows the estimates from the first four rows of Table 4. Column (2) is the estimated mean mechanical transfer at the threshold from increasing $w b a$. It is the intercept from a regression of the mechanical effect on a quintic polynomial in $X$ and $A \cdot X$, where $A=1[X \geqslant 0]$. Column (3) is (1) minus (2). Column (4) is the fuzzy RKD estimate of $w b a$ on tax receipts, calculated as in Column (1). Column (5) is the fuzzy RKD estimate of the effect of $w b a$ on UI payments net of tax receipts, divided by column (2), and minus 1 . Column (6) is (3) divided by (2). Column (7) is (5) minus (6). The bandwidths and orders of the RKDs for all columns except (4) are chosen to minimize MSE (polynomial order is selected between 1 and 3) where the outcome is UI payments. For column (4), the bandwidth and polynomial order are chosen using tax receipts as the outcome. Standard errors for Columns (5) to (7) are computed by jointly estimating their numerator and denominator, and allowing unrestricted covariances across equations, and then using the delta method. 


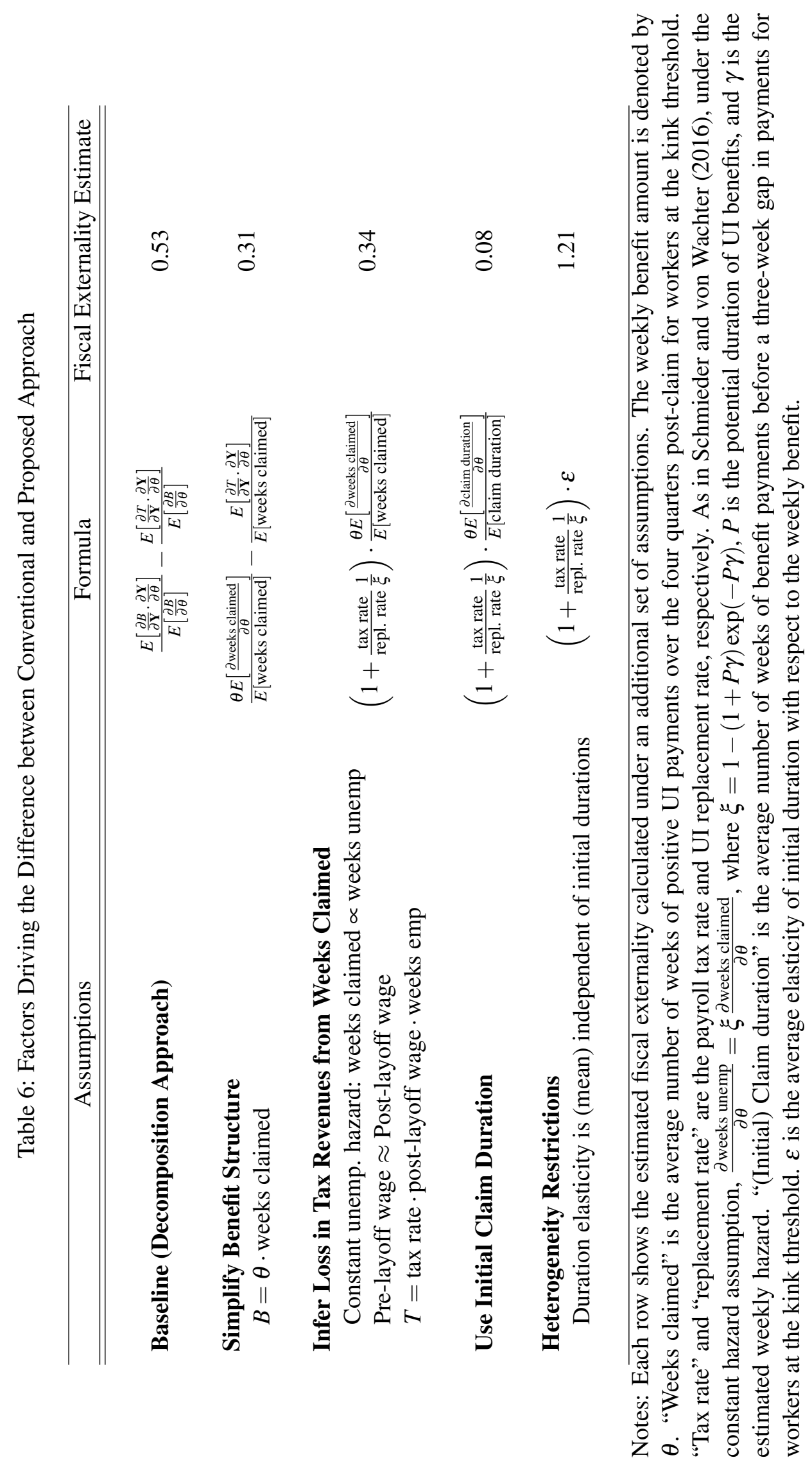




\section{Appendix}

\section{A Decomposition of a Large Reform}

In this section, we discuss the implementation of the decomposition approach when evaluating a nonmarginal reform. Consider government expenditures for a single individual, where we drop the $i$ subscript:

$$
B(\mathbf{Y}(\theta, \tau), \theta)-T(\mathbf{Y}(\theta, \tau), \tau)
$$

The impact of a marginal change in $\theta$ on the government expenditures is

$$
\frac{\partial B}{\partial \theta}+\left(\frac{\partial B}{\partial \mathbf{Y}}-\frac{\partial T}{\partial \mathbf{Y}}\right) \cdot \frac{\partial \mathbf{Y}}{\partial \theta}
$$

where the first term is the mechanical effect and the second term is the behavioral effect.

When we consider a non-marginal change in $\theta$, say from $\theta_{0}$ to $\theta_{1}$, the total impact on the government expenditures is

$$
\int_{\theta_{0}}^{\theta_{1}} \frac{\partial B}{\partial \theta} d \theta+\int_{\theta_{0}}^{\theta_{1}}\left(\frac{\partial B}{\partial \mathbf{Y}}-\frac{\partial T}{\partial \mathbf{Y}}\right) \cdot \frac{\partial \mathbf{Y}}{\partial \theta} d \theta
$$

where, again, the first term is the mechanical effect. Focusing only on the mechanical effect, note that it can be approximated using the trapezoid rule:

$$
\int_{\theta_{0}}^{\theta_{1}} \frac{\partial B}{\partial \theta} d \theta \approx \frac{\theta_{1}-\theta_{0}}{2}\left(\left.\frac{\partial B}{\partial \theta}\right|_{\theta_{1}}+\left.\frac{\partial B}{\partial \theta}\right|_{\theta_{0}}\right)
$$

Now consider the objects in parentheses. By a first order approximation,

$$
\begin{aligned}
\left.\frac{\partial B}{\partial \theta}\right|_{\theta_{1}} & =\frac{\partial B\left(\mathbf{Y}_{1}, \theta\right)}{\partial \theta} \\
& \approx \frac{B\left(\mathbf{Y}_{1}, \theta_{1}\right)-B\left(\mathbf{Y}_{1}, \theta_{0}\right)}{\theta_{1}-\theta_{0}}
\end{aligned}
$$


and

$$
\begin{aligned}
\left.\frac{\partial B}{\partial \theta}\right|_{\theta_{0}} & =\frac{\partial B\left(\mathbf{Y}_{0}, \theta\right)}{\partial \theta} \\
& \approx \frac{B\left(\mathbf{Y}_{0}, \theta_{1}\right)-B\left(\mathbf{Y}_{0}, \theta_{0}\right)}{\theta_{1}-\theta_{0}}
\end{aligned}
$$

where $\mathbf{Y}_{1}=\mathbf{Y}\left(\theta_{1}, \tau\right)$ and $\mathbf{Y}_{0}=\mathbf{Y}\left(\theta_{0}, \tau\right)$. Therefore the mechanical effect of a non-marginal reform can be approximated by averaging two quantities:

$$
\int_{\theta_{0}}^{\theta_{1}} \frac{\partial B}{\partial \theta} d \theta \approx \frac{\left[B\left(\mathbf{Y}_{1}, \theta_{1}\right)-B\left(\mathbf{Y}_{1}, \theta_{0}\right)\right]+\left[B\left(\mathbf{Y}_{0}, \theta_{1}\right)-B\left(\mathbf{Y}_{0}, \theta_{0}\right)\right]}{2}
$$

These terms represent alternative decompositions of the mechanical effect. When we apply the treatment group formula to the control group's earnings, we get the following decomposition

$$
B\left(\mathbf{Y}_{1}, \theta_{1}\right)-B\left(\mathbf{Y}_{0}, \theta_{0}\right)=\underbrace{B\left(\mathbf{Y}_{0}, \theta_{1}\right)-B\left(\mathbf{Y}_{0}, \theta_{0}\right)}_{\text {Mechanical1 }}+\underbrace{B\left(\mathbf{Y}_{1}, \theta_{1}\right)-B\left(\mathbf{Y}_{0}, \theta_{1}\right)}_{\text {Behavioral 1 }}
$$

while applying the control group formula to the treatment group's earnings will yield the alternative decomposition

$$
B\left(\mathbf{Y}_{1}, \theta_{1}\right)-B\left(\mathbf{Y}_{0}, \theta_{0}\right)=\underbrace{B\left(\mathbf{Y}_{1}, \theta_{1}\right)-B\left(\mathbf{Y}_{1}, \theta_{0}\right)}_{\text {Mechanical 2 }}+\underbrace{B\left(\mathbf{Y}_{1}, \theta_{0}\right)-B\left(\mathbf{Y}_{0}, \theta_{0}\right)}_{\text {Behavioral 2 }}
$$

Therefore, to get closer to the true mechanical effect (which is still approximate) for a large reform, we can average the two mechanical effect calculations.

\section{B Extrapolating Fiscal Externality Parameters Identified in an RKD}

In this section, we consider in greater detail a set of sufficient conditions under which the fiscal externality from an increase in the full weekly benefit amount can be inferred from the estimates obtained from the regression kink design. In the presence of unobserved heterogeneity, the RKD produces estimates that are "local" in nature. It is thus constructive to establish what restrictions on heterogeneity would permit one to interpret the RKD estimates as the fiscal externality for the policy change more generally.

Recall that if the outcome variable of interest is a smooth function $f(B, X, U)$ of the continuous treatment 
variable $B$, running variable $X$, and type variable $U$, the sharp RK estimand identifies the treatment effect

$$
E\left[f_{1}\left(b_{0}, 0, U\right) \mid X=0\right]
$$

where $f_{1}$ denotes the partial derivative of the causal response function $f$ with respect to its first argument, and $b_{0}$ is the value of the treatment when $X=0$ (Card et al., 2015b) ${ }^{57}$

As in Card et al. (2015b), we allow unrestricted heterogeneity to be represented by the variable $U$, and write the key components of UI benefit expenditures as functions of $U$ and the running variable $X$ :

Statutory UI amount for fully unemployed: $W B A_{t}=w b a^{t}(X, \theta, \lambda)=\theta+\min [\lambda X, 0]$

Earnings: $Y_{t}=y^{t}\left(W B A_{t}, X, U, \theta, \lambda, \rho\right)$

UI benefit accounting for disregarding a fraction of earnings: $B_{t}=b^{t}\left(W B A_{t}, Y_{t}, \rho\right)=\max \left[W B A_{t}-\rho Y_{t}, 0\right]$

Probability of take-up: $P_{t}=p^{t}\left(W B A_{t}, X, U, \theta, \lambda, \rho\right)$.

For concreteness, $t$ is the week indicator, so the total UI benefit received, for example, is $\sum_{t} B_{t} \cdot P_{t}$. The parameter $\theta$ is the maximum weekly benefit amount, $\lambda$ the scaled UI replacement rate, and $\rho$ the implicit tax rate in partial UI. ${ }^{58}$ For concreteness, we specify that behavioral responses are captured by earnings $Y_{t}$ and take-up probability $P_{t}$, which the individual jointly chooses, conditional on the parameters and other predetermined factors $U, X$. Note that we omit the tax component of the fiscal externality from this discussion. We focus solely on the benefits component of the fiscal externality to illustrate the types of behavioral assumptions that would be sufficient to extrapolate from the RKD estimates to the full population.

With this notation, we now derive the fiscal externality of marginally changing the UI benefit level for the fully unemployed for all UI claimants, which amounts to a small change in the parameter $\theta$. We will impose two exclusion restrictions regarding how $Y_{t}$ and $P_{t}$ respond to a change in $\theta$ (recall that $\theta$ is the fourth argument in both functions $y^{t}$ and $p^{t}$ ):

$$
y_{4}^{t}=p_{4}^{t}=0
$$

\footnotetext{
${ }^{57}$ In this section, we use $g_{k}$ to denote the partial derivative of a given function $g$ with respect to its $k$-th argument.

${ }^{58}$ For simplicity, we abstract away from the partial UI earnings disregard since it was very low (\$5) in Washington state during the sample period as mentioned in Section 3.
} 
The first restriction on $Y_{t}$ means that $\theta$ can only impact earnings through its impact on benefit levels, while the second restriction on $P_{t}$ similarly requires that $\theta$ can only impact take-up decisions through its impact on benefit levels and earnings.

Since the fiscal externality is the ratio of the behavioral and mechanical increase in total UI benefit expenditures, let us first consider the effect of changing $\theta$ on the total expected benefit payment in a particular week $t$ - we will drop the $t$ subscript for ease of exposition:

$$
\begin{aligned}
\frac{d E[P \cdot B]}{d \theta} & =E\left[\frac{d(P \cdot B)}{d \theta}\right] \\
& =E\left[\frac{d p}{d \theta} B+P \frac{d b}{d \theta}\right] \\
& =E\left[1[B>0] \cdot\left(p_{1} B+P\left(b_{1}+b_{2} \frac{d y}{d \theta}\right)\right)\right]
\end{aligned}
$$

where we have employed $p_{4}=0$ from assumption (A2), and have included the indicator function $1[B>0]$ to account for the fact that the partial derivative of $b$ with respect to its arguments will be zero when $B \leq 0$.

Using the other restriction $y_{4}=0$, we have that when $B>0$

$$
\begin{aligned}
\frac{d y}{d \theta} & =w b a_{2} y_{1}+y_{4} \\
& =y_{1}
\end{aligned}
$$

and with the assumptions stated in equation (A2), the above expression reduces to

$$
\begin{aligned}
& E\left[1[B>0] \cdot\left(p_{1} B+P\left(b_{1}+b_{2} y_{1}\right)\right)\right] \\
= & E\left[1[B>0] \cdot\left(p_{1} B+P\left(1+b_{2} y_{1}\right)\right)\right] \\
= & E\left[1[B>0] \cdot\left(p_{1} \frac{B}{P}-\rho y_{1}+1\right) P\right]
\end{aligned}
$$

Meanwhile, the mechanical effect is

$$
E\left[P \cdot b_{1}\right]=E[1[B>0] \cdot P]
$$

If we assume homogeneity across individuals in the behavioral component $p_{1} \frac{B}{P}-\rho y_{1}=\kappa$ (across individuals $U, X$ and benefit levels $B$ and probabilities $P$ ) then the fiscal externality reduces to 


$$
\frac{E\left[1[B>0] \cdot\left(p_{1} \frac{B}{P}-\rho y_{1}\right) P\right]}{E[1[B>0] \cdot P]}=\kappa
$$

Furthermore, if the homogeneity in this behavioral component extends across all $t$, then it can be shown that the fiscal externality for the accumulated benefit payment up to time $T$ is also $\kappa$.

A similar expression for the RKD fiscal externality estimand can be shown to be, for each week:

$$
\frac{E\left[1[B>0] \cdot\left(p_{1} \frac{B}{P}-\rho y_{1}\right) P \mid X=0\right]}{E[1[B>0] \cdot P \mid X=0]}=\kappa
$$

In summary, although we may allow for various forms of heterogeneity (note that the $p$ and $y$ functions contain $U$ as an argument), we must restrict the behavioral responses in some way to extrapolate from the RKD estimand to the fiscal externality quantity for the full population. We have shown that the constancy of $p_{1} \frac{B}{P}-\rho y_{1}$, along with the exclusion restrictions (A2), is sufficient for this extrapolation.

\section{Weights on Mechanical Effects in a Fuzzy Regression Kink Design}

As described in Section 2.2, the RK estimand and our mechanical effect estimand identify a weighted average of the total and mechanical effects, respectively, of raising the weekly benefit amount. Following the arguments in Lee (2008) and Card et al. (2015b), it is straightforward to show that the weights on the total and mechanical effects are the same in a sharp RKD. However, this is not generally true in a fuzzy RKD. In this section, we propose a testable condition tailored to our empirical context, under which the weights remain the same.

Card et al. (2015b) establish a general fuzzy RKD framework which allows for noncompliance with the benefit formula and measurement error in both the running variable $X$ and the weekly benefit amount $w b a$. The generality of the framework partly stems from the complexity of the Austrian UI system, which Card et al. (2015b) study. For example, there are multiple UI benefit schedules depending on the number of dependents, which is unobserved in the data, and noncompliance is motivated by the fact that the econometrician does not know how to assign a particular worker to a given schedule.

In Washington state, there was only one UI schedule, and the deviation from the formula in our data was most likely due to measurement error in the running variable $X$. If base period wages were missing or were discovered to contain errors (e.g., entry errors that result in outliers), employers were contacted directly and 
would report the correct base period wages. The weekly benefit amount was then recalculated based on the correction, but the original wage records, which we use, were not updated. Armed with this institutional knowledge, we focus on the impact of the measurement error in $X$ on the mechanical effect weights while abstracting away from noncompliance and treating the weekly benefit amount as measured without error.

With these simplifications, Proposition 2 of Card et al. (2015b) implies that the RK estimand for the total effects on benefit payout identifies

$$
E\left[\frac{d B}{d \theta} \mid X=0, U_{X}=0\right]=E\left[\omega \frac{d B}{d \theta}\right]
$$

where

$$
\omega=\frac{\operatorname{Pr}\left(U_{X}=0 \mid X=0, U=u\right) \frac{f_{X \mid U=u}(0)}{f_{X}(0)}}{\operatorname{Pr}\left(U_{X}=0 \mid X=0\right)} .
$$

In the equations above, $U_{X}$ denotes the measurement error in $X, U$ represents individual heterogeneity as in Appendix $\mathrm{B}$, and $f_{X \mid U=u}$ and $f_{X}$ denote the conditional and unconditional densities of the running variable $X$ respectively.

In comparison, the mechanical effect parameter we estimate in Section 4 is

$$
\begin{aligned}
E\left[\frac{\partial B}{\partial \theta} \mid X^{*}=0\right]= & \underbrace{E\left[\frac{\partial B}{\partial \theta} \mid X^{*}=0, U_{X}=0\right] \operatorname{Pr}\left(U_{X}=0 \mid X^{*}=0\right)}_{(a)}+ \\
= & \underbrace{E\left[\frac{\partial B}{\partial \theta} \mid X^{*}=0, U_{X} \neq 0\right] \operatorname{Pr}\left(U_{X} \neq 0 \mid X^{*}=0\right)}_{(b)} \\
& \underbrace{E\left[\frac{\partial B}{\partial \theta} \mid X=0, U_{X}=0, w b a=\theta\right] \operatorname{Pr}\left(U_{X}=0, w b a=\theta \mid X^{*}=0\right)}_{(c)}+ \\
& \underbrace{E\left[\frac{\partial B}{\partial \theta} \mid X^{*}=0, U_{X} \neq 0, w b a \neq \theta\right] \operatorname{Pr}\left(U_{X} \neq 0 \text { and } w b a \neq \theta \mid X^{*}=0\right)}_{(d)}
\end{aligned}
$$

where $X^{*}$ is the measured running variable with $X^{*}=X+U_{X} \cdot{ }^{59}$ In equation (A4), the terms (a) and (c)

\footnotetext{
${ }^{59}$ For notational simplicity, we abstract away from the distinction between measured and true $X$ in the other parts of the paper. In the empirical discussion in the main text, $X$ represents the observed running variable.
} 
are equal because a worker with $X^{*}=0$ and no measurement error has $X=0$ and receives the maximum UI weekly benefit amount ( $w b a=\theta)$; we express the term (b) as the sum of (d) and (e) by conditioning on whether or not a worker is assigned the maximum wba.

In order to identify $E\left[\frac{\partial B}{\partial \theta} \mid X^{*}=0\right]$, it is reasonable to assume that the conditional expectation function $E\left[\frac{\partial B}{\partial \theta} \mid X^{*}=x^{*}\right]$ is continuous, which is empirically supported by Figure 7. To a first order, the mechanical effect $\frac{\partial B}{\partial \theta}$ is simply the insured unemployment duration of the worker, which is often the outcome of interest in a standard regression kink design application. The identification assumptions in Card et al. (2015b) imply that for each unemployed worker the insured unemployment duration is a smooth function of $X^{*}$. Because of this continuity, we can identify the mechanical effect by extrapolating from the right of the threshold: $\lim _{x^{*} \rightarrow 0^{+}} E\left[\frac{\partial B}{\partial \theta} \mid X^{*}=x^{*}\right]$.

We now argue that we can approximate the mechanical effect $E\left[\frac{\partial B}{\partial \theta} \mid X^{*}=0\right]$ with the sum of the terms (c) and (d) from equation (A4), which will help to pin down a testable condition that implies the same weighting scheme between the total and mechanical effects identified in our RKD. First note that workers with $X^{*} \geq 0, U_{X} \neq 0$, and $w b a \neq \theta$, the subpopulation underlying term (e) in equation (A4), are just workers with $X^{*} \geq 0$ and $w b a \neq \theta$. Since these workers are directly observed and because of the continuity of $\frac{\partial B}{\partial \theta}$ as a function of $X^{*}$, we can extrapolate their mechanical effects to the threshold. Using a global quintic, we obtain an estimate of 5.69, which is statistically and economically significantly different from the mechanical effect estimate of 10.80 for the remaining workers. However, the workers underlying term (e) only constitute a small fraction of the sample - out of 49,426 observations with $X^{*}$ above the threshold, exactly 200 or $0.4 \%$ of the workers have a non-maximum wba. Therefore, the term (e) is small overall; in fact, including the 200 observations changes the estimate of $E\left[\frac{\partial B}{\partial \theta} \mid X^{*}=0\right]$ with a global quintic from 10.80 to 10.75 . Therefore, it is reasonable to invoke the approximation

$$
\begin{aligned}
& E\left[\frac{\partial B}{\partial \theta} \mid X^{*}=0\right] \approx \underbrace{E\left[\frac{\partial B}{\partial \theta} \mid X=0, U_{X}=0, w b a=\theta\right] \operatorname{Pr}\left(U_{X}=0, w b a=\theta \mid X^{*}=0\right)}_{(c)}+ \\
& \underbrace{E\left[\frac{\partial B}{\partial \theta} \mid X^{*}=0, U_{X} \neq 0, w b a=\theta\right] \operatorname{Pr}\left(U_{X} \neq 0 \text { and } w b a=\theta \mid X^{*}=0\right)}_{(d)}
\end{aligned}
$$

Now we propose a testable condition that will imply (approximately) the same weighting scheme be- 
tween the mechanical and total effects in the RK design:

$$
E\left[\frac{\partial B}{\partial \theta} \mid X=0, U_{X}=0, w b a=\theta\right]=E\left[\frac{\partial B}{\partial \theta} \mid X^{*}=0, U_{X} \neq 0, w b a=\theta\right]
$$

Note that with condition (A6), the right hand side of equation (A5) becomes

$$
\begin{aligned}
E\left[\frac{\partial B}{\partial \theta} \mid X^{*}=0, U_{X}=0\right] & =E\left[\frac{\partial B}{\partial \theta} \mid X=0, U_{X}=0\right] \\
& =E\left[\omega \frac{\partial B}{\partial \theta}\right]
\end{aligned}
$$

where $\omega$ as defined in (A3) is the identification weight for the total effects.

Although $U_{X}$ is not observed for the population with $X^{*} \geq 0$ and $w b a=\theta$, we argue that condition (A6) can be empirically tested. In particular, we can examine the continuity of the conditional expectation function $E\left[\frac{\partial B}{\partial \theta} \mid X^{*}=x^{*}, w b a=\theta\right]$ at $x^{*}=0$. Note that

$$
\begin{aligned}
E\left[\frac{\partial B}{\partial \theta} \mid X^{*}=x^{*}, w b a=\theta\right] \\
= \begin{cases}E\left[\frac{\partial B}{\partial \theta} \mid X^{*}=x^{*}, U_{X} \neq 0, w b a=\theta\right] & \text { if } x^{*}<0 \\
E\left[\frac{\partial B}{\partial \theta} \mid X^{*}=x^{*}, U_{X} \neq 0, w b a=\theta\right] \operatorname{Pr}\left(U_{X} \neq 0 \mid X^{*}=x^{*}, w b a=\theta\right) & \\
+E\left[\frac{\partial B}{\partial \theta} \mid X^{*}=x^{*}, U_{X}=0, w b a=\theta\right] \operatorname{Pr}\left(U_{X}=0 \mid X^{*}=x^{*}, w b a=\theta\right) & \text { if } x^{*} \geq 0\end{cases}
\end{aligned}
$$

which states that there is a sudden composition change as $X^{*}$ moves across the threshold. Below the threshold, there are only workers whose $X^{*}$ is measured with error, and we have a mixture of workers with and without measurement error in $X^{*}$ above the threshold. Assuming that $\frac{\partial B}{\partial \theta}$ evolves smoothly with $X^{*}$ in the population with $U_{X} \neq 0$ and $w b a=\theta$ and provided that $\operatorname{Pr}\left(U_{X}=0 \mid X^{*}=x^{*}, w b a=\theta\right)$ is nonzero, the continuity of $E\left[\frac{\partial B}{\partial \theta} \mid X^{*}=x^{*}, w b a=\theta\right]$ at $x^{*}=0$ is equivalent to condition (A6).

We present empirical evidence in support of condition (A6). In Appendix Figure A.1, the composition change is apparent through the sharp discontinuity at zero in the histogram of $X^{*}$ for workers at the maximum $w b a$, implying that $\operatorname{Pr}\left(U_{X}=0 \mid X^{*}=x^{*}, w b a=\theta\right) \neq 0$. Appendix Figure A.2 is the sample analog of the conditional expectation function $E\left[\frac{\partial B}{\partial \theta} \mid X^{*}=x^{*}, w b a=\theta\right]$ via a bin-scatter plot of the cumulative mechanical effect over the time period of Q1-Q4 against the observed running variable. There does not appear to be a salient discontinuity at $x^{*}=0$, and both the conventional and bias-corrected local linear confidence 
intervals of Calonico, Cattaneo and Titiunik (2014) fail to reject continuity at the 5\% level with $p$-values of 0.11 and 0.19 respectively.

Finally, we acknowledge that the number of observations below the threshold in Figure A.2 is small - a total of 2,419, and we may lack the power to detect a discontinuity. The conventional local linear point estimate of the discontinuity in $E\left[\frac{\partial B}{\partial \theta} \mid X^{*}=x^{*}, w b a=\theta\right]$ is 1.34 , indicating that workers subject to measurement error in earnings contribute a lower mechanical effect on average. We have noted above that workers captured by term (e) of equation (A4) also have a lower mechanical effect on average. Taken together, this means that in our fuzzy regression kink design, measurement error in the running variable lowers the average estimated mechanical effect, which in turn raises the estimated behavioral effect. As a result, the "true" fiscal externality (i.e., that applies the same weights in the total and mechanical effects) of a policy reform that marginally increases the $w b a$ will have an even lower deadweight loss than estimated. 
Figure A.1: Distribution of Observed Running Variable for Workers with Maximum wba

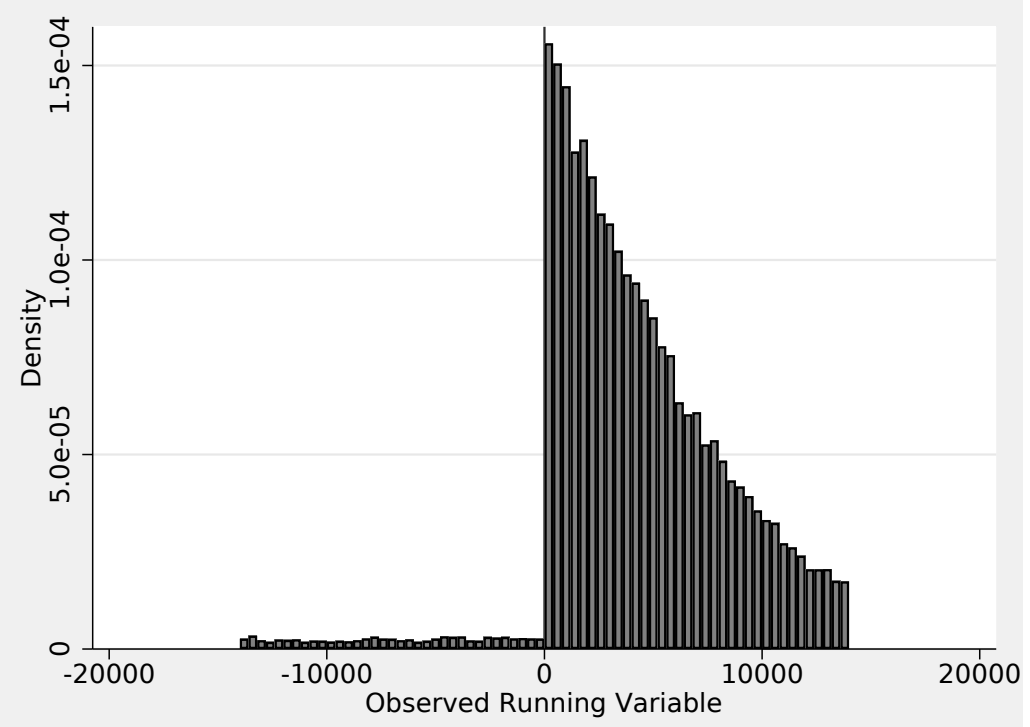

Figure A.2: Mechanical Effect v. Observed Running Variable for Workers Assigned Maximum Weekly Benefit Amount $(w b a)$

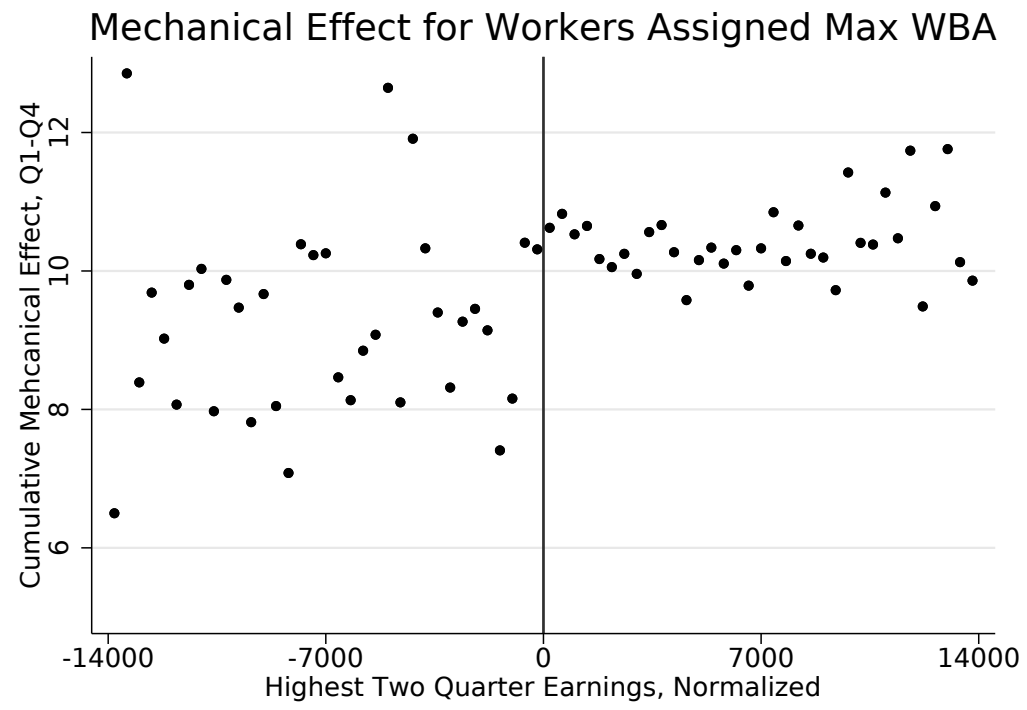




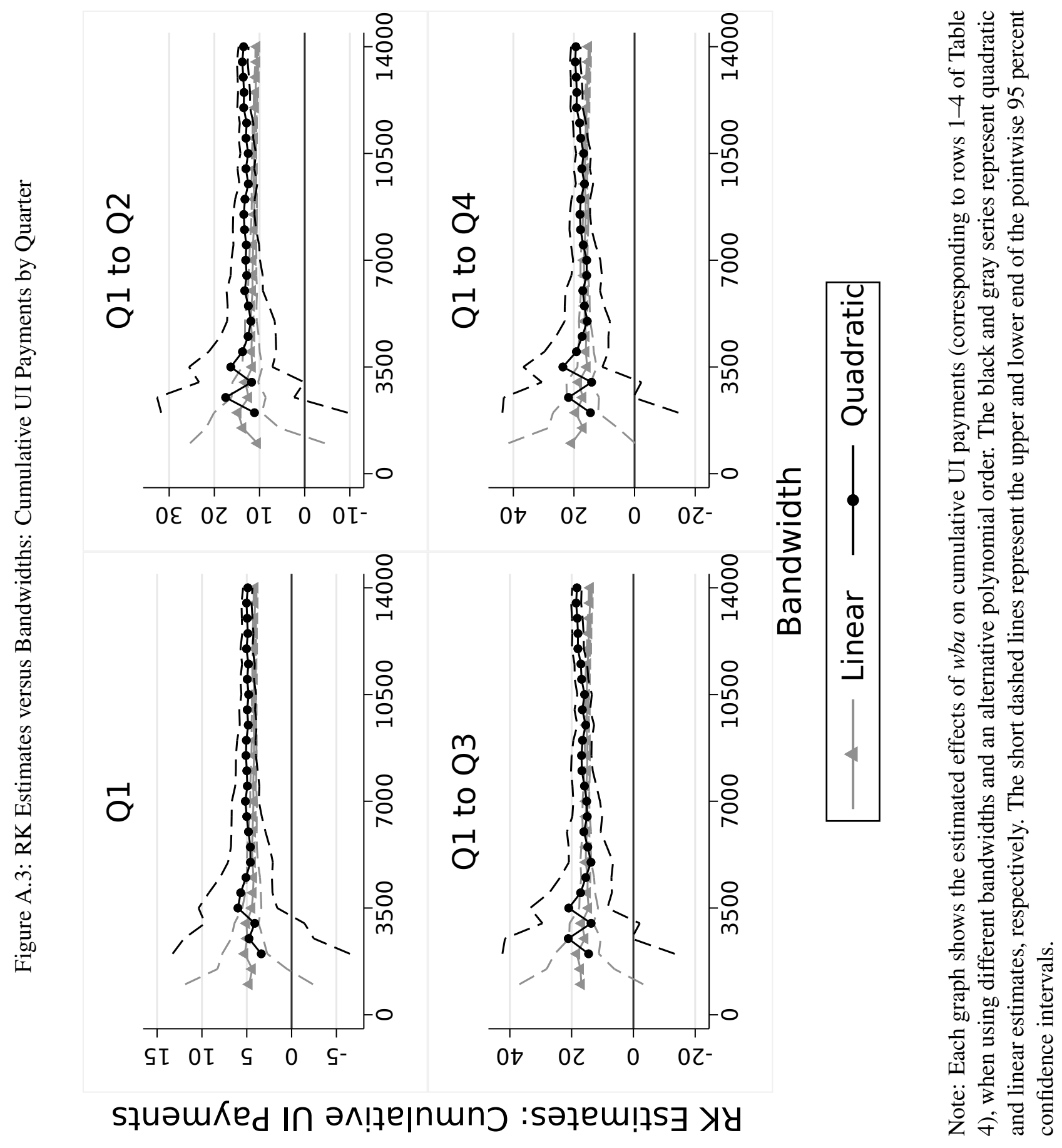




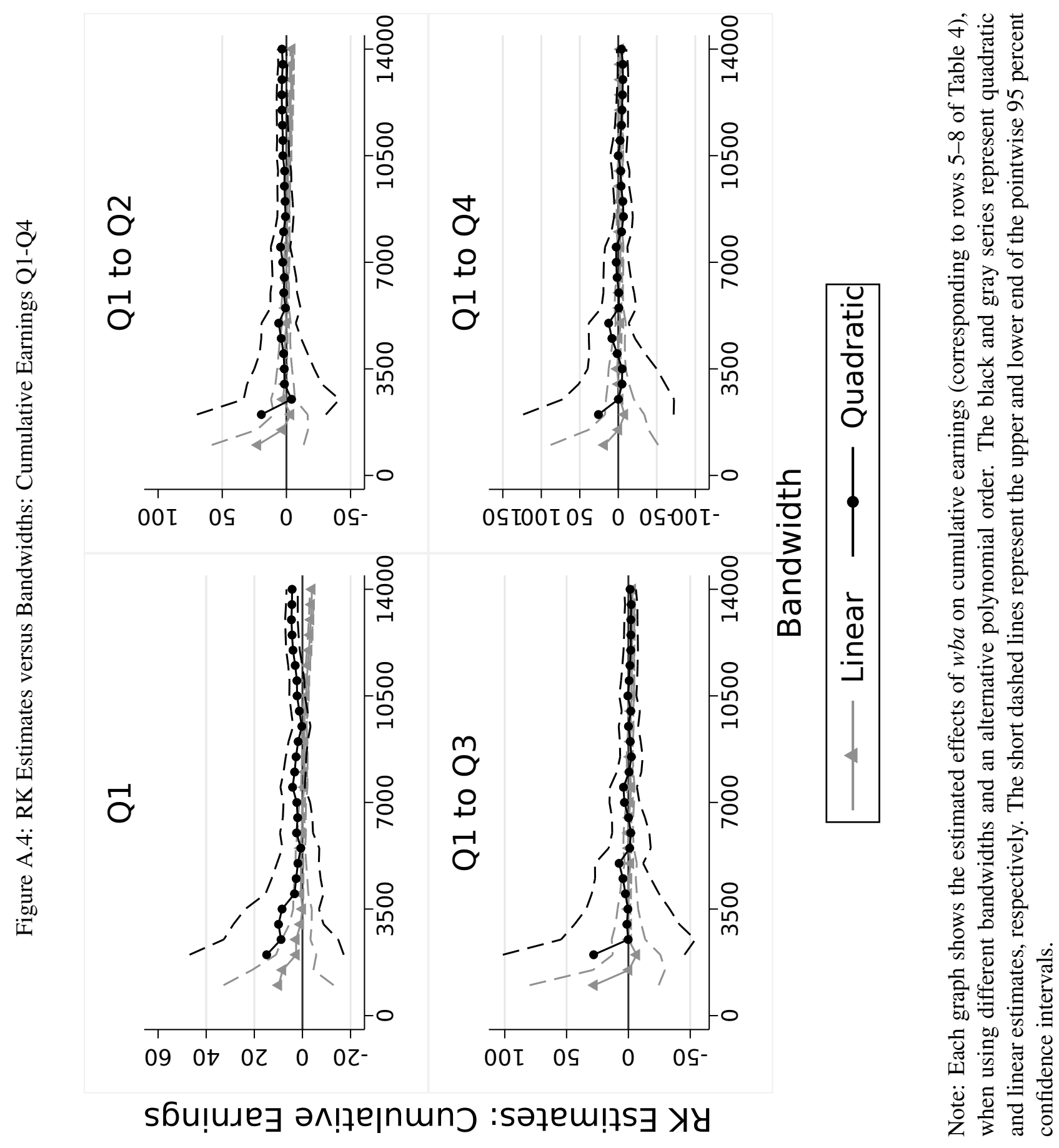


Table A.1: Earnings Deduction Experiment: Separating the Mechanical and Behavioral Effects (Full Tax Wedge)

\begin{tabular}{|c|c|c|c|c|c|c|c|}
\hline & (1) & (2) & \multirow[t]{2}{*}{ (3) } & (4) & $(5)$ & (6) & (7) \\
\hline & \multicolumn{2}{|c|}{ UI Payments } & & \multirow[b]{2}{*}{ Tax Receipts } & \multicolumn{3}{|c|}{ Fiscal Externality } \\
\hline & Total & Mechanical & Behavioral & & $\beta+\gamma$ & $\beta$ & $\gamma$ \\
\hline Q1 & $\begin{array}{l}15.52 \\
(4.04)\end{array}$ & $\begin{array}{c}7.73 \\
(0.05)\end{array}$ & $\begin{array}{c}7.79 \\
(4.04)\end{array}$ & $\begin{array}{l}-9.11 \\
(7.76)\end{array}$ & $\begin{array}{c}2.19 \\
(1.14)\end{array}$ & $\begin{array}{c}1.01 \\
(0.52)\end{array}$ & $\begin{array}{c}1.18 \\
(1.00)\end{array}$ \\
\hline $\mathrm{Q} 1$ to $\mathrm{Q} 2$ & $\begin{array}{l}44.66 \\
(8.79)\end{array}$ & $\begin{array}{l}19.83 \\
(0.12)\end{array}$ & $\begin{array}{l}24.84 \\
(8.79)\end{array}$ & $\begin{array}{l}-22.08 \\
(12.34)\end{array}$ & $\begin{array}{c}2.37 \\
(0.78)\end{array}$ & $\begin{array}{c}1.25 \\
(0.44)\end{array}$ & $\begin{array}{c}1.11 \\
(0.62)\end{array}$ \\
\hline Q1 to Q3 & $\begin{array}{c}62.29 \\
(11.92)\end{array}$ & $\begin{array}{l}26.37 \\
(0.17)\end{array}$ & $\begin{array}{c}35.92 \\
(11.92)\end{array}$ & $\begin{array}{c}-23.54 \\
(15.60)\end{array}$ & $\begin{array}{c}2.26 \\
(0.77)\end{array}$ & $\begin{array}{c}1.36 \\
(0.45)\end{array}$ & $\begin{array}{c}0.89 \\
(0.59)\end{array}$ \\
\hline Q1 to Q4 & $\begin{array}{c}66.92 \\
(12.60)\end{array}$ & $\begin{array}{l}28.15 \\
(0.20)\end{array}$ & $\begin{array}{c}38.77 \\
(12.61)\end{array}$ & $\begin{array}{l}-18.33 \\
(19.81)\end{array}$ & $\begin{array}{c}2.03 \\
(0.85)\end{array}$ & $\begin{array}{c}1.38 \\
(0.45)\end{array}$ & $\begin{array}{c}0.65 \\
(0.70)\end{array}$ \\
\hline
\end{tabular}

Note: Column (1) are the estimates from the first four rows of Table 2. Column (2) is the cumulative UI payments that the control group would gain if it was mechanically subject to the treatment group's earnings deduction schedule. Column (3) is (1) minus (2). Column (4) is the experimental impact on tax receipts. Column (5) is equal to the estimate from a regression of tax receipts on the treatment indicator, then divided by column (2). Column (6) is (3) divided by (2). Column (7) is (5) minus (6). Tax receipts are calculated using assuming that the tax rate on earnings is 31.54 percent. 
Table A.2: RK Estimates: Separating the Mechanical and Behavioral Effects (Full Tax Wedge)

\begin{tabular}{|c|c|c|c|c|c|c|c|}
\hline & (1) & (2) & (3) & \multirow[b]{3}{*}{ Tax Receipts } & (5) & $(6)$ & (7) \\
\hline & \multicolumn{3}{|c|}{ UI Payments } & & \multicolumn{3}{|c|}{ Fiscal Externality } \\
\hline & Total & Mechanical & Behavioral & & $\beta+\gamma$ & $\beta$ & $\gamma$ \\
\hline Q1 & $\begin{array}{c}4.67 \\
(1.12)\end{array}$ & $\begin{array}{c}3.75 \\
(0.04)\end{array}$ & $\begin{array}{c}0.92 \\
(1.09)\end{array}$ & $\begin{array}{c}1.30 \\
(0.45)\end{array}$ & $\begin{array}{l}-0.01 \\
(0.50)\end{array}$ & $\begin{array}{c}0.24 \\
(0.29)\end{array}$ & $\begin{array}{l}-0.26 \\
(0.32)\end{array}$ \\
\hline $\mathrm{Q} 1$ to $\mathrm{Q} 2$ & $\begin{array}{l}13.31 \\
(2.45)\end{array}$ & $\begin{array}{c}9.06 \\
(0.09)\end{array}$ & $\begin{array}{c}4.25 \\
(2.40)\end{array}$ & $\begin{array}{c}0.33 \\
(0.98)\end{array}$ & $\begin{array}{c}0.44 \\
(0.41)\end{array}$ & $\begin{array}{c}0.47 \\
(0.26)\end{array}$ & $\begin{array}{l}-0.03 \\
(0.21)\end{array}$ \\
\hline Q1 to Q3 & $\begin{array}{l}15.11 \\
(0.47)\end{array}$ & $\begin{array}{l}10.13 \\
(0.12)\end{array}$ & $\begin{array}{c}4.98 \\
(0.44)\end{array}$ & $\begin{array}{l}-0.26 \\
(1.35)\end{array}$ & $\begin{array}{c}0.56 \\
(0.08)\end{array}$ & $\begin{array}{c}0.49 \\
(0.04)\end{array}$ & $\begin{array}{c}0.07 \\
(0.04)\end{array}$ \\
\hline Q1 to Q4 & $\begin{array}{l}15.88 \\
(1.36)\end{array}$ & $\begin{array}{l}10.23 \\
(0.13)\end{array}$ & $\begin{array}{c}5.66 \\
(1.30)\end{array}$ & $\begin{array}{l}-0.77 \\
(1.48)\end{array}$ & $\begin{array}{c}0.53 \\
(0.24)\end{array}$ & $\begin{array}{c}0.55 \\
(0.12)\end{array}$ & $\begin{array}{l}-0.02 \\
(0.15)\end{array}$ \\
\hline
\end{tabular}

Note: Robust standard errors in parentheses. Column (1) shows the estimates from the first four rows of Table 4. Column (2) is the estimated mean mechanical transfer at the threshold from increasing $w b a$. It is the intercept from a regression of the mechanical effect on a quintic polynomial in $X$ and $A \cdot X$, where $A=1[X \geqslant 0]$. Column (3) is (1) minus (2). Column (4) is the fuzzy RKD estimate of $w b a$ on tax receipts, calculated as in Column (1). Column (5) is the fuzzy RKD estimate of the effect of $w b a$ on UI payments net of tax receipts, divided by column (2), and minus 1 . Column (6) is (3) divided by (2). Column (7) is (5) minus (6). The bandwidths and orders of the RKDs for all columns except (4) are chosen to minimize MSE (polynomial order is selected between 1 and 3) where the outcome is UI payments. For column (4), the bandwidth and polynomial order are chosen using tax receipts as the outcome. Standard errors for Columns (5) to (7) are computed by jointly estimating their numerator and denominator, and allowing unrestricted covariances across equations, and then using the delta method. Tax receipts are calculated using assuming that the tax rate on earnings is 31.54 percent. 